\title{
IMPLEMENTATION OF ELECTRICAL ENERGY BY PAIRED HALF-CENTERS AS REVEALED BY STRUCTURE AND FUNCTION
}

\author{
ROBERT GESELL, CHARLES R. BRASSFIELD \\ AND RICHARD H. LILLIE
}

The Physiology Laboratory, University of Michigan, Ann Arbor

FIFTY-ONE FIGURES

"Neither anatomy nor physiology has any biological significance apart from the other." - C. JUDson HeRRICK.

\section{INTRODUCTION}

Of the infinite number of chemical, physical and biological systems which have evolved from an originally homogeneous state of matter, the nervous system is the most comprehensive of all; more fascinating than the universe of which it is but an infinitesimally small part, for it encompasses not only the mysteries common to matter, but in addition, displays a strange array of forces which have appeared and grown in complexity with the evolution of the brain.

Small as it is, the nervous system of man is estimated by Herrick to be composed of approximately 16 billion nerve cells. These exquisitely sensitive structures live in highly organized communion with one another. With the aid of specialized sensory receptors this community of cells reacts in diverse ways to internal and to external environment. Unlike any other part of nature, so far as is known, it is conscious of its existence and of the state of its environment, and most remarkable of all, possesses the capacity of implementing the physical and chemical forces of nature to its immediate advantage. It does indeed display a most remarkable variety of phenomena: initiation of nerve impulses 
at the sensory receptors; transmission of nerve impulses by nerve fibers to and away from the central nervous system; integration of sensory nerve impulses into coordinated reflexes; and integration of nerve impulses into states of consciousness, emotion, conscience, intelligence, imagination, abstraction, etc. These are but a few of its manifestations which puzzle the neuroanatomist and the neurophysiologist.

About one hundred years ago, Claude Bernard emphasized the dependence of vital phenomena upon structure in most significant terms. "There is in reality only one general physics, only one chemistry and only one mechanics, in which all phenomenal manifestations of nature are included, both those of living bodies as well as those of inanimate ones. In a word, the phenomena which make their appearance in a living being obey the same laws as those outside of it. So that one may say that all manifestations of life are composed of the phenomena borrowed from the outer cosmic world, so far as their nature is concerned, possessing however, a special morphology in the sense that they are manifestations under characteristic forms by the aid of special physiological instruments."

THE ELECTRICAI, NATURE OF NERVOUS INTEGRATION

Despite the difficulty of interpreting higher neurophysiological manifestations in terms of natural laws, there is a steadily growing belief that the nervous system performs its multifarious functions by instrumentation of electrical energy. This belief took root in the discovery of animal electricity by Galvani in his famous "second experiment" in which the gastrocnemius muscle of the frog was seen to twitch on bringing the cut end of the sciatic nerve in contact with the tendon of Achilles, in the manner illustrated in figure 1. Shortly thereafter, Humboldt observed a similar muscle twitch on bringing the cut end of the sciatic back on itself, illustrated in figure 2. DuBois Reymond, in turn, demonstrated that the cut end of a nerve is electrically negative with respect to its intact surface, thus indicating that 
the stimulation of muscle observed by Galvani and Humboldt was indeed electrical in nature (see fig. 3). Helmholtz's theory of polarization of the neuromembranes, as schematized in figure 4, suggested the existence of a semi-permeable neuromembrane as a biological means of creating and storing electrical energy, a concept which continues to play a major role in the interpretation of electrical and functional manifestations of nervous matter (Adrian and Bronk, '29a). Demonstrable potential drops across the neuromembrane, amounting

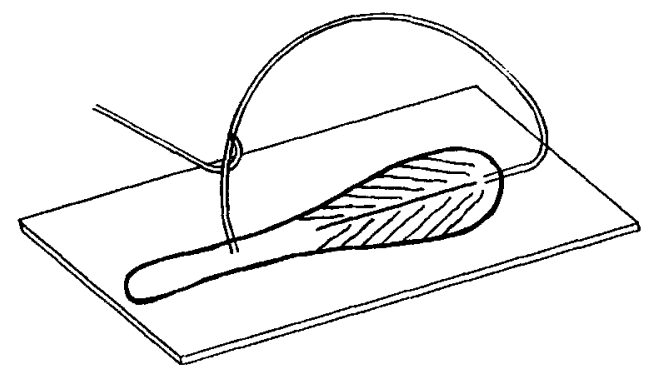

Fig. 1 Galvani's second experiment demonstrating the phenomenon of animal electricity. The muscle rests on a glass plate and twitches when the cut end of the sciatic nerve is brought back in contact with the tendon.

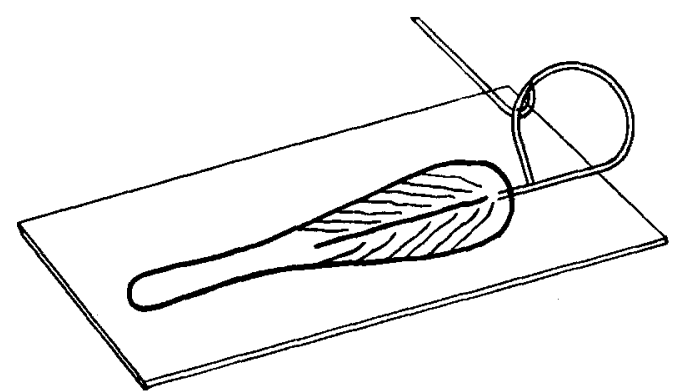

Fig. 2 Humboldt's experiment confirming Galvani's demonstration of animal electricity. The musele twitches when the eut end of the aciatic nerve is brought back upon itself.

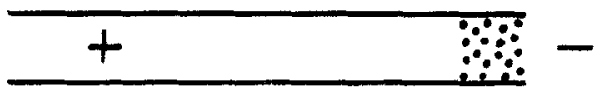

Fig. 3 DuBois Raymond's demonstration of the current of injury in the isolated nerve. The cut end of a nerve was shown to be electronegative with respect to the uninjured portion. 
to $120 \mathrm{Mv}$., indicated great capacity for creation and utilization of electrical energy by nervous structures. Lillie's iron nerve model and his membrane theory of propagation of nerve impulses offered simple explanation of how electrical

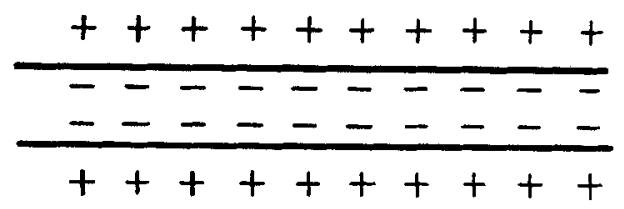

Fig. 4 Polarization of neuromembrane postulated by Helmholtz. The negativity of inside, with respect to outside of nerve cell agrees with DuBois Raymond's demonstration in figure 3 .
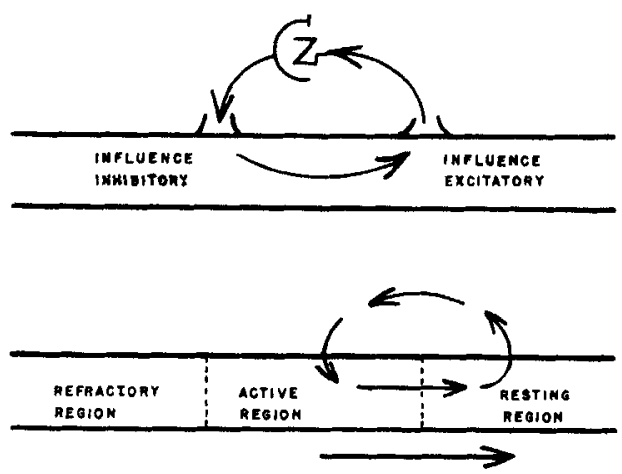

Figs. 5 A and B Lillie's theory of transmission of the nerve impulses in nerve fiber. Figure $5 \mathrm{~A}$ illustrates excitatory influence of a galvanic eurrent where it leaves the nerve at the cathode, and the inhibitory influence where the current enters the nerve at the anode. Figure $5 \mathrm{~B}$ illustrates the so-called negative sink in the activated region of the nerve where outflow of current increases permeability of the neuromembrane. The effect of this sink is to draw current from the resting nerve and to eause stimulation in advance. Repetition of this process propagates the impulse in a saltatory manner.

energy of polarization may be utilized to transmit electrical pulses, namely, nerve impulses (see fig. 5). Repetitive response of a transected nerve to its own steady current of injury, as postulated by Adrian and Bronk ('29b) and Gasser ('37) schematized in figure 6, called attention to another possible mechanism of nerve cell function, namely, rhythmical 
generation of nerve impulses by continuing neurocellular currents, a theory to be considered below. The studies of Barron and Matthews ('38) and of Skoglund ('42) point to a possible role of slow potentials.

These selected observations mark great advances in neurophysiology and suggest the desirability of further enquiry into the role of structure in the creation of, and the utilization of, electrical energy in nervous function.

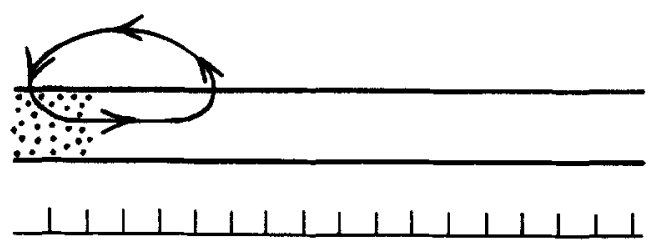

Fig. 6 Repetitive response of nerve to its current of injury [Adrian ('30) and Gasser ('37) ]. Injury creates a negative sink and draws current from the uninjured segment to which the nerve responds rhythmieally, as indicated in Jower tracing.

THE NERVE IMPULSE; TRANSMISSION IN NERVE AND MUSCLE FIBER AND IN SECONDARY NEURONS

The nature of the nerve impulse, its transmission in the nerve and in secondary neurons, and neuro-motor transmission in muscle, constitute basic problems in neurophysiology.

The passage of a nerve impulse along a nerve fiber has been explained in part by Lillie on the basis of permeability and polarization changes of the neuromembrane produced by local excitatory circuits (see figs. 5 A and B). A galvanic current, when artificially directed through a segment of nerve fiber, is known to exert an excitatory influence at the cathode where it leaves the neuraxon, and an inhibitory influence where it enters the neuraxon. Outflow of current increases the permeability of the neuromembrane at the cathode and thereby creates a "negative sink" which withdraws current from a forward, relatively positive, resting segment of the nerve fiber, as indicated in figure $5 \mathrm{~B}$. Excitation at this forward point now sets up a new and more 
advanced "negative sink" and local excitatory circuit and thus accomplishes a saltatory progression of the nerve impulse along the neuraxon. Forward movement of the impulse is assured in two ways : first, by stimulation in advance where current leaves the neuraxon; and second, by inhibition in the rear where current enters the neuraxon.

A motor nerve impulse stimulates the muscle fiber upon which it impinges through the motor end-plate which, on becoming electrically negative to the resting muscle, acts

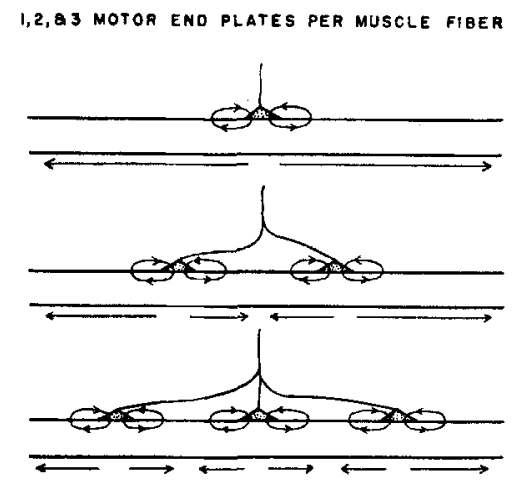

Fig. 7 Indirect stimulation of voluntary muscle fiber via 1, 2, and 3 motor end-plates respectively. Each plate acts as a negative sink and sets up two muscle impuises by two local cireuits as indicated in the figure. Thus 2, 4, and 6 impulses may be initiated in a single muscle fiber and spread in the manner shown by the horizontal arrows. (See text for details.)

as a "negative sink" and withdraws current from both sides in suffcient amount to set up two muscle impulses. These impulses travel to their respective ends of the muscle in the manner described for the nerve fiber, and in due time excite the whole fiber to contraction. Both muscle impulses die on reaching the ends of the muscle fiber after fulfilling their function (see fig. 7).

A simultaneous arrival of two nerve impulses on a single muscle fiber possessing two motor end-plates would set up 4 instead of two muscle impulses, as pictured in the second frame. The outer impulses would travel unimpeded to the 
ends of the muscle fiber, whereas the inner impulses would collide and destroy each other in the equatorial zone. The spread of 4 instead of only two muscle impulses would obviously reduce the time required to stimulate the entire fiber by one-half.

Simultaneous arrival of three nerve impulses would shorten the period of stimulation still more, possibly advantageously where speed of muscle twitch is at a premium.

The existence of hundreds or thousands of synapses on a single neuron compared with the sparsity of motor endplates on muscle fiber constitutes a significant contrast and presents a paradoxical situation if the neuron is assumed to function as a transmitter of impulses in the manner described for muscle (see fig. 8). A nerve impulse arriving at the tip of the left dendrite via afferent $A$ would travel unimpeded to the axon hillock with a functional efficiency of $100 \%$. Another hypothetical impulse, impinging midway on the dendrite $B$, would set up two nerve impulses. The antidromically moving impulse would perish at the end of the dendrite for lack of means of further transmission. The other would move dromically and emerge at the axon hillock to be transmitted by the neuraxon. Efficiency of transmission in this instance is cut from $100 \%$ to $50 \%$. Of the 4 impulses set up at the two synapses of afferent $\mathrm{C}$, two would perish by collision, one would vanish for lack of means of transmission, leaving only one of the original 4 to emerge at the axon hillock. Of the 6 impulses set up by three synapses on dendrite $\mathrm{D}, 5$ of the original 6 impulses would perish. Efficiency of a neuron as a transmitter of nerve impulses would therefore decrease with an increase of impulses impinging simultaneously upon it. This conclusion, however, does not conform with spatial summation of stimuli by sympathetie ganglia where an increase in number of impulses impinging on the secondary neuron increases the intensity of its response.

Radial spread of impulses impinging on the cell body leads to destruction of their identity, comparable to the destruction 


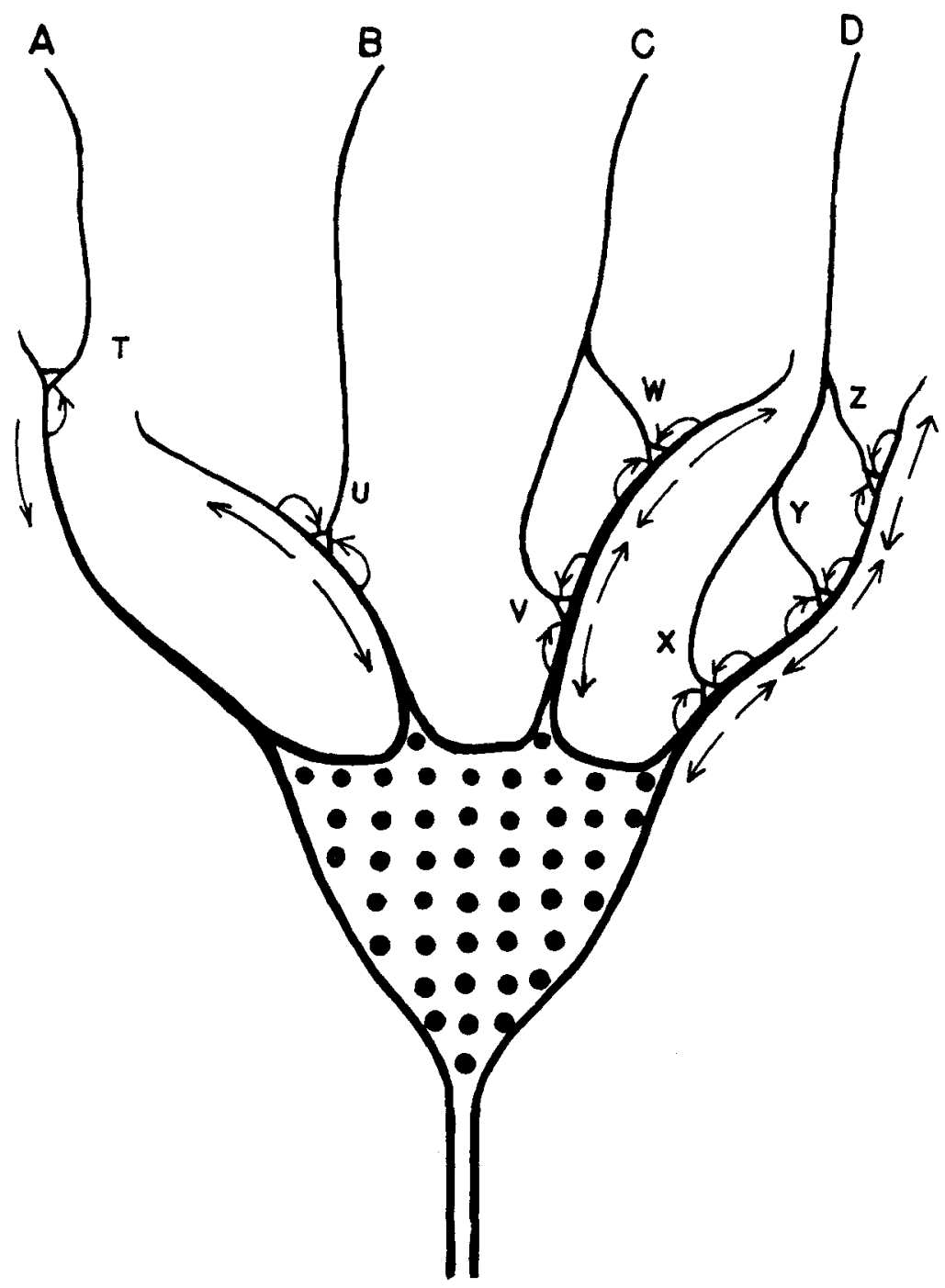

Fig. 8 Theoretical schematization of synaptic transmission of nerve impulses based on figure 7 analyzing indirect stimulation of a muscle fiber through its motor end-plates. Impulses arriving over afferents $A, B, C$, and $D$ theoretically set up 1, 2, 4, and 6 impulses respectively (see text). Of the 6 impulses initiated by afferent $D, 5$ perish and only one remains functional. of the impulses im. pinging on the body of the cell, almost all must suffer mutual destruetion. (See text.) 
of water waves produced by rain drops falling on a pond. Like the mechanical waves, few of which reach the outlet of the pond, only a minute fraction of those impulses impinging on a neuron could possibly arrive at the neuraxon, thus leaving most to waste away without fulfilling transmission function.

Faced with the difficulties of interpreting the neuron as a transmitter of nerve impulses it seemed desirable to explore other possible mechanisms of nerve cell function based on specialization of structure and function (Gesell, '40).

\section{SPECIALIZATION OF STRUCTURE AND FUNCTION OF THE NERVE CELL}

(See figure 9)

The rhythmic beating of an isolated ventricle in response to a continuing galvanic current; the repetitive discharge of the Nitella to a local current of injury (Osterhout and Hill, '30); the rhythmic generation of nerve impulses by a nerve subjected to its own current of injury (Adrian, '30 and Gasser, '37) and to artificial galvanic current (Skoglund, '42); illustrate a tendency of excitable tissue to react periodically to a steady current, and suggest that a nerve cell may so function normally.

A specialization of structure and function of the nerve cell was therefore proposed (Gesell, '40) according to which the dendrites and cell body function as source of self excitatory current. Due to their high rate of metabolism and to their expansive surface the dendrites form a negative sink of great capacity, which draws current from the region of the axon hillock. This current causes rhythmic discharge of the neuromembrane in the manner observed by Adrian, Gasser and Skoglund. Nerve impulses impinging on the neuron superimpose non-propagated synaptic negative sinks on the expansive sink of metabolic origin, and thereby increase the neurocellular current in proportion. These two fractions of neurocellular current, endogenous and exogenous, are mutu- 


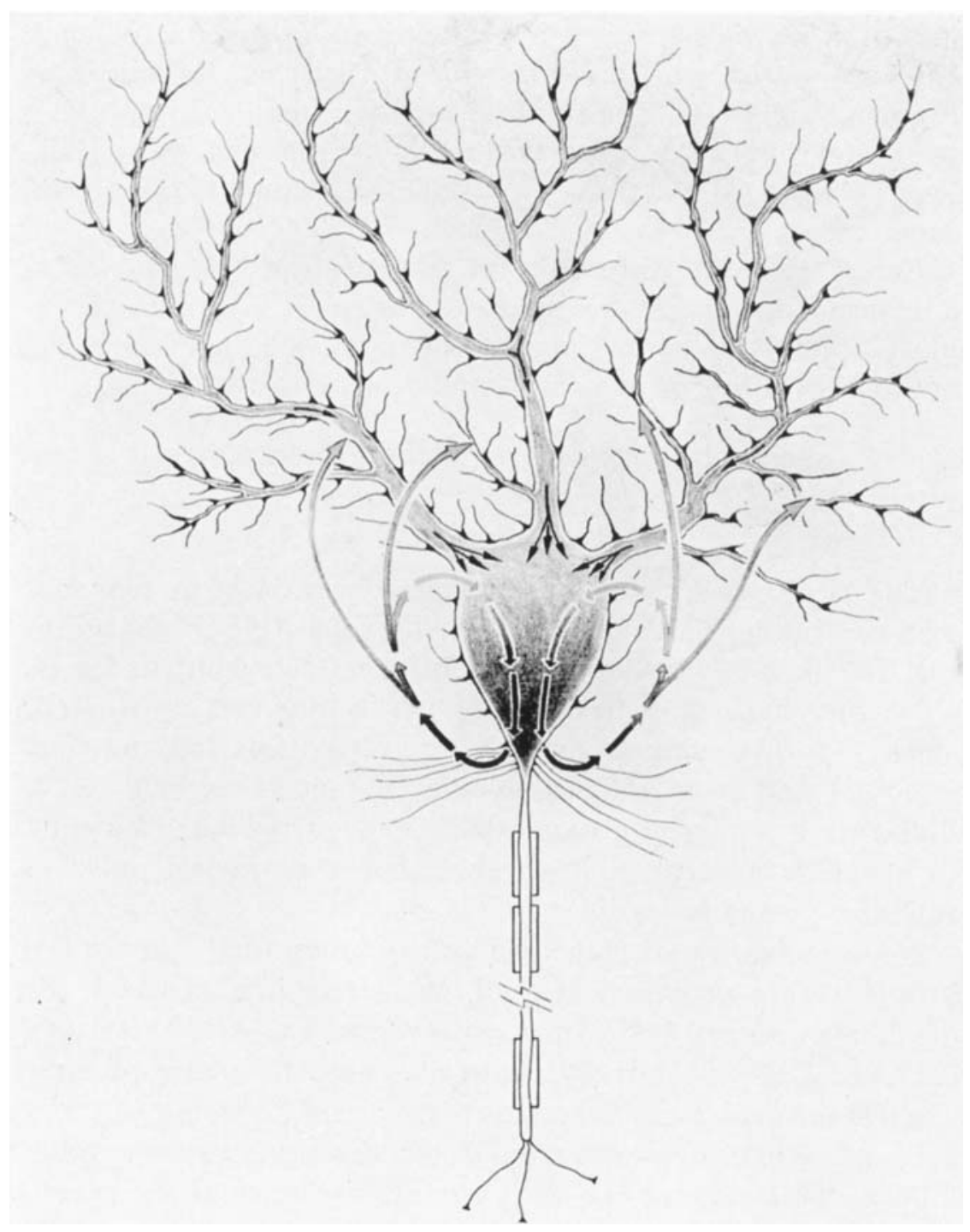

Fig. 9 Concept of electrical specialization of the nerve cell. 1. Generation of exeitatory neurocellular eurrent by dendrites and cell body, follow arrows showing the flow of neurocellular current. 2. Generation of nerve impulses by the axon hillock membrane under the excitatory influence of outflowing current. 3. Generation of counter potential at axon hillock in opposition to outflowing excitatory current to inhibit functional activity of neuron. 4. Conduction of nerve impulses by local circuits of neuraxon. 5. Terminal conversion of nerve impulse into nonpropagated synaptic depolarizations. For comparison of nerve cell with hydroelectric plant see text. 
ally additive and importantly coordinated. Of the two, the centrogenic or metabolic fraction serves to hold the cell in readiness to respond to the rapidly changing reflexogenic current, which constitutes the main regulation of nerve cell activity.

The number of nerve impulses impinging on a neuron is a highly variable factor. In the case of the anterior horn cell and the Mauthner cell, provided with approximately 1,000 and 10,000 synapses respectively, the flow of impulses might be as high as 30,000 to 300,000 per second. In consideration of the randomness of impingement of nerve impulses, conditions presented by the nerve cell are strikingly analogous to those existing in an hydroelectric plant designed to convert the energy of rain drops falling on the watershed into electricity. In the hydroelectric plant, rivulets and streams carry distant waters to the reservoir where hydrostatic pressure is converted into alternating electrical pulses. In the neuron (see fig. 9), outstretched dendrites carry current to the axon hillock where it is diverted by the high resistance of the neuraxon through the neuromembrane and "transformed" into rhythmical nerve impulses. These impulses are then transmitted to their respective terminal stations for final implementation (see fig. 9).

It may, therefore, be suggested, in summary, that the neuron is specialized for the performance of 5 distinct functions: (1) electrochemical generation of a self-excitatory neurocellular current by the dendrites and cell body; (2) a rhythmical generation of nerve impulses by the axon-hillock in response to the neurocellular current flowing through its membrane; (3) conduction of these impulses by the neuraxon to the secondary neuron or end organ; (4) conversion of these impulses into non-propagated depolarizations at the end boutons; (5) inhibition of nerve cell activity by synaptic depolarizations at the axonic pole which function to oppose outflow of neurocellular current. 
INHIBITION, A POLAR FUNCTION OF THE NEURON

(See figures $10 \mathrm{~A}$ and $10 \mathrm{~B}$ )

Figures $10 \mathrm{~A}$ and $10 \mathrm{~B}$ illustrate structural features which suggest polar function of the neuron. (See also Coghill, '34.) This concept has become an integral part of our own views on how the nerve cell functions.

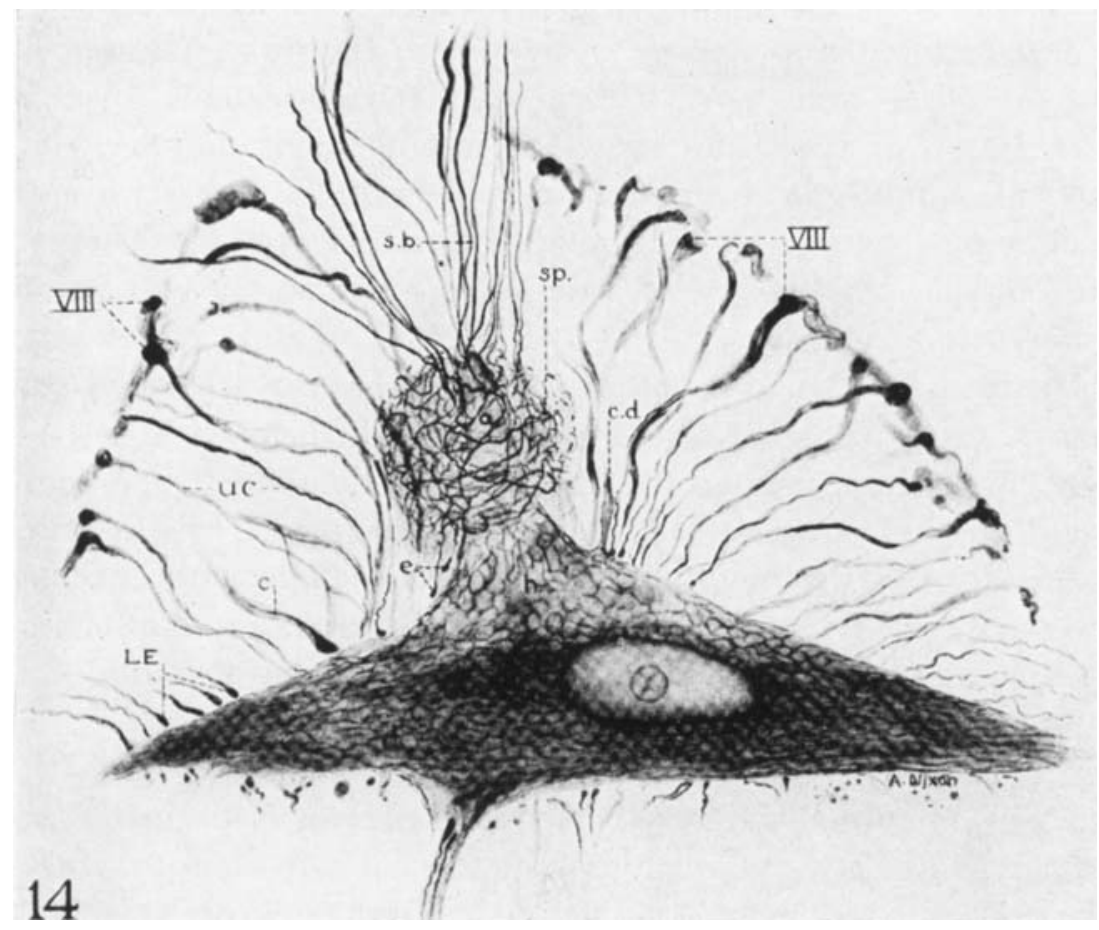

Fig. 10A Structural basis of polar function. See Coghill ('34) on Mauthner cell of fish. Note the large cell body and dendrites and the copious supply of exeitatory afferents. (Bodian). J. Comp. Neur., 68: 117, 1937.

The great expanse of the dendrites and cell body, and the large number of synapses of Mauthner's cell are ideal for generation of neurocellular current. The specialized axon cap with its spiral winding creating an effective negative field about the tapering inhibitory pole, and the tightly-packed 
synapses affording access to great numbers of inhibitory afferents give strategic control to the outflow of excitatory current.

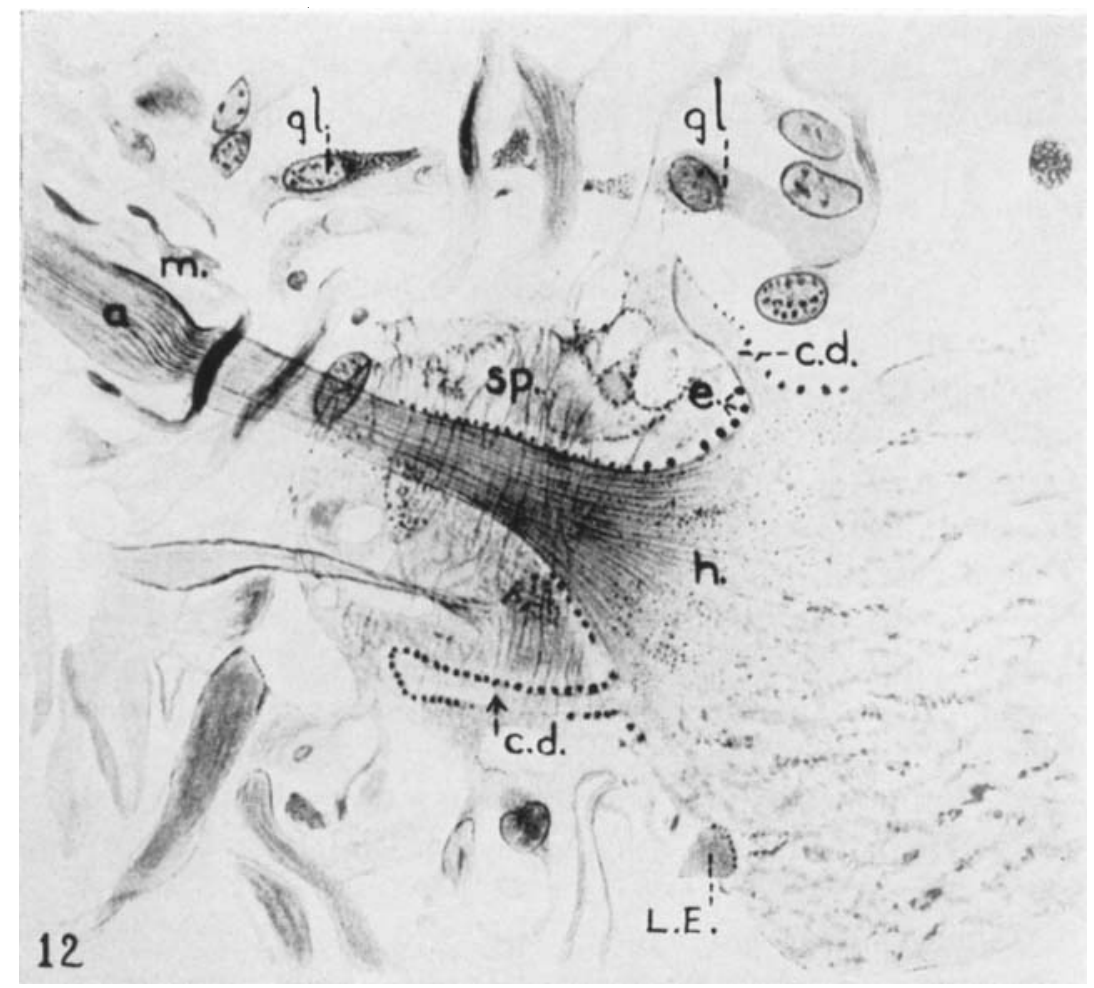

Fig. 10B Cross section of axon hillock region of Mauthner cell. Note tightlypacked synapses on "inhibitory pole" and their spiral windings. (Bodian). J. Comp. Neur., 68: 117, 1937.

The neurophysiological observations of Mr. Retzlaff, reported in this issue, reaffirm the polar function of the neuron, postulated by Coghill ('34), in 5 varieties of nerve cells.

Theoretically the inhibitory pole may function in diametrically opposite ways depending upon whether impulses impinging on it are increasing or decreasing in number. Increase of impulses would oppose the flow of neurocellular current and reduce or inhibit nerve cell activity, whereas decrease 
of impulses would augment the flow of current and increase nerve cell activity. Both excitation and inhibition of a neuron may therefore come about in two ways: excitation by impingement of impulses on the excitatory pole, or withdrawal of impulses from the inhibitory pole; and inhibition by withdrawal of impulses from the excitatory pole, or impingement of impulses on the inhibitory pole. Experiments illustrating each of these 4 adjustments of nerve cell function will be presented below.

\section{IMPLEMENTATION OF POLAR FUNCTION IN PAIRED NEURONS}

T. Graham Brown ('11) had proposed a central reciprocal inhibition between antagonistic neurons (flexor and extensor neurons e.g.) as a means of coordinating their activity. This postulate was based on experiments showing that progression movements were not abolished, either by deep narcotization or deafferentation of the spinal animal. As a result of these observations, Brown was led to announce his concept of the functional unit of the nervous system: "It is not the activity of the reflex arc as is usually assumed it is the activity of a unit which we may term the 'half-center' - or perhaps the center composed of the linked 'half-centers.",

Existence of mechanisms, innate to nerve centers, capable of integrating coordinated movements without reflex support is now well established (see Coghill, '29; and Tinbergen, '51).

We have therefore tried to explain the rhythmical act of breathing, using it as a general illustration of motor integration, by combining the theory of polar function postulated by Coghill ('34), and reciprocal interlocking postulated by Brown ('11) with our views on nerve cell function.

The explanation is postulated in simplified form in figure 11 in which the respiratory center is represented by two nerve cells, interlocked centrally by reciprocal inhibitory collaterals, and joined peripherally by dichotomized dual excitatory afferents ending on opposed half-centers. Afferents 
2,3 , and 4 would tend to excite both half-centers simultaneously. The reciprocal inhibitory collaterals would tend to prevent simultaneous excitation and assure coordinated alternation. Thus, when the inspiratory neurons discharge they would dispatch impulses to the inhibitory pole of expiratory neurons via the reciprocating collaterals. Imposition of nonpropagated synaptic negative sinks at the inhibitory pole

STRUCTURAL BASIS FOR DUAL EXCITATION AND INHIBITION BY SENSORY AFFERENTS

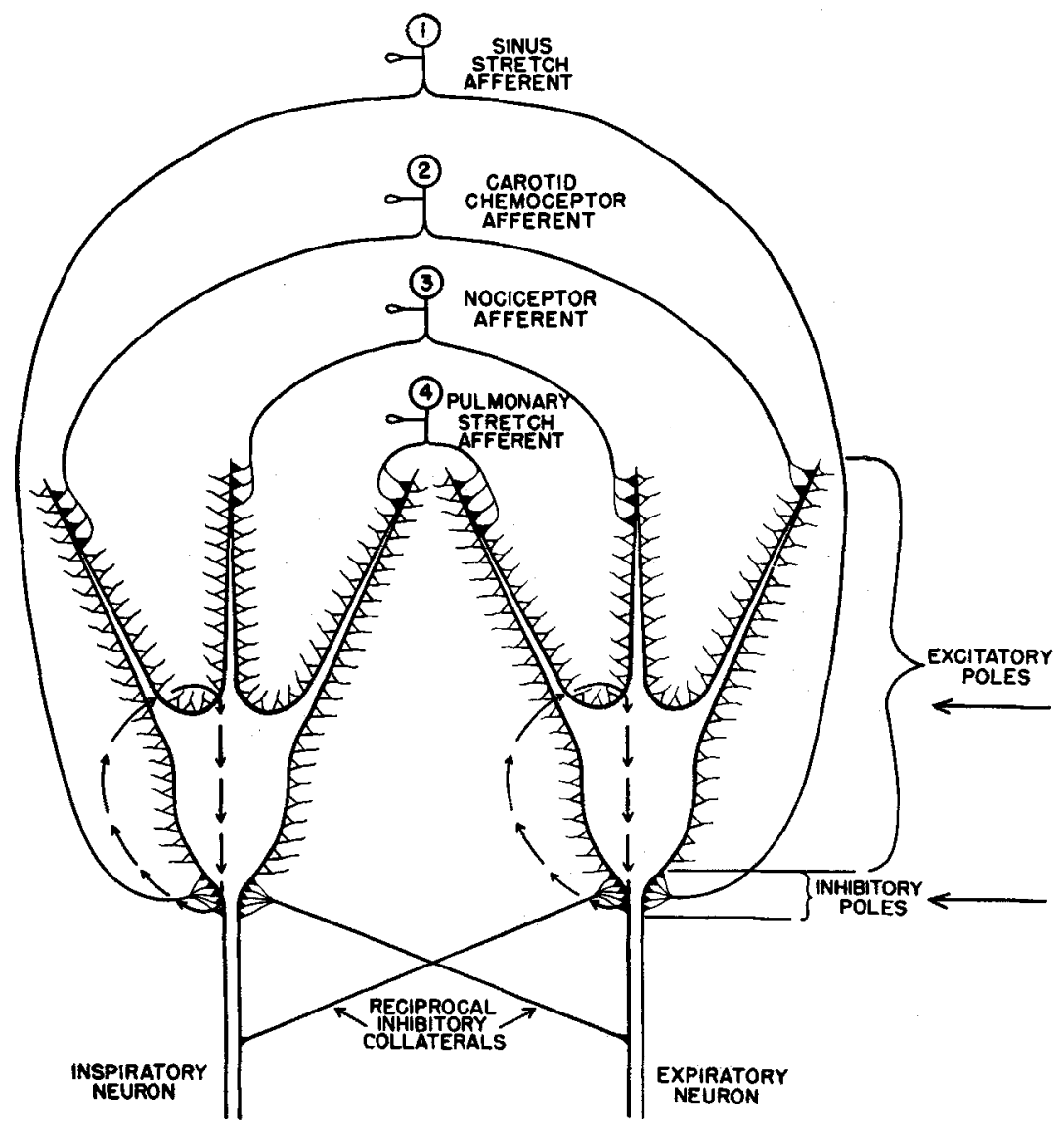

Fig. 11 A simplified concept of paired half-centers showing sensory reciprocal inhibitory interlockings (see text for details). 
would decrease the polar gradients and neurocellular currents of the expiratory neurons to subthreshold value, and keep them from interfering with inspiration. When next the inspiratory neurons ceased discharging, they would withdraw inhibitory impulses from the expiratory neurons and thereby increase their polar potentials and neurocellular currents to threshold value, allowing expiration to take over.

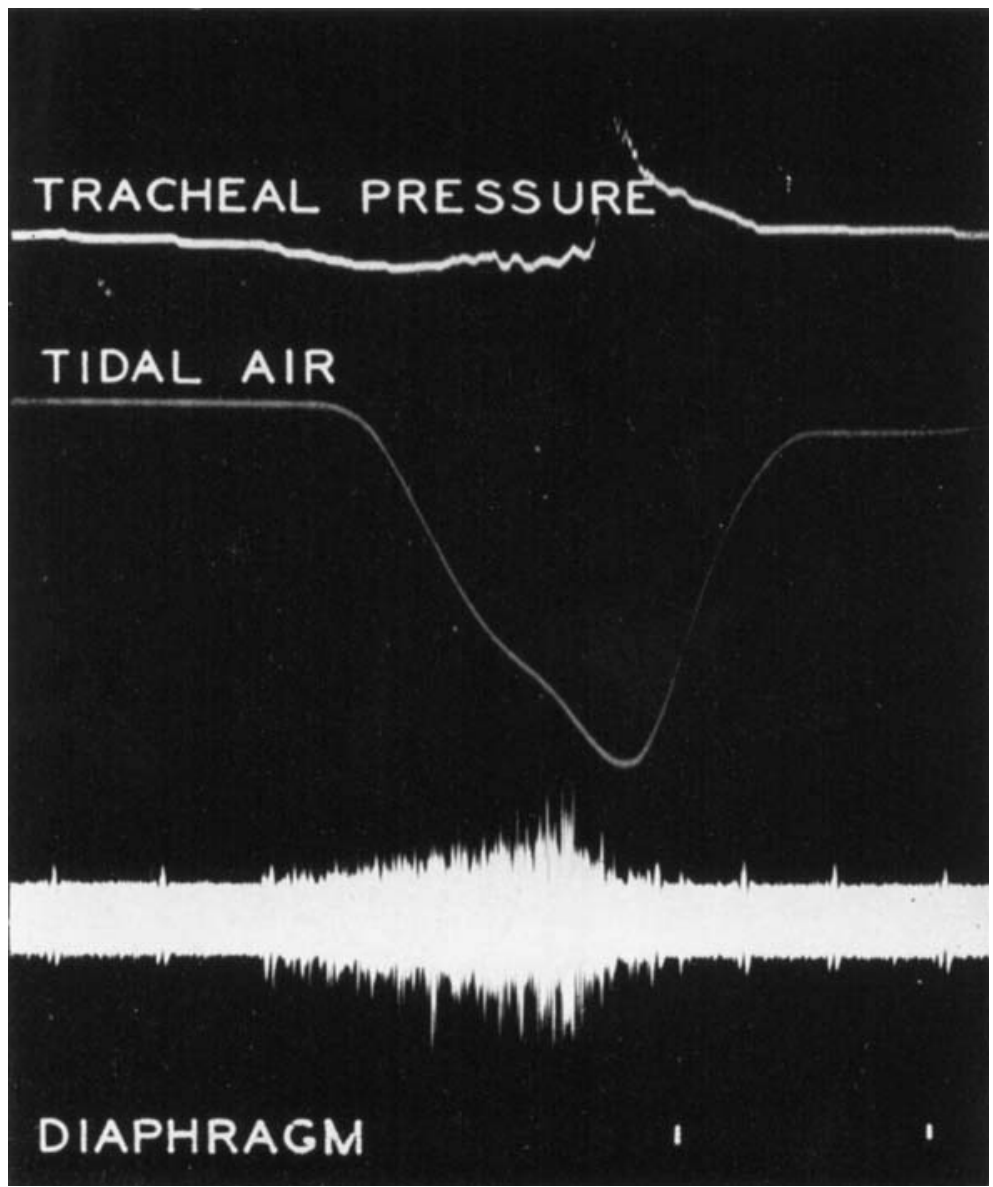

Fig. 12 Inspiratory fusillade showing progressive increase of action potentials of the diaphragm in the lower record. The tidal air record shows corresponding filling of the lungs. The tracheal pressure tracing of the changes in tracheal pressure shows the necessity of correcting for lag of the spirometer in the tidal air tracing. 
Expiratory neurons would now dispatch impulses to the inhibitory pole of the inspiratory neurons and hold inspiration in abeyance until expiration had finished, and so on. The details of these mechanisms will be expanded below.
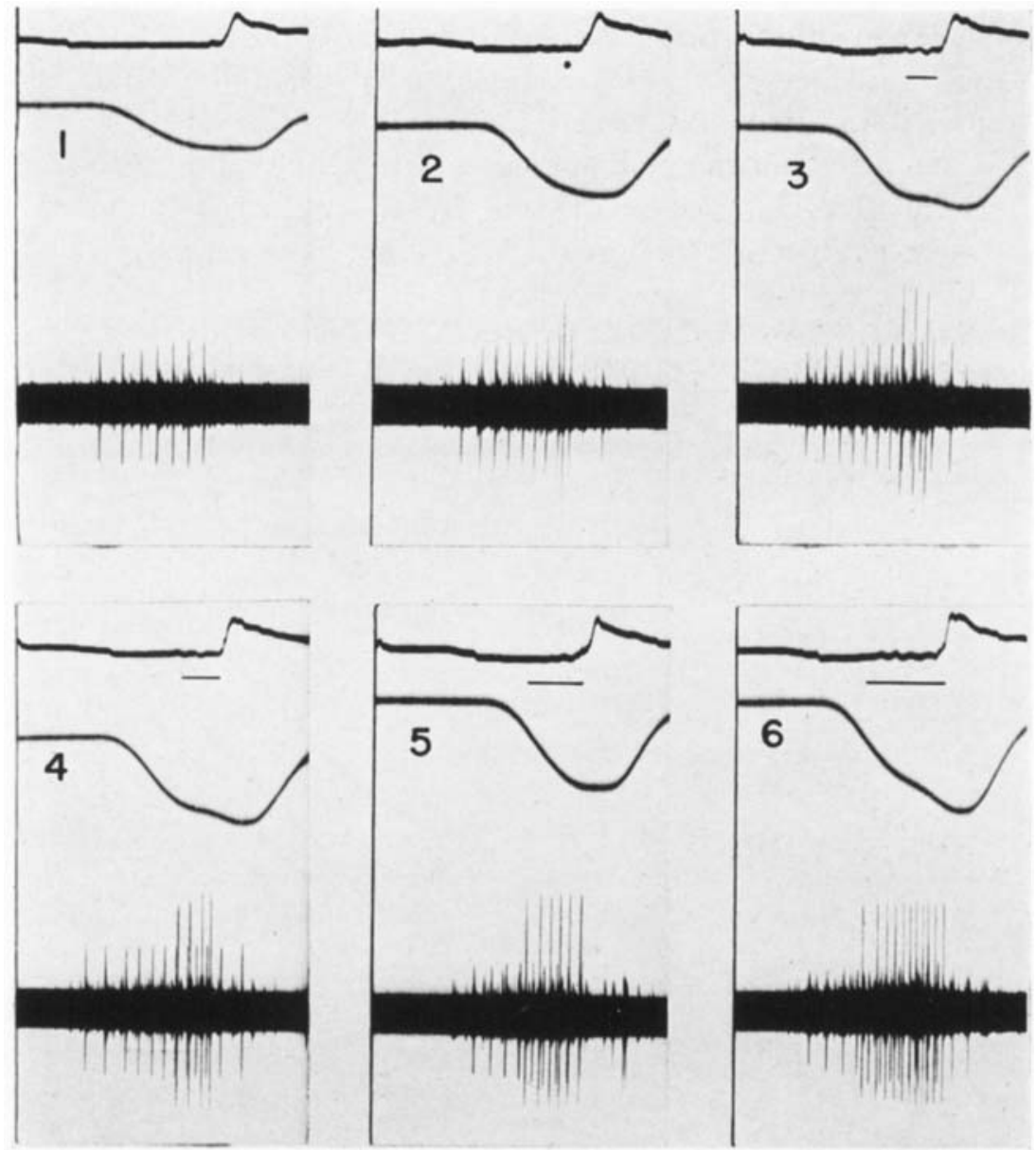

Fig. 13 Note increase of twitch potentials of inspiratory muscle during progressive asphyxia resulting from rebreathing into a confined space. Note increase of twitch frequency of individual units which occurs with each inspiration, and also reeruitment of new units which attends increase of depth of breathing. 


\section{ACTIVITY PATTERN OF INSPIRATION}

It seems desirable at this stage to give attention to pattern of motor activity, and to conceive of a neurostructural arrangement of neurons which could explain pattern. The act of inspiration was selected as the most suitable for this purpose because, of all patterns, that of inspiration has been established in greatest detail (Adrian and Bronk, '29a, '29b; Bronk and Ferguson, '35; Atkinson, Brown and Gesell, '40; Winterstein, '11; and Gesell, Atkinson and Brown, '40).

When air is normally inspired into the lungs, an increasing mechanical resistance is offered by the deformation of the thoracic cage and the lungs which must be overcome if the

\section{SCHEMATIC REPRESENTATION OF RECRUITMENT, INSPIRATORY ENCROACHMENT, AND COINCIDENCE OF MUSCLE FIBER ACTIVITY}

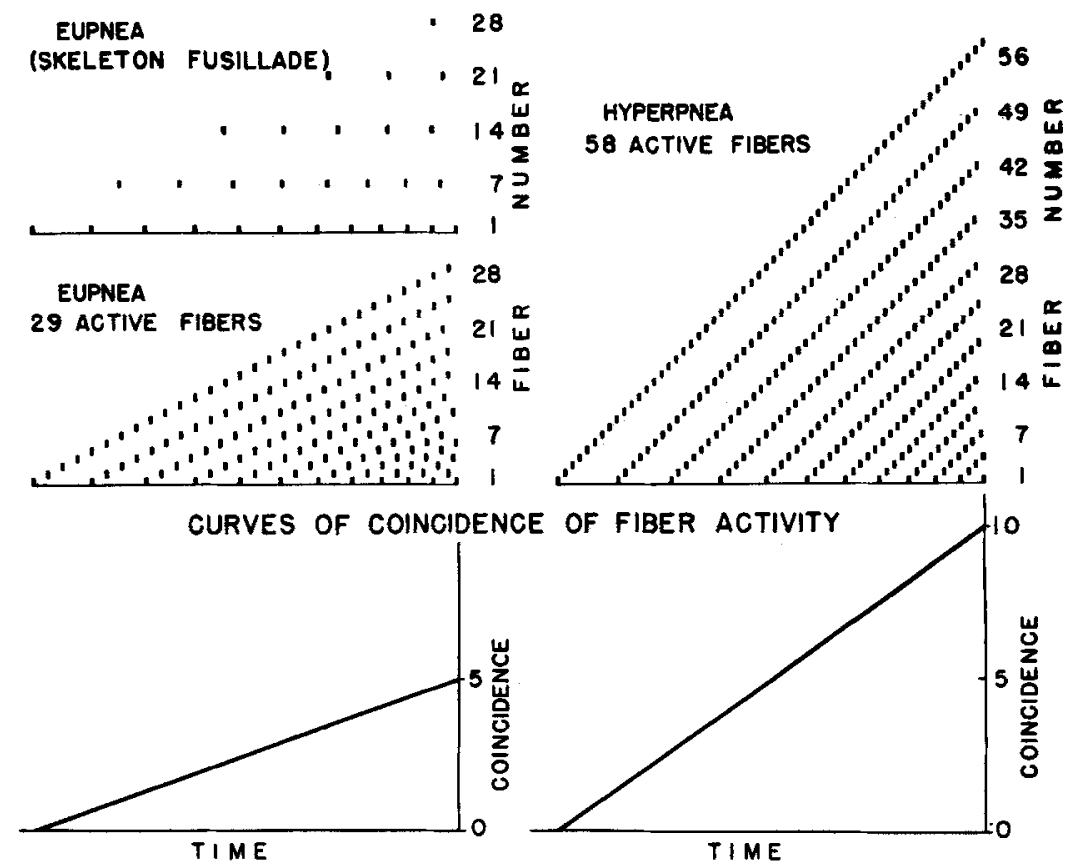

Fig. 14 Typical patterns of inspiratory contractions during eupnea and hyperpnea showing change of twitch frequency and addition of new musele units by reeruitment (see text). 
lungs are to be adequately filled. The effectiveness with which this requirement is met is illustrated in figure 12. The electrical record was obtained with the aid of widelyseparated electrodes placed on the outer surface of the diaphragm. This arrangement picks up action potentials from a large area of muscle and therefore indicates change of strength of contraction of the diaphragm as a whole. Inspiration is seen to begin with a weak contraction and to increase in strength up to the end of the act, when resistance is highest and the mechanical energy is most needed.

Such a composite fusilade can be broken down into its constituent components with the aid of closely-approximated electrodes which pick up the twitch potentials of more restricted groups of muscle units (see fig. 13, e.g.). An inspiratory contraction so analyzed reveals typical patterns, like those schematized in figure 14. Inspiration begins with twitching of a single unit at a relatively slow rhythm of about 5 to 10 per second. The tempo increases as inspiration advances towards completion. This muscle unit thus contributes an increasing number of tugs per unit of time as mechanical resistance mounts. Succeeding muscle units are recruited, one after another in rapid succession, up to the end of inspiration. Thus, a pulling together of an increasing number of units also meets increasing resistance (see lower curve of fig. 14). All successively recruited units go through the typical increase of twitch frequency noted in unit one. The number of twitches contributed by each added unit, however, diminishes progressively up to the last unit which may add, as in record 2 of figure 13, but a single tug to the myriads of muscle fiber twitches composing inspiration.

When an animal is forced to increase its strength of breathing above normal it employs two methods. It increases existing activity of individual muscle units and it recruits additional muscle units into activity. It will be seen that the recently recruited unit which delivered a single twitch in breath 2 , delivered $2,3,4,6$, and 11 twitches in the succeeding breaths. The more important strengthening of inspiration 
occurs by recruitment of inactive units into active service, in the manner schematized for hyperpnea involving 58 muscle fibers instead of 29 in the right half of figure 14 .

A central nervous mechanism underlying this remarkable gradation of strength is postulated in the following section.

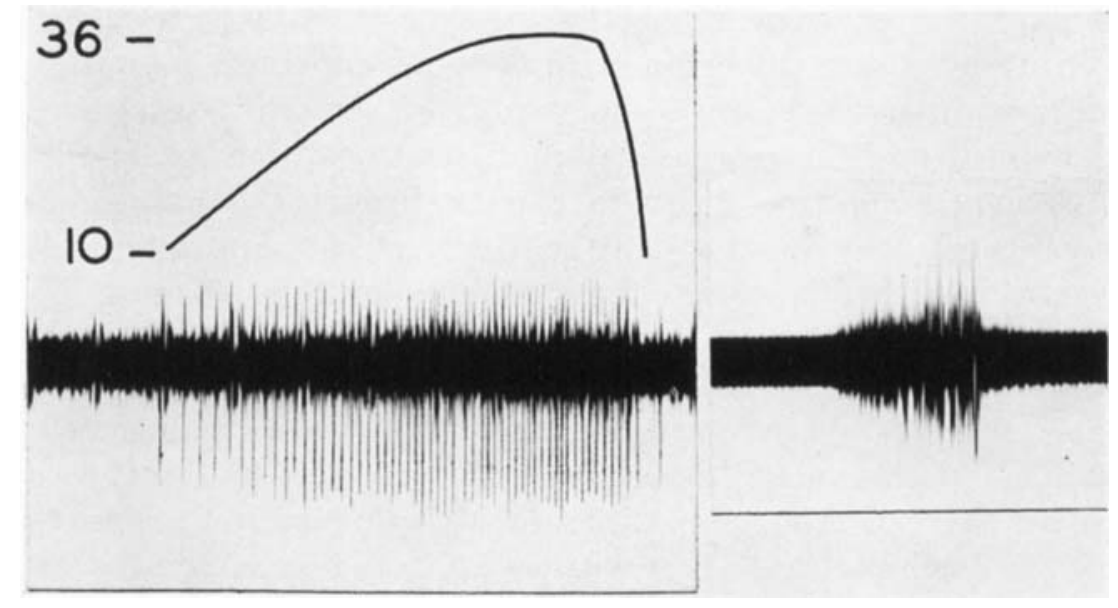

Fig. 15 Electrical activity of inspiratory neurons during curari paralysis showing that the central mechanisms of acceleration and recruitment remain intact despite abolition of periodic reflex support. The record on the left shows acceleration of discharge of a single inspiratory unit during the inspiratory act. The record on the right is recorded from the phrenic trunk and illustrates the phenomenon of recruitment.

\section{A THEORETICAL CONCEPT OF STRUCTURAL AND FUNCTIONAL ORGANIZATION OF INSPIRATORY NEURONS}

The activity of the respiratory center is little affected by curarization, as is evidenced by the electrical activity of the phrenic nerve. Since muscular paralysis abolishes all periodic reflex support of the vagus and muscular proprioceptor afferents, Winterstein ('11) and Bronk and Ferguson ('35) inferred that automaticity is inherent in the centers. The added fact that the pattern of inspiration remains undisturbed in curarization, even as to details (Gesell, Atkinson and Brown, '40), shows the existence of an innate structural 
mechanism responsible for motor pattern. This point is illustrated in figure 15. Note that frequency of impulses of a single phrenic nerve fiber increases from 10 to 30 impulses a second in the left hand record, and recruitment in the right hand record.

The mechanisms of acceleration and recruitment must, therefore, be sought in the centers. We have turned to the so-called recurrent collaterals illustrated in figures 16,17 , and 18. These recurrents are presumed to have two functions, depending on their site of origin and termination.

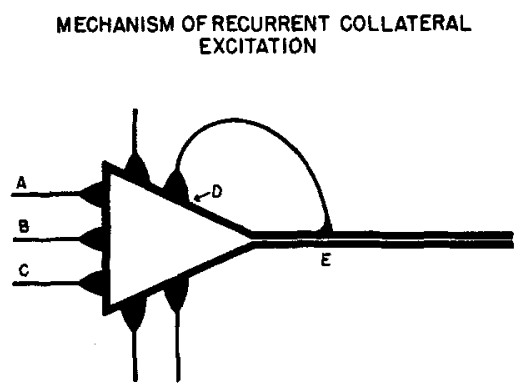

Fig. 16 Schematic representation of recurrent collateral. An impulse "transmitted" from synapse A to $E$ would theoretically return to $D$ while membrane is in a refractor state due to the short recurrent transmission time involved. That impulse should however be usable to boost neurocellular current (see text).

In figure 16, the recurrent collateral turns back and ends on the excitatory pole of the parent cell. A discharging neuron should therefore return impulses to itself and automatically reinforce its neurocellular current by providing additional synaptic depolarizations.

Figure 17 and its accompanying table offers an explanation of acceleration in conformance with this theory. The tabulated increase of frequency of discharge is based on the assumption that the number of impulses generated by a nerve cell varies with the number of impulses impinging on the excitatory pole. Granting that 1,000 impulses impinge on the nueron each second, and that one impulse is generated by every 200 impinging impulses, the nerve cell will discharge 
5 times per second. Impulses so generated are tapped and returned in the multiple of 20 to the parent, with the result that the cell now receives 1,100 instead of 1,000 impulses per second, and therefore generates 5.5 instead of 5 impulses per second. A progressively increasing feed-back increases the sum-total of synaptic depolarizations in the parent neuron,

AN HYPOTHETICAL MECHANISM OF RYTHMICAL ACCELERATION AND INTERRUPTION OF THE STEADY STATE DISCHARGE
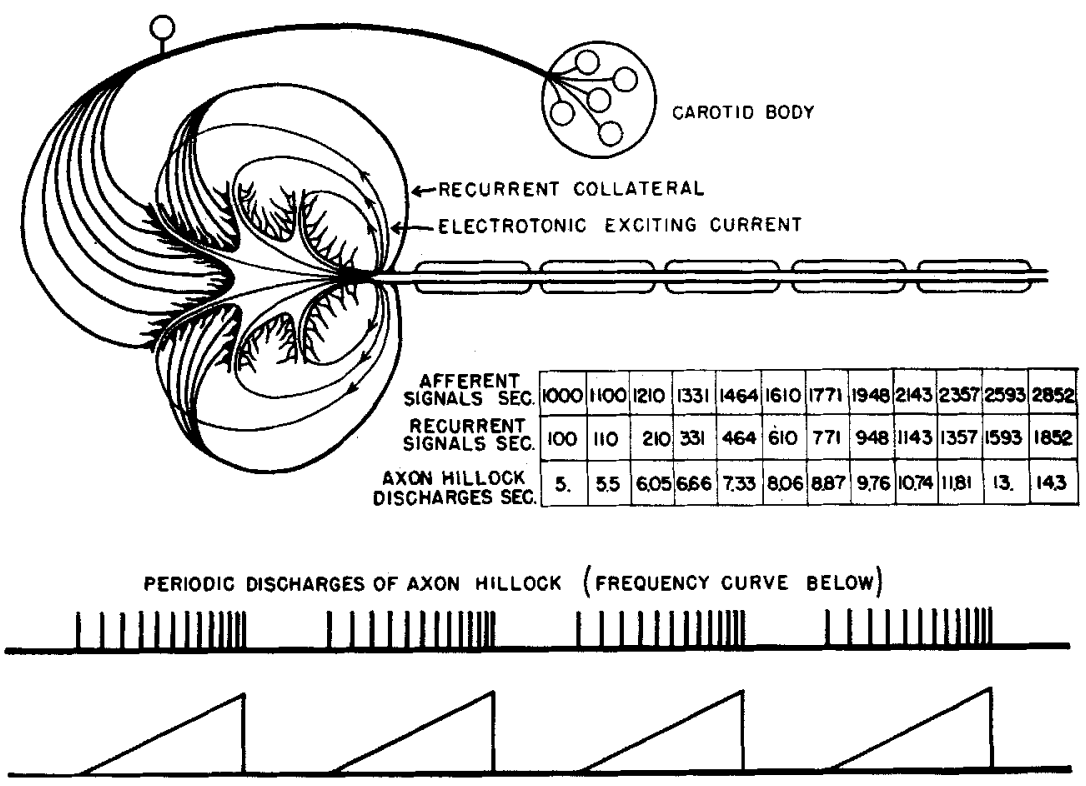

Fig. 17 Schematic representation of the mechanism of acceleration of inspiratory twitch frequency (see text).

thus causing neurocellular current and frequency of discharge to mount progressively until automatically interrupted by a mechanism to be discussed in the following section.

Recruitment is theoretically explained with the aid of recruiting collaterals, illustrated in figure 18. Cell 1 is assumed to act as pace-setter and until it discharges, cells $2,3,4$, and 5 are assumed to be dormant due to a subthreshold neurocellular current. Discharge of cell 1 delivers additional 
impluses to cell 2 via recruiting collaterals and brings the neurocellular current to threshold level, whereupon cell 2 is recruited. Cell 2 , by similar method, recruits cell 3 , and so on down the line.

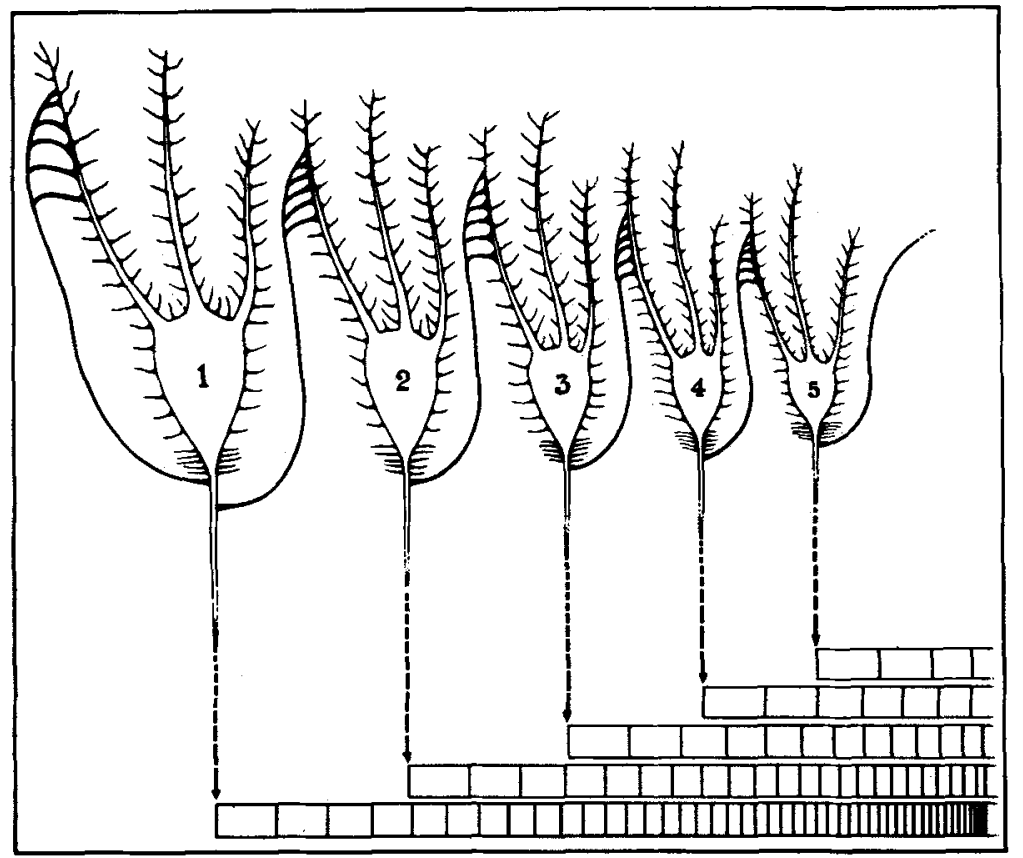

Fig. 18 Theoretical structural basis of recruitment. Note that nerve cells 1, 2, 3 , and 4 connect by recruiting collaterals with cells $2,3,4$, and 5 .

It is to be noted that a recruiting collateral should also have the effect of increasing frequency of discharge, since it passes the general pattern of activity from one cell to another.

\section{INITIATION AND TERMINATION OF INSPIRATION}

The causes underlying the beginning and the ending of each cycle of an innate rhythm: swimming, flying, walking, gill movement, breathing, etc., (see Brown, '11; Coghill, '29; and Tinbergen, '51) must be sought centrally and not peripherally. 
In explanation of these miscellaneous rhythms we tried, some years ago, to account for the onset and termination of inspiration (Gesell, '40) with the aid of a graph, illustrated in figure 19. This graph is constructed on the assumption that the functional activity of a neuron is the resultant of two factors, namely strength of excitatory current, and degree of excitability of the neurons to this current. These factors are shown to fluctuate differentially in significant relation to each other with each rhythmic cycle.

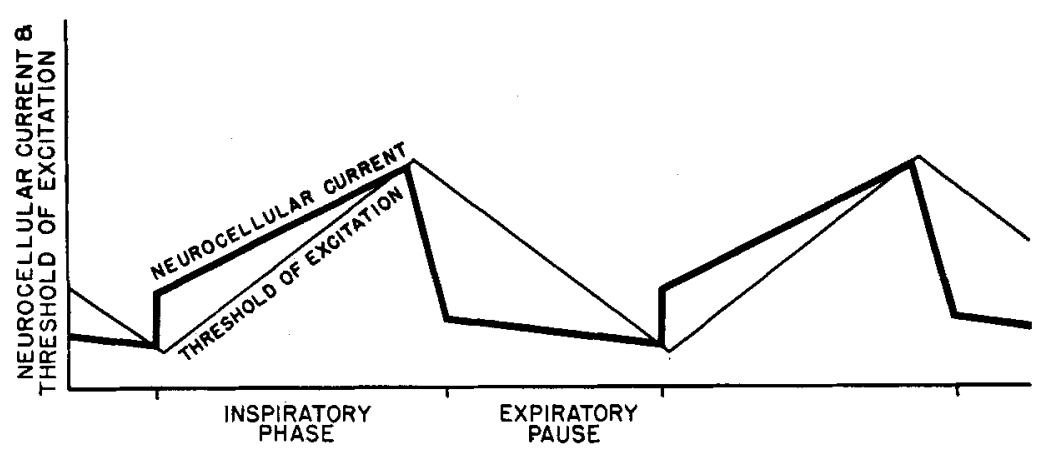

Fig. 19 Differential changes of neurocellular current and of threshold of excitation which theoretically are believed responsible for rhythmic initiation and termination of the inspiratory act. (See text for details.)

Inspiratory neurocellular current is represented as subthreshold at the end of inspiration and remaining subthreshold up to the end of expiration when, due to the more rapid increase of excitability (diminishing threshold), it attains superthreshold strength and sets off the inspiratory discharge. This discharge is self-augmenting due to the innate feed-back via reinforcing recurrent collaterals. Neurocellular current increases in proportion to feed-back, but threshold of excitation rises more rapidly and ultimately cuts the cell off at the crossing of the curves indicated in the graph.

Stoppage of inspiratory discharge withdraws reinforcing feed-back with the result that neurocellular current decreases, abruptly at first, then more slowly up to the next inspiration. 
The new inspiratory cycle begins at the next crossing of the differentially fluctuating curves of neurocellular current and threshold of excitation whereupon the cycle repeats itself.

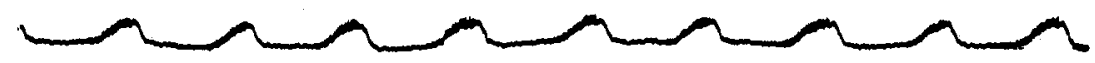

Fig. 20 Slow and spike potentials of a phrenic rootlet during eupnea. Note that slow and spike potentials increase progressively with each inspiration. Com. pare results with theoretical schematization of figure 19 (see text).
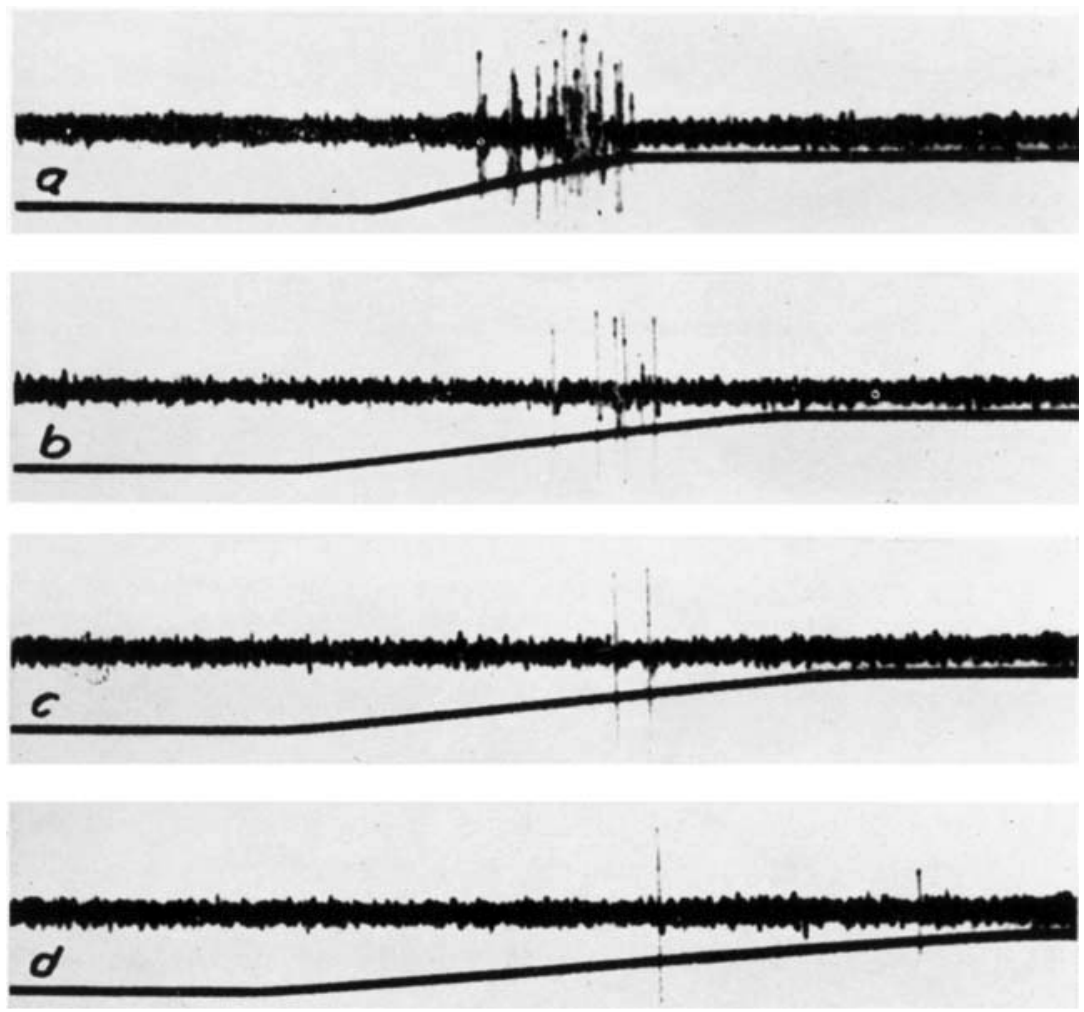

Fig. 21 Repetitive response of sciatic nerve of the cat to linearly increasing eurrents. Note that current rises to same maximum but that response is greatest to the most rapidly increasing gradient. Note also that the discharge of the nerve ceases when the current remains at a steady maximum thus demonstrating "adaptation." (Skoglund). 
To put the matter in another way, it may be said that inspiration comes to a close by the process of "adaptation" to an increasing current which might be referred to as "positive adaptation" and that similarly inspiration comes into being by a process of adaptation to a decreasing current that is a "negative adaptation."

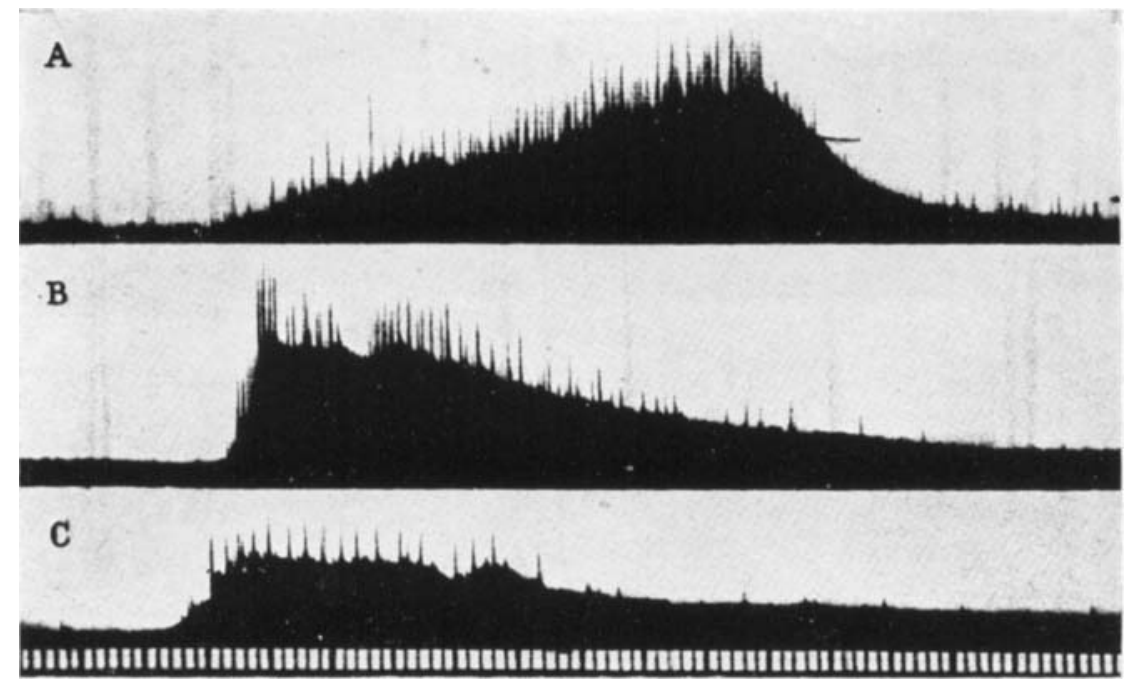

Fig. 22 Electrical changes in ventral roots of spinal frog showing relation of spike potentials to magnitude of slow potentials: stimulus-pinching of ipsilateral toes. (A) Pressure increased gradually and suddenly removed. (B) Pressure suddenly applied and gradually removed. (C) Nerve subdivided to reveal response of single unit. (Barron and Matthews).

In evidence of this view, attention is called to figures 20,21, 22,23 , and 24. Electrical potentials of the proximal phrenic rootlet registered in figure 20 (see figs. 18, 19, and 20) with the method used by Barron and Matthews ('38) for studying the slow and spike potentials of motor sensory spinal roots, are to be compared with the predicted changes graphed in figure 19. Of particular interest is the regularity of the electrical changes which occurred with each respiratory cycle. This no doubt was due to the uniformity of the eupnea. In agreement with the theoretical graph of figure 19 there 
is, with each inspiration, a gradual rise of negativity of the proximal with respect to the distal electrode indicating an increasing negativity of the cell body during inspiration. Spike potentials superimposed on this rise of negativity increase in frequency as depicted in figures 13 and 15.

Close inspection of the record reveals cessation of spike activity just short of maximum neurocellular current. This interruption of spike activity in figure 20 prior to attainment of maximum negativity agrees with the view that inspiration is brought to conclusion by a "positive adaptation" to an increasing current. This result has been duplicated in linearly increasing galvanic stimulation of the sciatic nerve of the cat by Skoglund ('42), in which spikes increased with current and disappeared when current was held at a steady maximum (see fig. 21).

Barron and Matthews ('38) (see fig. 22) record a result on the spinal root of the frog remarkably similar to figure 20. They apply progressively increasing mechanical pressure to the foot (fig. 22) and elicit a gradual rise of slow potential and progressive increase of superimposed spike potentials.

Partridge ('52) observed comparable ventral root potentials on repetitive volley stimulation of sensory afferents of the spinal frog (fig. 23). He evoked a rise and fall of slow potential and an increase and decrease of spike activity with each volley. The slow potentials were summed more rapidly and to a higher level with the greater frequency of stimulation, and spikes increased in proportion. Similar results have been reported in the extensive experiments of Bonnet and Bremer ('52).

Brassfield and Steinberger ('51) have made significant observations on the sartorius muscle nerve preparation of the frog, by paralyzing the preparation with curare which, in effect, transforms this multicellular structure into a macroscopic neuron. Stimulation of the motor nerve sets up myriads of non-propagated motor end-plate potentials in the muscle, the total effect of which is electrically recorded. In figure 24 , to be read from right to left, Brassfield and Stein- 

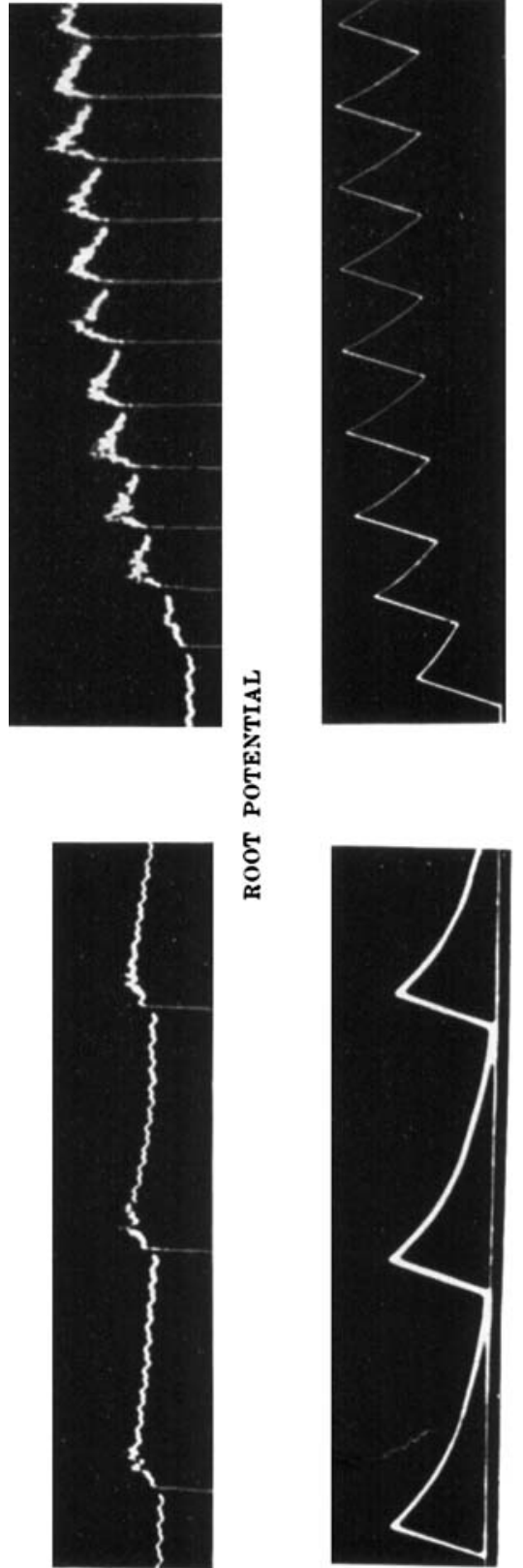

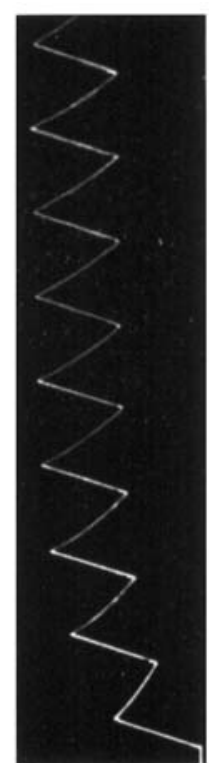

害

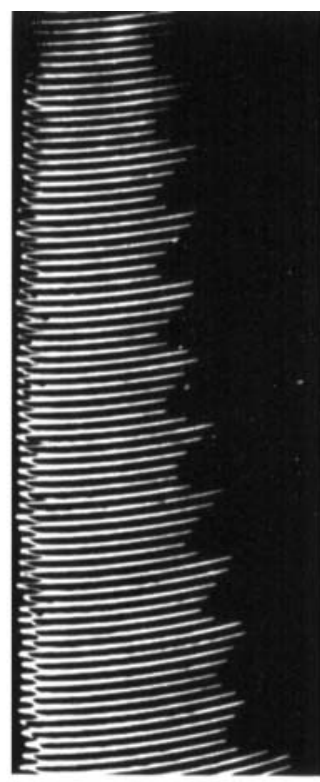

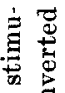

胥

药

क

s.

$\underbrace{2}$

象

范

4

so

冚

क्ष क्ष

$\dot{0} . \dot{0}$

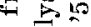

उำ

要

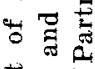

응

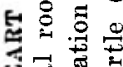

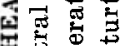

응

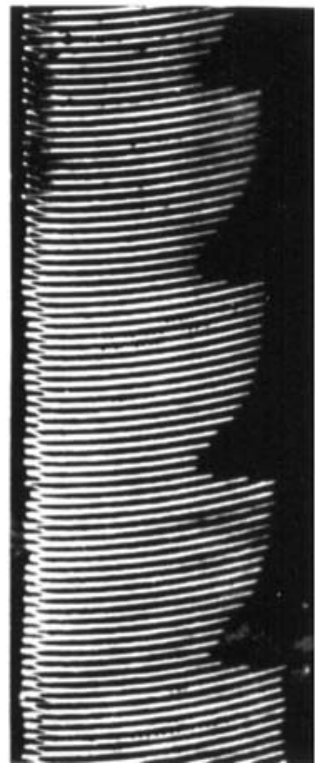

㝳丞

on

预

娄

‥ 훙

品

폴

해

쿵

浔

है

क

$\ddot{0}$.

要

$\pm \&^{\circ}$

部

용

点要

路岁辛

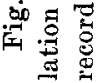



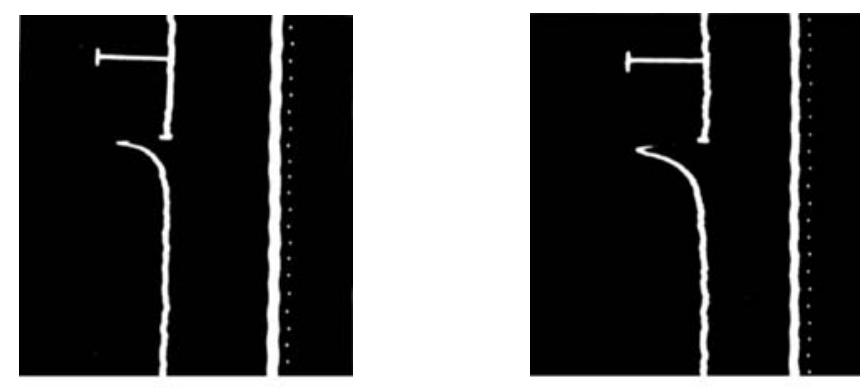

音 要
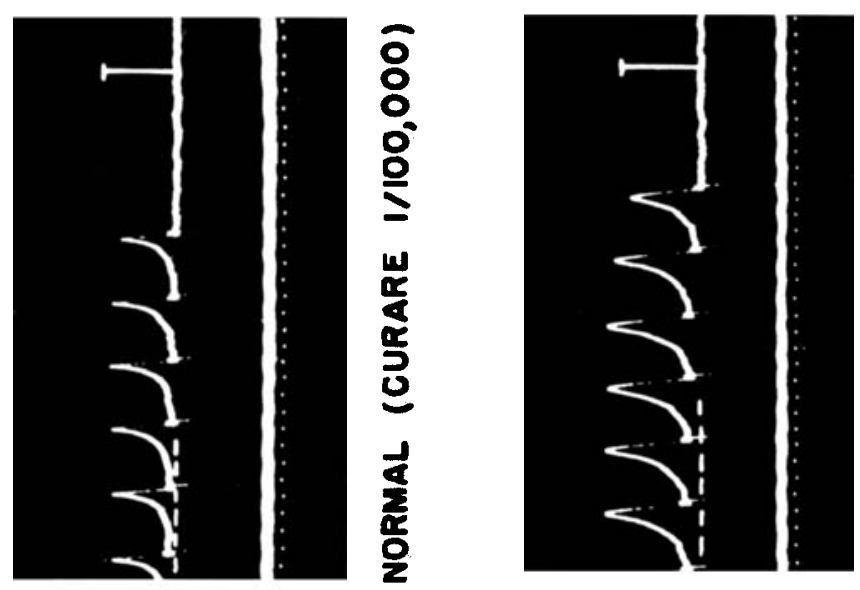

营兽 氙包

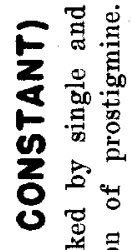
w 200 5 네 9 항 之造芶 음요 x ก (4) Z क् 둥
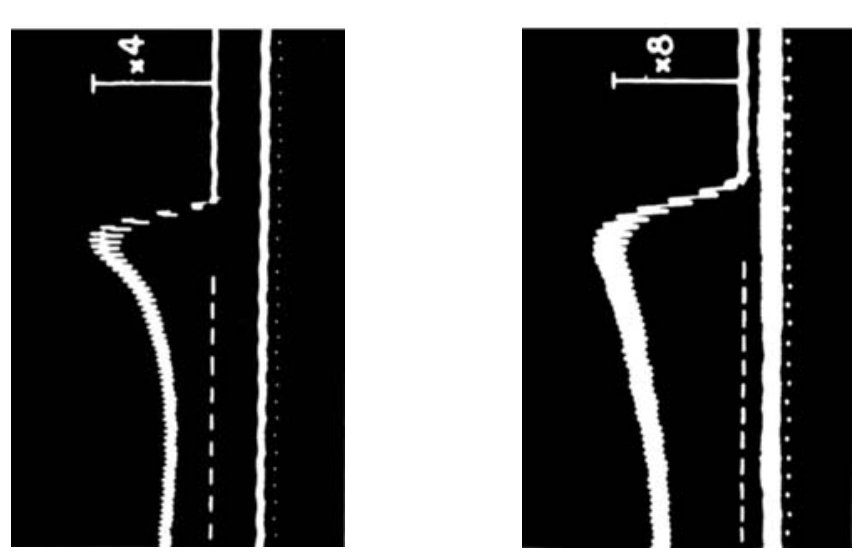

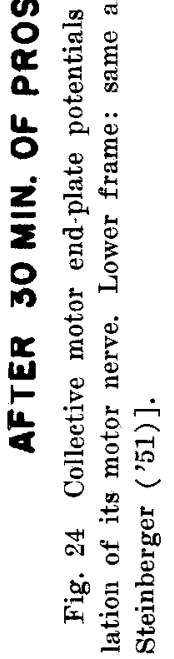


berger placed one electrode over the center of motor endplate population and the other on a plate-free pole and recorded the slow potentials resulting from single shocks and from shocks at low and high frequencies of stimulation. A single shock (see upper right record) caused a sudden rise of collective end-plate potential followed by an exponential decay. The relatively small summation of residual slow potentials at low frequency stimulation, in the upper middle record, and the greater summation at high frequency, in the upper left record, are in fact in excellent agreement with those of Partridge on the spinal cord.

The sartorius was next immersed in a solution of prostigmine to study the effects of retardation of hydrolysis of acetylcholine by cholinesterase. A single shock now produced a greater rise of potential followed by a retarded decay and the greater residual potentials of repetitive stimuli summed to higher levels. The significance of these findings will be apparent in relation to the neurohumoral theory of Loewi and of Dale to be discussed below.

\section{ELECTRICAL SOUNDINGS OF CENTRAL RESPIRATORY NEURONS}

In view of the participation of miscellaneous types of neurons in the respiratory act it seemed desirable to learn more about the coordination of their activities (Gesell, Magee and Bricker, '40; Gesell, '40). This seemed possible by conducting systematic electrical soundings of the medulla and spinal cord and registering the electrical potentials of respiratory neurons audibly recognized with the aid of a loud speaker. After photographing the action potentials and associated respiratory movements the sites of electrical activity were marked electrolytically. The cellular structures involved were later identified in histological sections with the aid of Doctor Crosby.

Outstanding in the results was the similarity of the activity pattern at the various stations composing the respiratory mechanism whether they were sensory, motor, or 

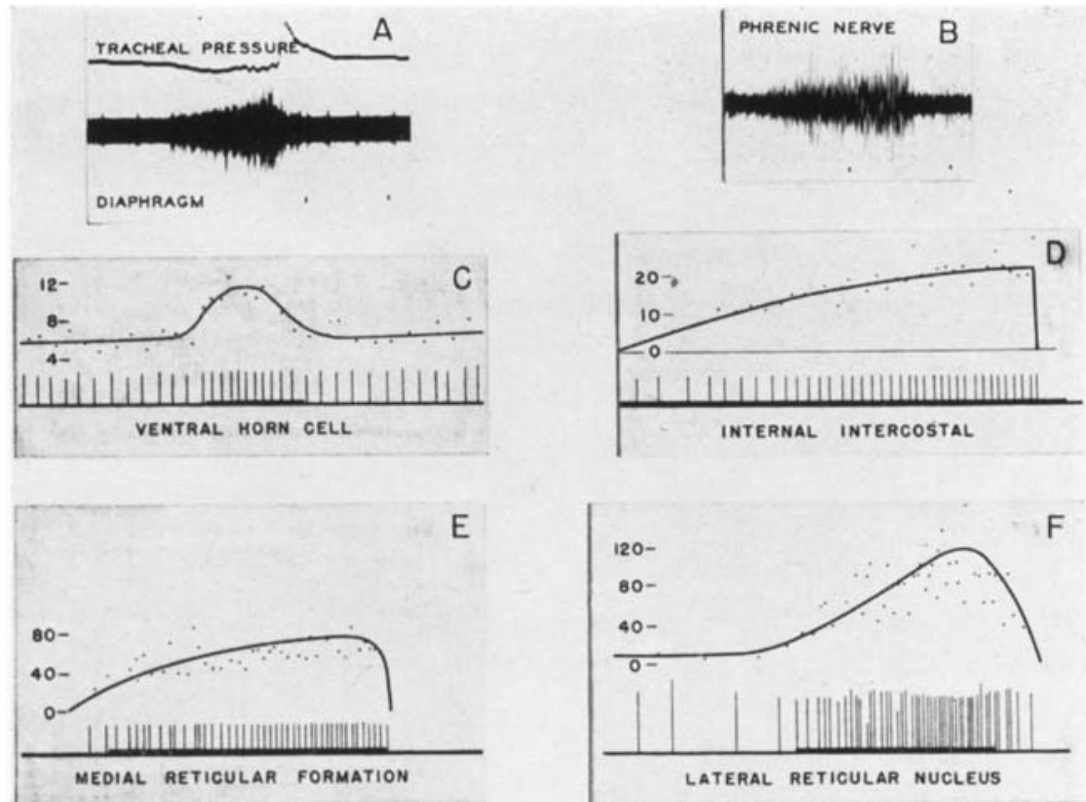

$E$
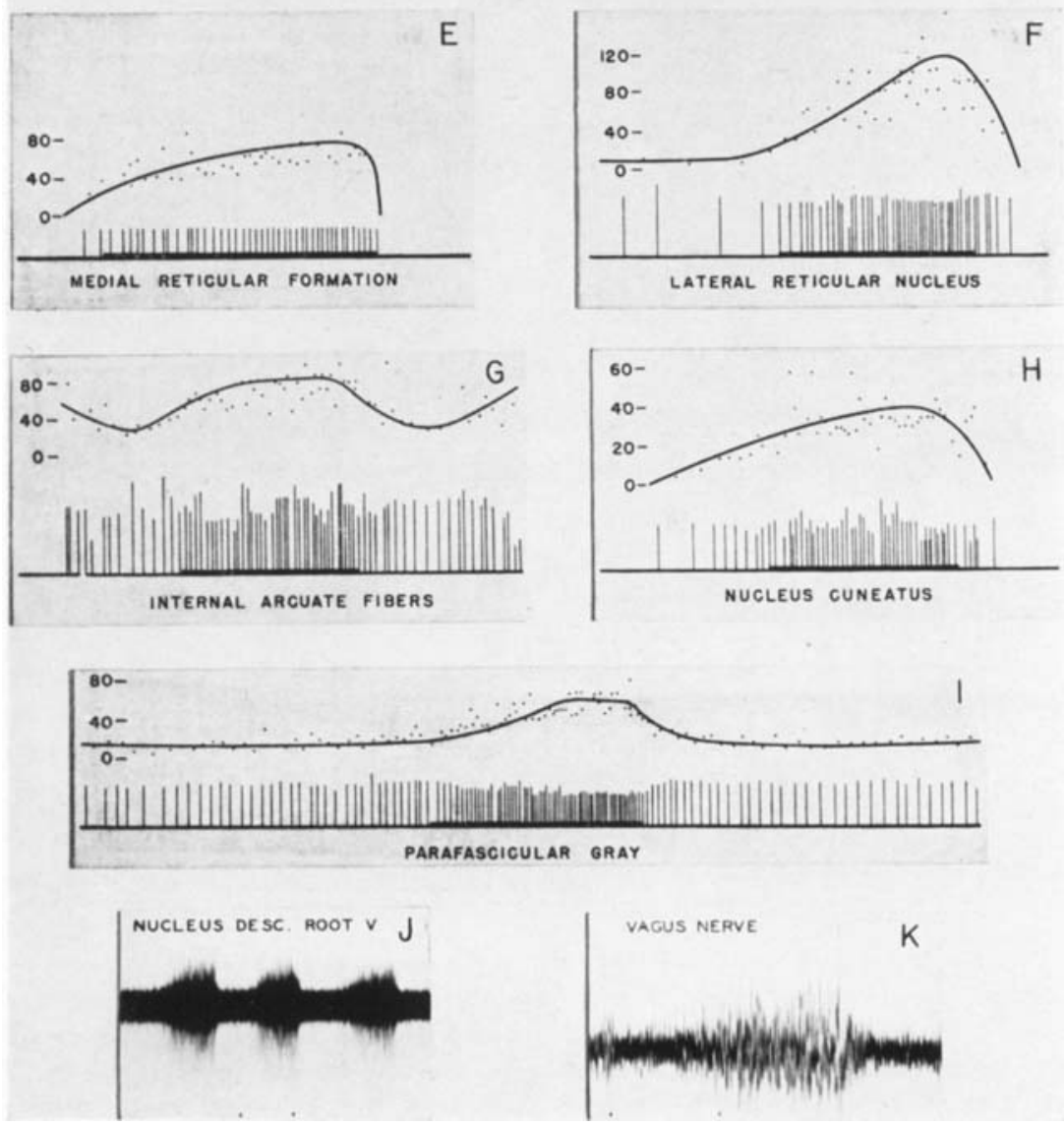

Fig. 25 Inspiratory action potentials recorded by electrical sounding of 11 inspiratory stations. 
intermediate structures. This point is illustrated for the inspiratory act in figure 25. The inspiratory pattern originates, we believe, in the reticular cells of the medulla from which it is transmitted to the subsidiary inspiratory motor

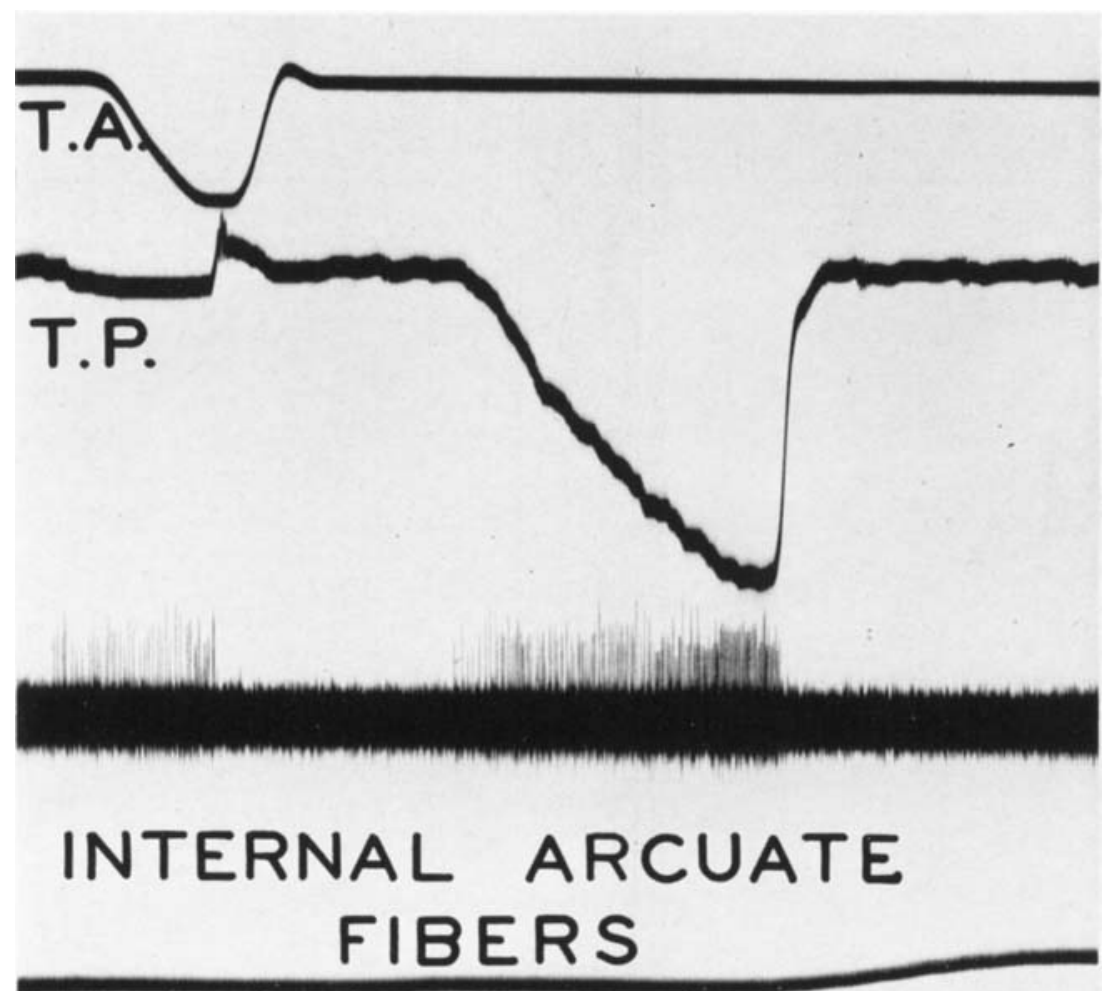

\section{INTERNAL ARCUATE FIBERS}

Fig. 26 Feed-back reinforcement of inspiratory act. The first inspiration occurred under normal experimental conditions. The second inspiration was opposed by tracheal occlusion. The augmented deformation of inspiratory proprioceptor endings in the latter feeds back more reinforcing impulses which in this instance are recorded as internal areuate spikes. The tracheal pressure record shows that the second inspiration was by far the more powerful. 
neurons in the cord via the reticulo-spinal tract. Each resulting increase of tension in inspiratory muscles and each inflation of the lungs, feeds two groups of proprioceptive impulses back to the respiratory center in patterns indistinguishable from the motor activity which created them. Compare records $\mathrm{A}, \mathrm{B}$ and $\mathrm{K}$, e.g., of the diaphragm and phrenic and vagus nerves. That the innate activity pattern

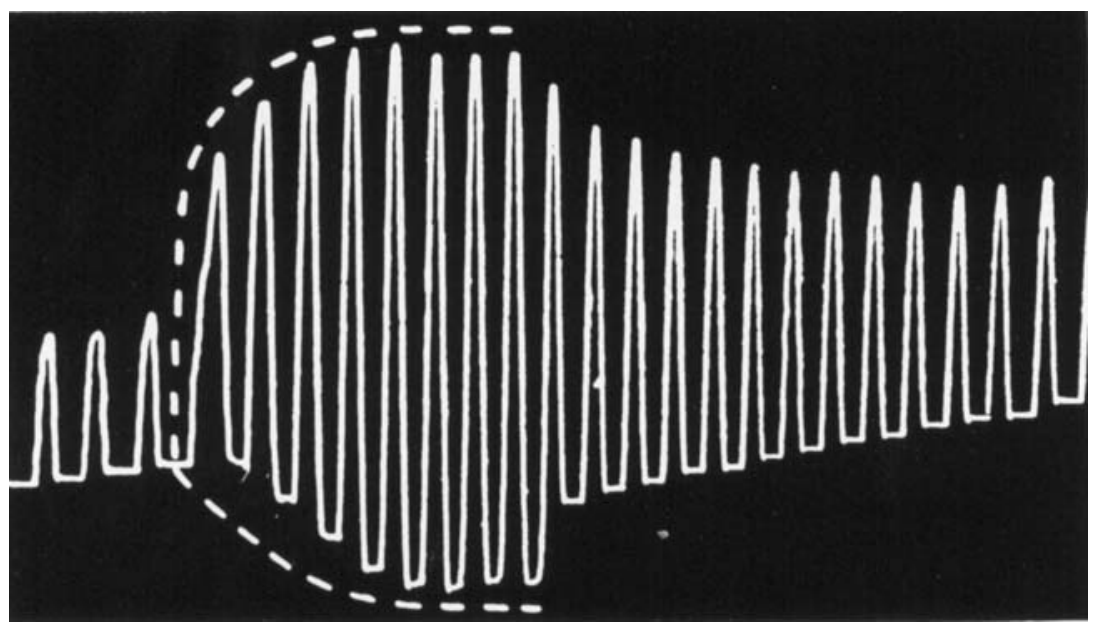

Fig. 27 Effects of prolonged stimulation of the carotid nerve on breathing, showing alternate reinforcement of inspiration and expiration. The relatively greater reinforcement of inspiration indieates that the carotid nerve is dominantly inspiratory, excitatory. The broken curves indicate the course of temporal summation at the respective half-centers (see text).

of inspiration automatically reinforces itself by a reflex feed-back is unquestionable.

The nicety with which this mechanism reinforces inspiration is suggested in figure 26 showing two respiratory cycles, a natural breath and a second breath opposed by tracheal occlusion. The tracheal pressure record shows that the second inspiration was by far the stronger of the two and that it was associated with a greatly increased activity of the internal arcuate fibers. It is, therefore, concluded that innate pattern and reflex feed-back were intimately coordinated. 


\section{DUAL EXCITATION AND DUAL INHIBITION}

(See figure 11)

Brief bursts of repetitive shocks applied to excitatory sensory afferents produce diametrically opposite reflex effects on breathing depending upon the moment of stimulation.

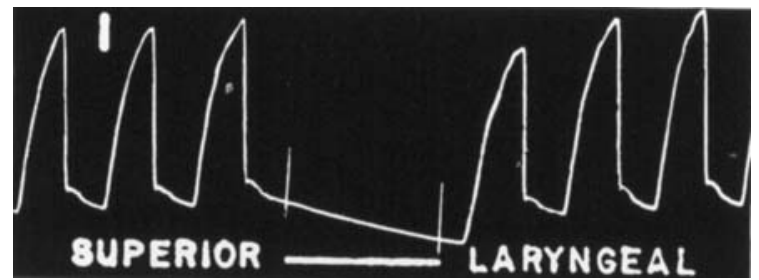

Fig. 28 Effects of stimulation of the superior laryngeal nerve. Note that stimulation begins during the expiratory phase. The prolonged expiration indicates that the superior laryngeal nerve is dominantly expiratory, excitatory. The progressive deepening of expiration suggests temporal summation at the expiratory half-center.
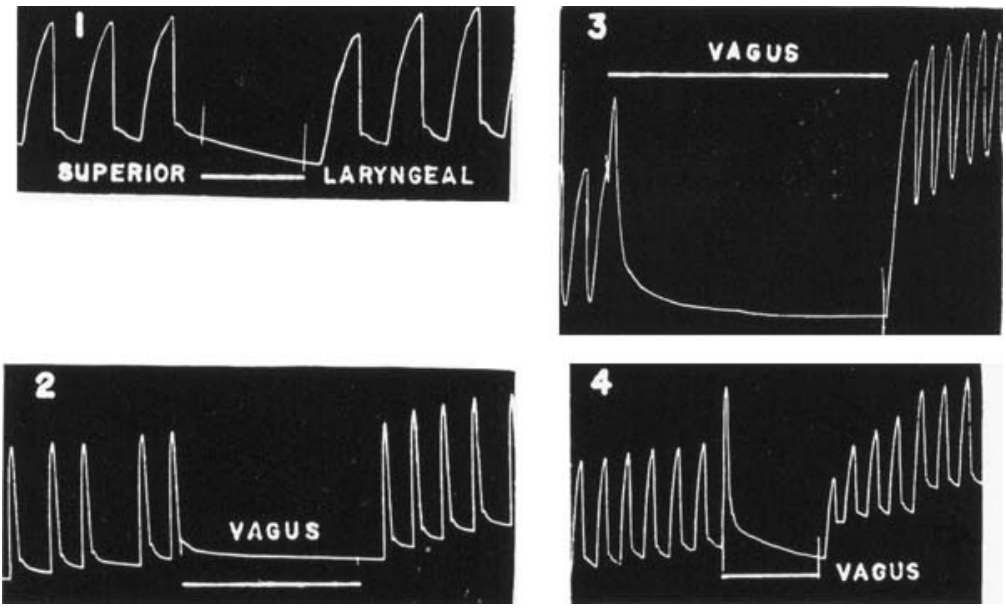

Fig. 29 Effects of stimulation of the vagus nerve. When stimulation begins in phase with expiration the effects are similar to those of figure 28 . The initial reinforcement of inspiration when stimulation begins with inspiration is similar to that produced by brief stimulation of any dual excitatory nerve in phase with inspiration. The later prolongation of expiration is similar to that produced by the superior laryngeal and indicates that the expiratory component is dominant in the vagus as well as in the superior laryngeal nerve. 
When e.g., the carotid, saphenous, vagus or superior laryngeal nerve is stimulated in phase with inspiration, there is a deepening of inspiration. When, on the other hand, stimulation is in phase with expiration, the expiratory act is strengthened exclusively (see fig. 29). These observations led to the view that sensory respiratory nerves are dual excitatory, that the individual afferents dichotomize and terminate on opposing half-centers as represented in figure 11 .

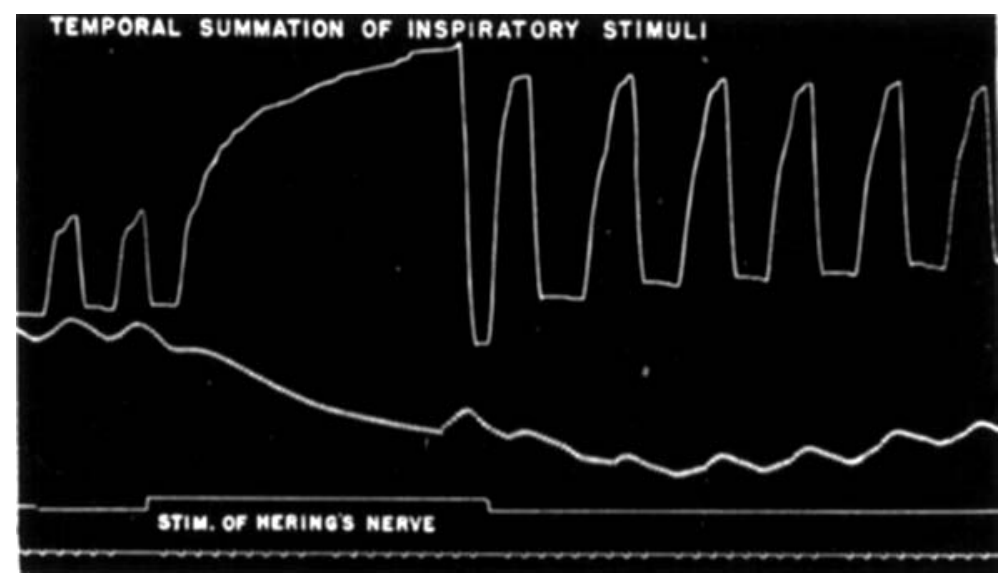

Fig. 30 Unbroken inspiratory tetanus produced by repetitive stimulation of the earotid nerve showing progressive temporal summation of the inspiratory component. This record was obtained after double vagotomy which removes the dominantly expiratory influence of that nerve. The supernormal strength of the final escape expiration shows that temporal summation of the expiratory component of the carotid nerve occurred during the inspiratory tetanus.

Prolonged stimulation of these nerves on the other hand shows that composition of the nerve as well as time of stimulation is an important factor in determining the nature of the reflex response. Continued stimulation of the carotid nerve in figure 27 , e.g., produces an hyperpnea in which inspiration and expiration are alternately reinforced above normal strength. As a rule, inspiration is deepened decidedly more than expiration. Prolonged stimulation of the saphenous nerve tends to produce a more evenly balanced hyperpnea 
which indicates that the inspiratory and expiratory components of this nerve are of approximately equal strength. In contrast to these results, prolonged stimulation of the superior laryngeal or vagus nerve (see figs. 28 and 29) causes an enduring expiration which holds inspiration in abeyance.

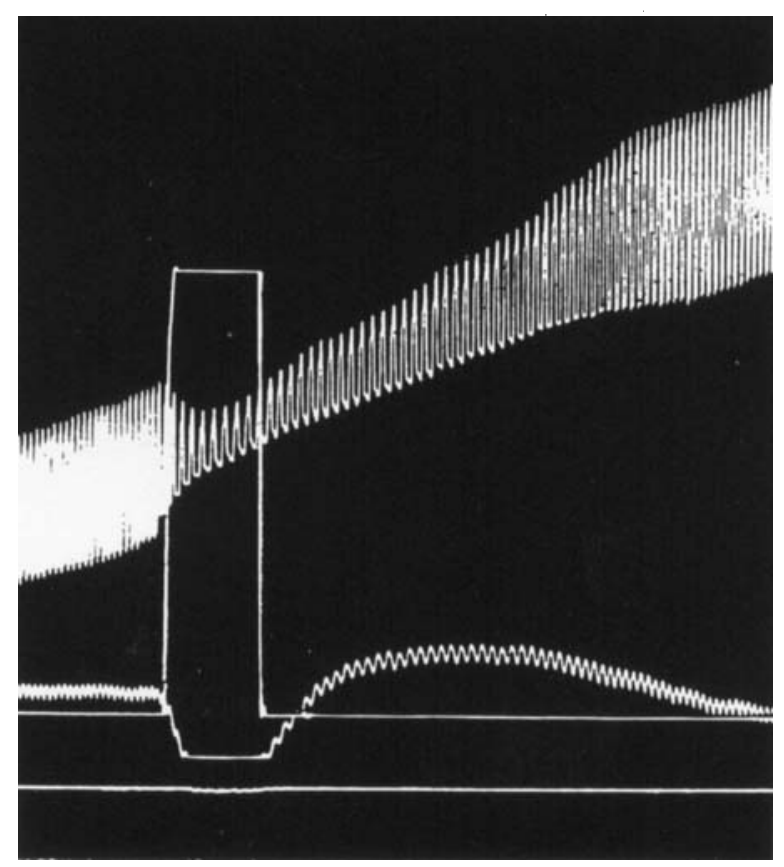

Fig. 31 Dual inhibitory effects on breathing produced by distention of the carotid sinus during hyperpnea. See corresponding allocation of terminal inhibitory boutons of sinus streteh afferents in figure 11 .

This effect is attributed to the dominance of the expiratory component.

When, however, the normal balance of the respiratory center is changed, in favor of the inspiratory component, by double vagotomy, which removes a powerful expiratory component, stimulation of the carotid nerve frequently produces a prolonged inspiratory tetanus attended by reciprocal inhibition of expiration (see fig. 30). The result is similar to the expiratory tetanus produced by stimulation of the vagus 
or superior laryngeal nerve in which instance the expiratory component dominates. (Compare fig. 30 with figs. 28 and 29.) The conclusion to be drawn from figures 27, 28, 29, and 30 is that balance and imbalance of components play a most pertinent role in the behavior of paired half-centers.

Figure 11 attempts to schematize the relative strengths of the inspiratory and expiratory components of excitatory afferents 2,3 , and 4 by arbitrary allocation of end boutons to the antagonistic neurones, namely 4 inspiratory and two expiratory chemoceptor boutons; three inspiratory and three

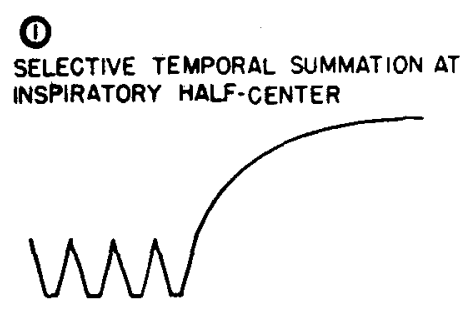

STIMULATION OF HERINGS NERVE

(2) SELECTIVE TEMPORAL SUMMATION AT EXPIRATORY HALF-CENTER

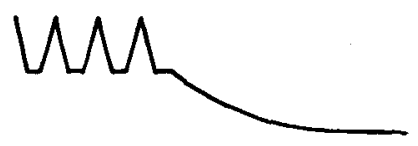

STIMULATION OF SUPERIOR LARYNGEAL NERVE

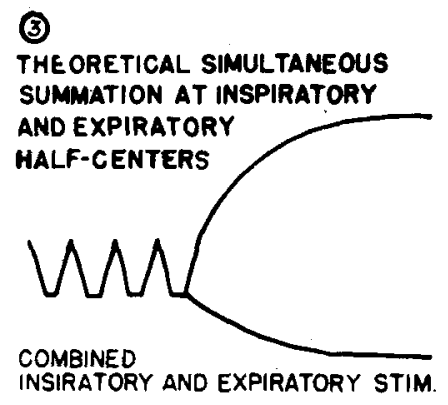

(4) EXPERIMENTAL SUMMATION AT
BOTH HALF-CENTERS

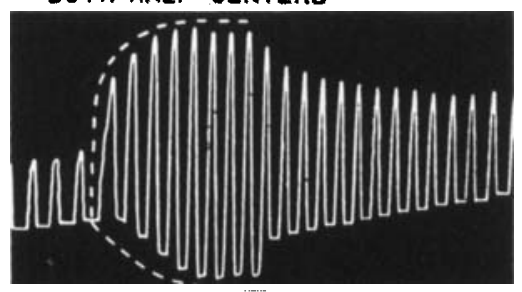

STIMULATION OF DUAL

EXCITATORY HERINGS NERVE

Fig. 32 Analysis of dual summation resulting from stimulation of the dual excitatory carotid nerve.

Graph 1. Selective summation of inspiratory component of carotid nerve similar to that in figure 30 .

Graph 2. Selective summation of expiratory component of dual excitatory vagus or superior laryngeal (see figs. 28 and 29 ).

Graph 3. Combination of graphs 1 and 2 showing theoretical simultaneous summation of inspiratory and expiratory components.

Graph 4. Aetual simultaneous summation at both half-centers resulting from stimulating the dual excitatory stimuli of the carotid nerve. 
expiratory nociceptor boutons; and two inspiratory and 4 expiratory pulmonary stretch receptor boutons.

The dual inhibition of inspiration and of expiration produced by distension of the carotid sinus afferents in figure 31 is represented by equal allocation of end boutons to the inhibitory poles of the inspiratory and expiratory neurons.

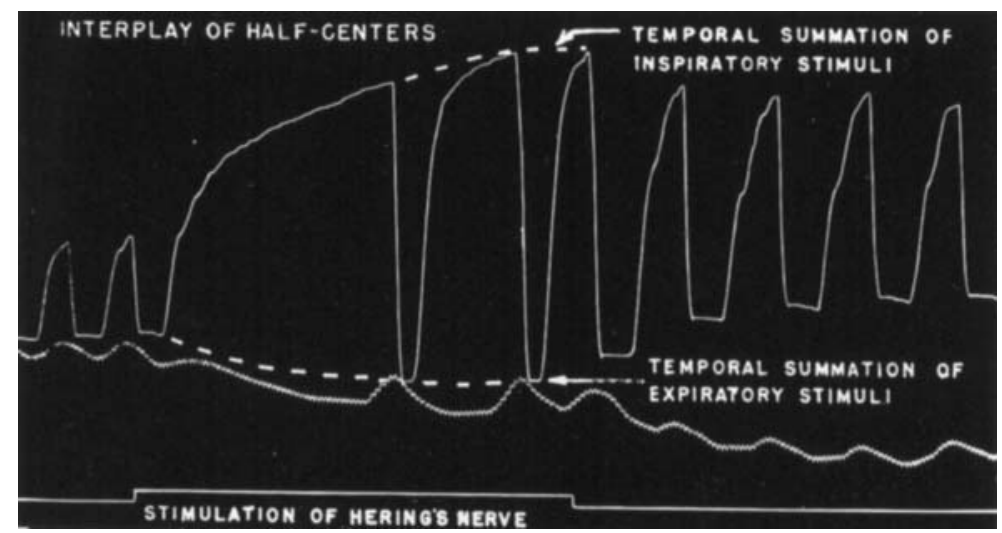

Fig. 33 Simultaneous summation of dual excitatory stimuli of the carotid nerve under conditions of strong inspiratory imbalance showing that temporary interruption of either inspiration or expiration does not interfere with the established course of summation at the paired half-centers.

SIMULTANEOUS SUMMATION OF STIMULATION AT ANTAGONISTIC HALF-CENTERS

Figure 27 and insert 4 of figure 32 illustrate typical effects of prolonged stimulation of the carotid nerve on the volume of breathing. The concurrent increase of depth of inspiration and of expiration indicate that temporal summation of stimuli occurred simultaneously at both half-centers. The crests of inspiration and the troughs of expiration are assumed to represent the degree of summation of the central excitatory state then existing at the respective half-centers. The envelopes joining these points would therefore represent the curves of summation, a rise of the inspiratory and a fall of the expiratory curve indicating increasing excitatory state. 
The greater inspiratory summation as compared with expiratory summation is attributed to the greater strength of the inspiratory component of the carotid nerve.

A similar simultaneousness of summation is to be seen in stimulation of the carotid nerve after double vagotomy in figure 33. Under these circumstances a prolonged inspiratory tetanus often occurs which reveals the course of inspiratory summation without the usual periodic interruption of the inspiratory act. It will be noted that the curve is similar to that obtained by joining the crests of inspiration in figure 27. And the depth of the escape expirations shows that summation occurred at the expiratory half-center during the prolonged inspiratory tetanus. In other words, prolonged reciprocal inhibition of expiration did not prevent summation of stimuli in the expiratory half-center.

It is therefore concluded that summation of stimuli occurs simultaneously and independently at the paired half-centers and that these circumstances promote a continuing and well sustained synaptic drive at the antagonistic neurons. For a further analysis consult figure 32 .

\section{SIMULTANEOUS DECAY OF AFTER DISCHARGE OF ANTAGONISTIC HALF-CEN'TERS}

Summation of stimuli and reflex after-discharge to stimulation are basically related phenomena; both originate in the finite duration of synaptic negativities, and one is the counterpart of the other. In other words, summation is caused by the addition of overlapping residual negativities; whereas after-discharge is the decay of such summations (see figs. 20, $22,23,24$, and 27 ).

It was seen in figure 27 of the preceding section that temporal summation of the stronger inspiratory component was greater than that of the weaker expiratory component. It may now be noted that the decay of the stronger summation was also greater than the decay of the weaker summation. This is in agreement with the observation of Sherrington 
that spinal reflex after-discharges vary with the strength of stimulation.

It may therefore be concluded that the decay of afterdischarge to stimulation of dual excitatory nerves occurs simultaneously and independently in the paired half-centers; and that the strength of after-discharge of either half-center is determined by the central excitatory state existent at the respective half-center.

\section{A MODIFIED CONCEPT OF SYNAPTIC DRIVE}

Brown and Eceles ('34) had concluded in their studies on the eat that, "the vagus exerts its inhibitory action on the heart by liberating a substance which biological tests have been unable to distinguish from acetylcholine;' and that the after-effects of vagal volleys are proportional to the concentrations of acetylcholine existing at the moment. The decline of inhibition, subsequent to an inhibitory shock was therefore attributed to the rate of hydrolysis of acetylcholine which was observed to decay along an exponential curve being halved every 0.8 to 0.4 second.

In the observations of Peters and Gesell ('52), illustrated in figure 34, the inhibition of auricular contraction produced by a single submaximal shock reached its maximum effect slowly, in about 40 seconds, and then decayed exponentially in the manner previously described by Brown and Eecles. Summation of these inhibitory effects varied with the frequency of stimulation. The fact that temporal summation occurred when stimuli were delivered at a frequency as low as one in 120 seconds suggested the possibility that stimulations at higher frequencies could result in accumulation of vast numbers of residual inhibitory effects and thereby exercise a continuing inhibitory influence. Repetitive stimuli at 30 per second, e.g., would store as many as 3,600 overlapping inhibitory effects at the end of two minutes and put the heart under a continuing influence of at least 3,600 vagal volleys. 
Comparably long lasting synaptic depolarizations in nerve centers suggest that 3,600 residual effects, in progressive stages of decay, could accumulate under a single synapse stimulated 30 times per second and that 1,000 synapses so stimulated could result in a storage of as many as $3,600,000$
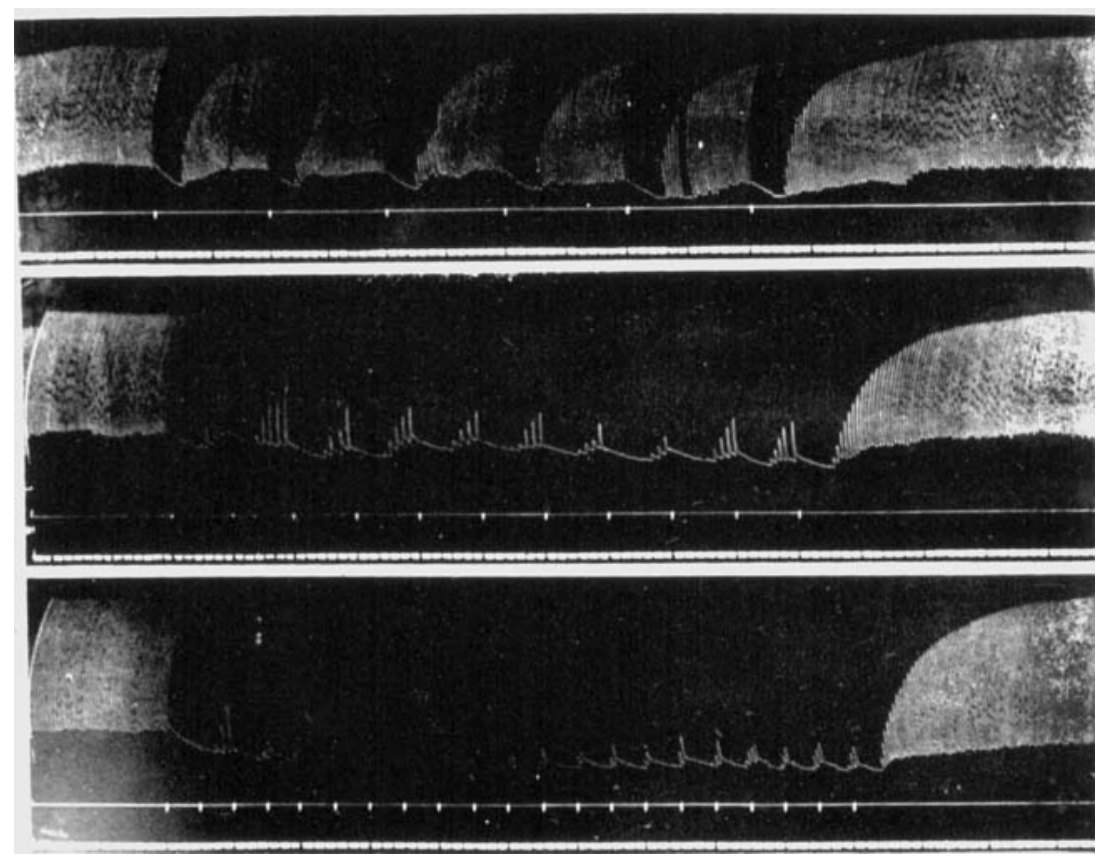

Fig. 34A Inhibition of the auricle of a turtle produced by single shocks applied to the vagus nerve at frequencies of one in 120,60 , and 30 seconds respectively, from above downward. The temporal summation of stimuli noted in the upper frame show that single shocks produce inhibitory effects lasting more than 120 seconds.

residual effects thus putting the nerve cell under a steadying influence of vast numbers of synaptic depolarization residua.

Figure $34 \mathrm{~B}$ schematizes synaptic depolarizations in various stages of decay and their theoretical superimposed effects. Cylinder A- B- C- D- represents accumulation of acetylcholine from the synapse above and depletion by hydrolysis from below. This situation is compared with the effects of 
inflow and outflow of water on the water content of cylinder $A^{\prime} B^{\prime} C^{\prime} D^{\prime}$.

Schrödinger ('40), in his monograph on "What is Life?" points out that "Only in the cooperation of an enormously large number of atoms do statistical laws begin to operate and control the behavior of these assemblies with an accuracy increasing as the number of atoms involved increases. It is in this way that the events acquire truly orderly features. All physical and chemical laws that are known to

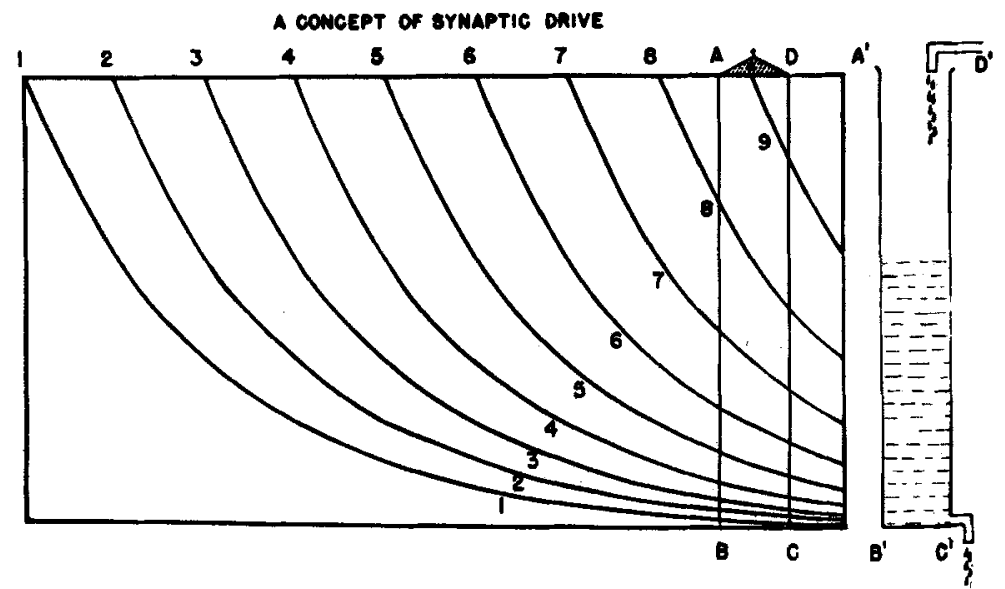

Fig. 34B A concept of synaptic drive emphasizing the continuing effeets of overlapping synaptic depolarization. The significance of the vast numbers of depolarizations constituting continuing effects is discussed in detail in the text.

play an important part in the life of the organisms are of this particular kind."

The degree of expected inaccuracy in any physical law as expressed by $\sqrt{\mathbf{n}}$ indicates that errors of the magnitude of $10 \%$ and $0.1 \%$ may occur with numbers equal to 100 and $1,000,000$ respectively. In view of the theoretically large number of residual effects continually existent in a normally bombarded neuron, it is proposed that statistical laws operate and control the behavior of a neuron with the necessary degree of accuracy. The myriads of residual effects should, in other words, have a profound steadying influence on nerve 
cell function and prevent it from being tossed about, so to speak, by random nerve impulses in the manner that a falling droplet of fog is knocked out of its expected course by random heat vibrations.

\section{HETEROGENEITY OF SYNAPTIC DRIVE}

Herrick ('24) refers to the intensively studied Mauthner cell of the fish as follows: "No less than 12 different kinds

\section{A COMPARISON OF THE MULTIPLICITY OF SYNAPTIC DRIVES IN}

$$
\text { TWO FORMS OF MOTOR INTEGRATION }
$$

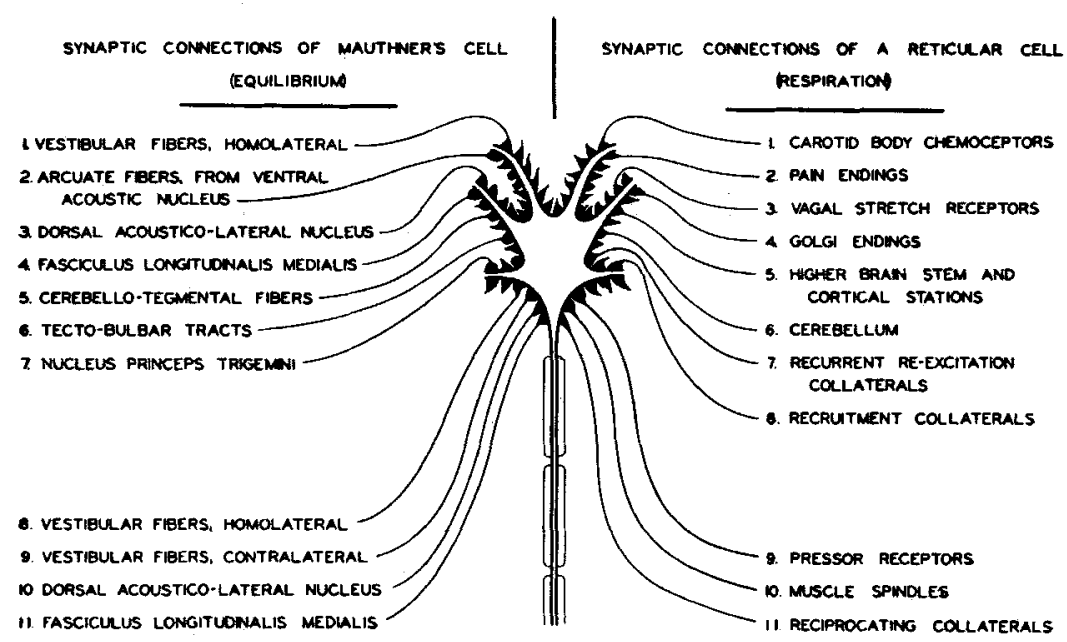

Fig. 35 Diagram comparing the heterogeneity of synaptic drive in the Mauthner cell of the fish and the respiratory reticular cell of the mammal. Gesell ('40).

of sensory fibers end by synaptic junctions upon the dendrites or bodies of these neurons, chief of which are peripheral fibers from the vestibular nerves."

Equally heterogeneous is the synapsing of at least 11 types of afferents ending on the reticular cells of the respiratory center (fig. 35; Gesell, '40).

Coghill's ('29) analysis of the architectural basis of gill movements of the embryonic Amblystoma is an excellent elucidation of the origin of heterogeneity of afferents im- 
pinging on a single neuron. "At the time Amblystoma begins to swim it has no mobile appendages. There is still no mouth. There are external gills through which the blood serves the respiratory requirements, but these organs have as yet no power of movement."

"The motor cells of the group which are to innervate the muscle of the gills are situated in the most dorsal part of the motor division of the nervous system. Large dendrites from these cells invade all sources of afferent impulses through the sensory system, the ascending trigeminal tract, and the lateral line tract. They reach also into the zone of synapse between the commissural cells of the floor plate and the motor neurons that innervate the trunk muscles. The muscles of the external gills are therefore subjected to excitation, not only by those afferent impulses which are on the way to the motor mechanism of the trunk, but also by those efferent impulses of the motor path which are on the way directly to the muscles of the trunk."

The "synaptic drive" of gill movement would, therefore, seem to be derived from the primitive swimming drive, also heterogeneous in nature.

In his "Study of Instinct" Tinbergen ('51) cites excellent examples of heterogeneity of drive, in which several sign stimuli combine their effects to produce innate releasing mechanisms of instincts. The pursuit of the female butterfly Eumis, e.g., is released by three sign stimuli, namely: fluttering movement, dark shade, and proximity. Deficiency of one stimulus can, however, be experimentally compensated by greater intensity of the other sign stimuli.

Tinbergen comments as follows: "The fact that the various sign stimuli, though usually qualitatively very different, do not differ in their effect on the motor response as a whole and can replace each other quantitatively, means that their influence is, somewhere in the central nervous system, added in a purely quantative way (underlining ours). It is as if the 'impulse flow' started by each sign stimulus, qualitatively different though it may be from the impulses arriving from 
other receptorfields, acts upon the motor center in a purely quantitative way. In other words, either before they reach the motor center or in the motor center itself, the effects of the external stimuli are brought together and added. As we will see later, there are indications suggesting that this addition is effected in the innate releasing mechanism itself, that is, before the impulses reach the motor center.

"These facts are highly significant in two respects. First, the additive cooperation of sign stimuli releasing a reaction as a whole, indicates that the afferent impulses are collected into one single 'container,' which acts in a purely quantitative way on the motor center. Second, the configurational character of the motor responses itself shows that the motor center redispatches the stimuli and distributes them according to configurational principles. This 'container' is, in the terms of neurophysiology, a center, or a system of centers."

It seems most pertinent that the quantitative release of instincts by the addition of qualitatively differing stimuli should find such close analogy in the motor neuron which as postulated above is assumed to act as a container, or reservoir for the conversion of qualitatively differing nerve impulses into a common electrical force, namely neurocellular current.

\section{INTERPLAY OF SPATIAL AND TEMPORAL SUMMATION OF STIMULI}

The greater hyperpnea produced by combined stimulation of the left and right carotid nerve in figure 36, as compared with that of stimulation of either nerve alone, illustrates the phenomenon of spatial summation of stimuli, namely the effect of numbers of stimuli impinging on a neuron. The greater reduction of breathing produced by combined, as compared with single stimulation of either the left or right sinus nerve in figure 37 suggests that spatial summation of excitatory and inhibitory stimuli is basically similar.

The progressive increase of breathing resulting from uniform repetitive stimulation of the carotid nerve in figures 
28,30 , and 32 illustrates typical temporal summations of excitatory stimuli in which succeeding stimuli build upon the residual effects of preceding stimuli. The mechanism by which this summation occurs will be analyzed in greater detail below in relation to the neurohumoral theory. The progressive reduction of depth of breathing produced by

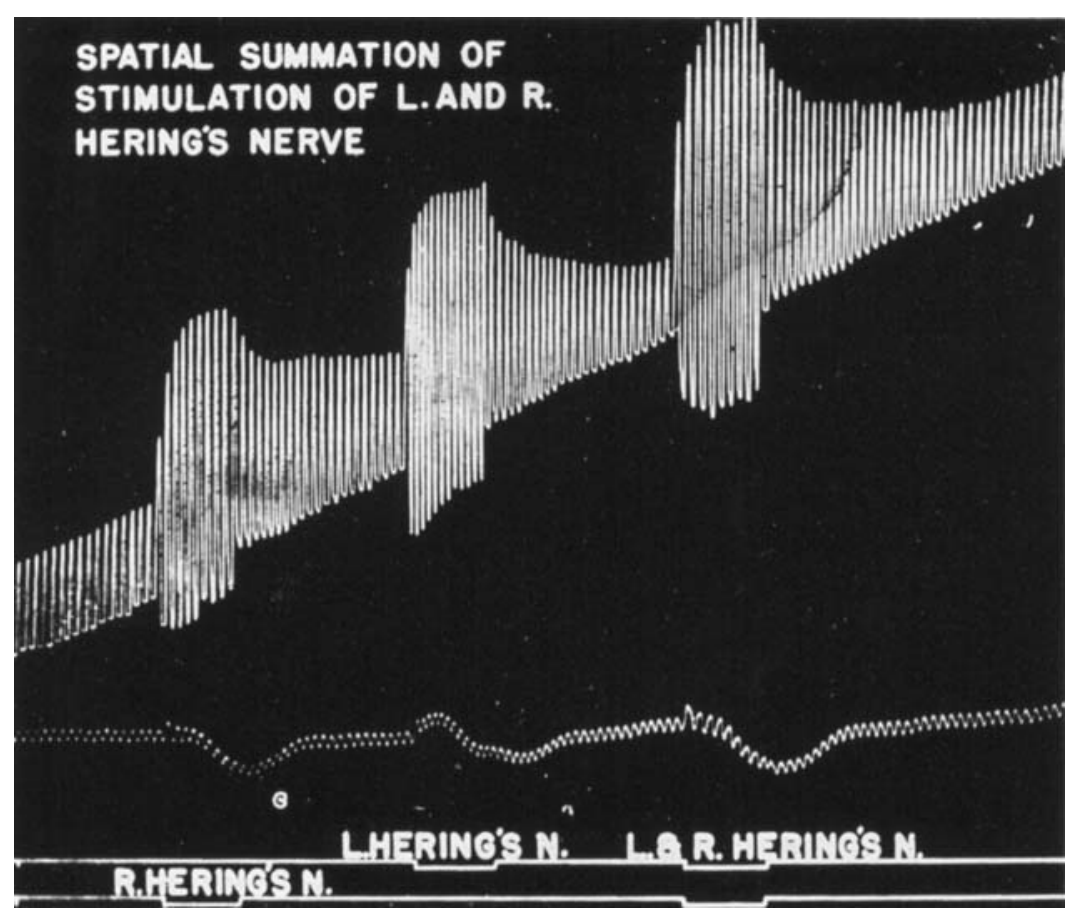

Fig. 36 Spatial summation of excitatory stimuli demonstrated by combining the stimulation of the left and right carotid nerves.

repetitive stimulation of the sinus afferents indicates that temporal summation of inhibitory and excitatory stimuli are basically similar phenomena.

The effects of spatial and temporal summation should theoretically be additive. Consider, e.g., a specific instance in which pace-setter neuron number 1 , of figure 18 , opens the inspiratory act. On dispatching its own nerve impulses 

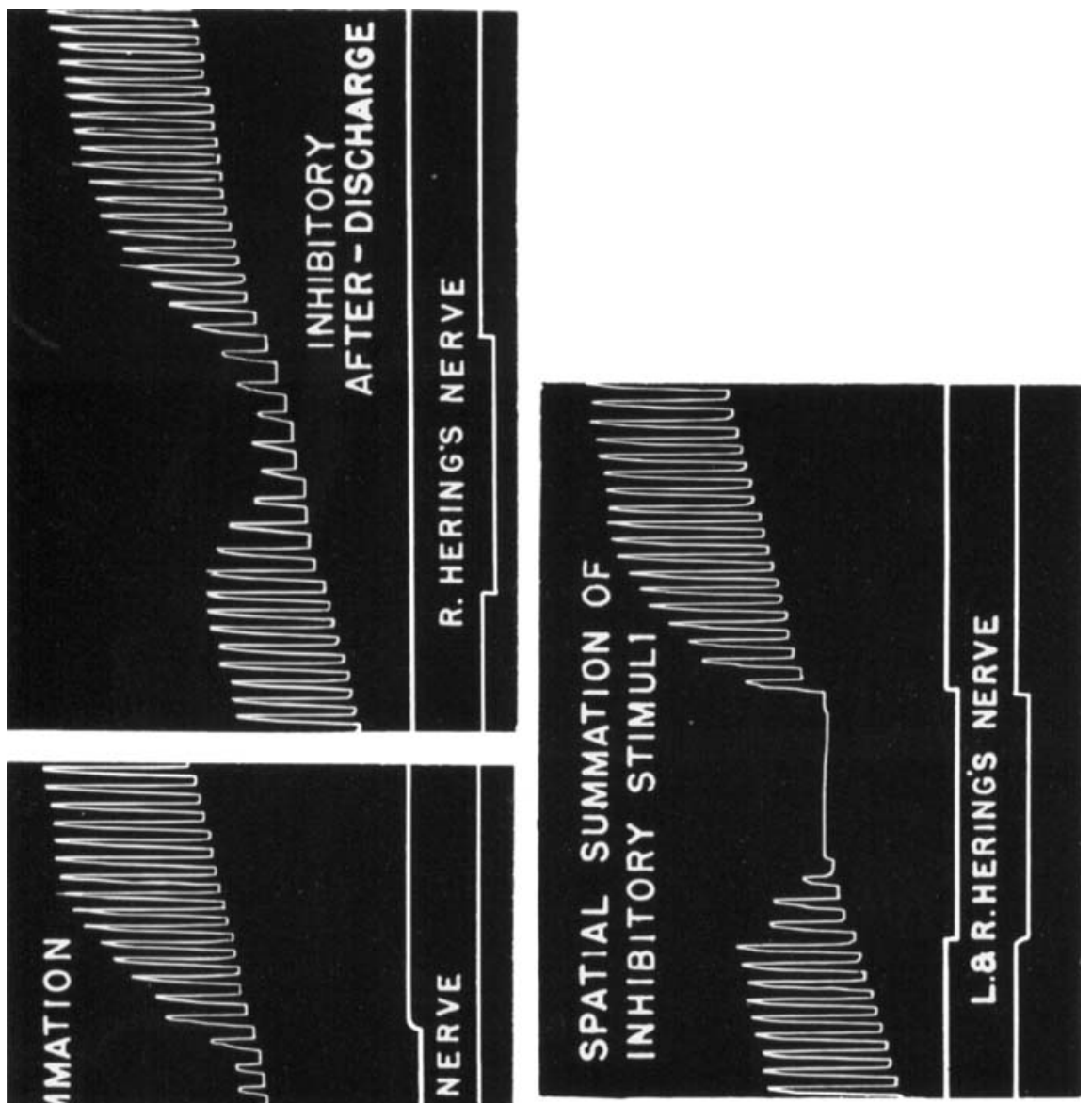

可苛苛 㱐害

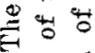
ธี $\circ$ 过 ऽ 密 总导 \& 8 $\stackrel{9}{ \pm} \overrightarrow{0}$ 范 홍 总兽 E 点 节 要 㩆 요 뭉 要要

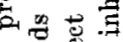
둥 है웡 के 崖 司的总点 ․ 4 용 ‡

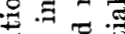

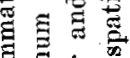

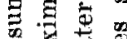
550 密到急 过 总焉兽 포웡 0 恶

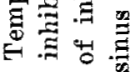
然范 要 की 我苛哥 
back onto itself, over previously dormant recurrent collaterals, the neuron invokes the phenomenon of spatial summation, i.e., it increases the number of active synapses on the surface of the neuron. Subsequent repetitive impingement of nerve impulses over these same pathways. superimposes temporal upon the newly established spatial summation. Thus, spatial and temporal summation of impulses pool their synaptic depolarizations in the neurocellular current.

Recruitment works in the same way. Neuron 1, e.g., dispatches impulses to neuron 2 via previously dormant recruiting collaterals and invokes spatial summation at neuron 2, and subsequent repetitive impulses superimpose temporal summation upon spatial summation.

The reflex reinforcement of inspiration, which occurs with every filling of the lungs, invokes spatial summation with each newly recruited pulmonary proprioceptor stimulated by the stretching of the lungs. Repetitive discharge of the newly recruited receptor invokes temporal summation.

THE NEUROHUMORAL THEORY

The discoveries of Loewi ('21) and of Dale ('14) have had a profound influence in neurophysiology. They have stimulated greater enquiry into the origin and implementation of electrical energy. Some physiologists have found the neurohumoral theory unacceptable on the basis that the cholinergic system is too sluggish to meet the requirements of synaptic transmission of nerve impulses, but overlook the need of explaining how further retardation of the system by anticholinesterases favors nervous function. It is this question that calls for clarification.

Sherrington ('06) had clearly demonstrated that spinal reflex after-discharge varied with the strength and with the duration of sensory stimulation. Much to our surprise (Gesell, Brassfield and Hamilton, '42), the after-hyperpnea produced by stimulation of the carotid nerve varied inversely as the duration of stimulation. It will be seen in figure 38 that stimu- 
lations of 17,35 , and 85 seconds duration were followed by after-discharges lasting 44, 38, and 8 seconds respectively.

Dale's observation that acetylcholine is more labile in alkaline than in acid media called attention to the excessive elimination of carbon dioxide and to the alkalinization of tissues, which must have resulted from prolongation of hyperpnea. Inasmuch as the experiments of Sherrington were
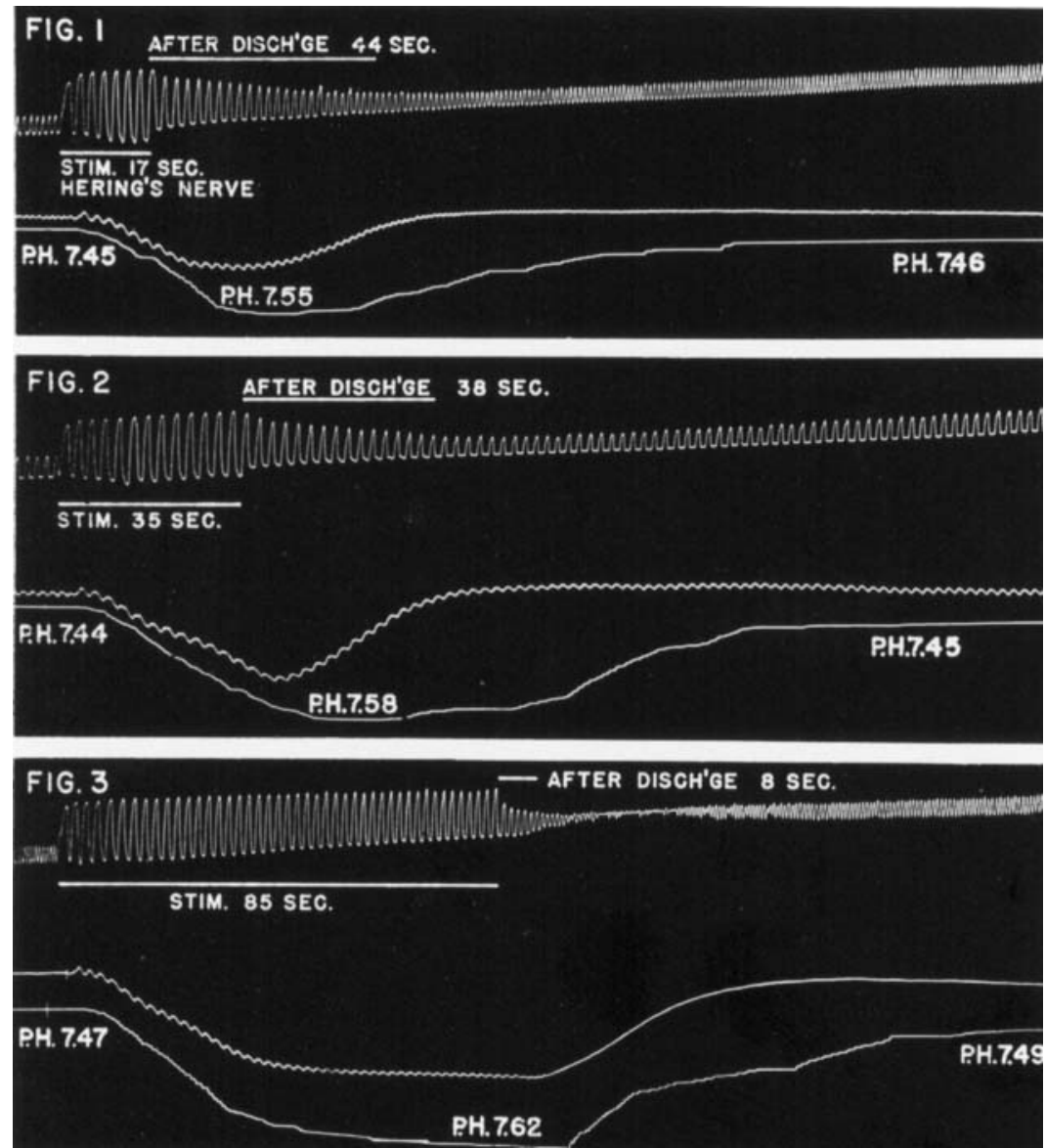

Fig. 38 Inverse relation of after-discharge to duration of stimulation of the carotid nerve. For comparison with diametrically opposite finding on spinal reflexes see text. 
not complicated by hyperpnea, it seemed desirable to run a series of stimulations of the carotid nerve under conditions resembling more closely those of Sherrington's experiments. With uniform artificial ventilation (Gesell and Hansen, '45) taking care not to over- or under-ventilate so as to keep the acid-base equilibrium constant, it was found that the duration of after-hyperpnea varied with the duration of stimulation as described above by Sherrington.

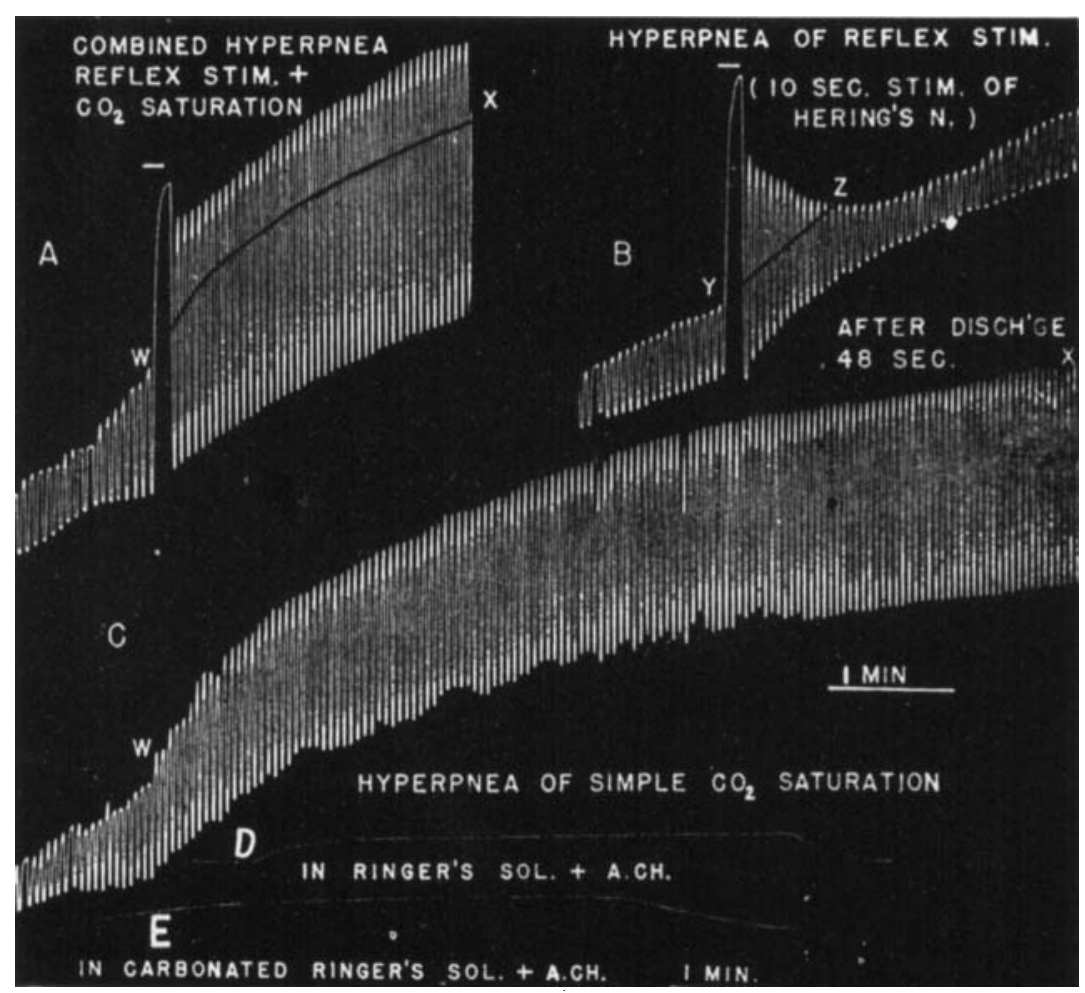

Fig. 39 Acid potentiation of reflex response to repetitive stimulation of the carotid nerve, of response to normally existing respiratory reflexes and of humoral stimulation of striated muscle. Records $A$ and $B$, response to stimulation of the carotid nerve after and before administration of carbon dioxide. Record $\mathrm{C}$, potentiation of breathing produced by saturation of the body with carbon dioxide. Records $D$ and $E$, response of rectus abdominus musele of frog to acetyleholine before and after saturation of muscle with carbon dioxide. 
Agreement of these results with those of Sherrington indicated the possibility that respiratory and spinal reflexes are similarly potentiated by acid which in its turn led to the postulation of the acid humoral theory of control of breathing (Brassfield and Gesell, '42). According to this theory of control the hypercapnic hyperpnea illustrated in record $\mathrm{C}$ of figure 39, is caused by a potentiation of the existing respiratory synaptic drive. Assuming an equal distribution of inspiratory and expiratory end boutons for afferents 2, 3 , and 4 as represented in figure 11 and an equal inspiratory and expiratory liberation of acetylcholine by these boutons, it follows that acidification of the respiratory center should result in an equal accumulation of acetylcholine at opposed neurons and therefore to a balanced hyperpnea such as illustrated in record C. Readministration of room air should reduce brain acidity, increase the rate of hydrolysis of acetylcholine and thus lessen pulmonary ventilation.

That carbon dioxide does actually potentiate respiratory reflexes is illustrated in inserts $A$ and $B$ which compare the duration of after-discharge to stimulation of the carotid nerve before and after carbon dioxide administration. Stimulation lasting 10 seconds under normal conditions in B produced a relatively short after-discharge as compared with similar stimulation during saturation with carbon dioxide in record $\mathrm{C}$.

If our premises are sound, it follows that an increase of anticholinesterase activity produced by the injection of one of the well-known pharmaceutical anticholinesterases should evoke hyperpnea similar in character to that produced by carbon dioxide. This proved to be the case in figure 40 in which D.F.P. was injected directly into the vertebral artery. This manner of injection would tend to confine the acetylcholine sparing action of D.F.P. to the centers. The increase of breathing is, therefore, attributed to a progressive accumulation of acetylcholine in the respiratory centers. In other words, the hyperpnea produced by D.F.P. was due to a potentiation of normally existing respiratory reflexes. 


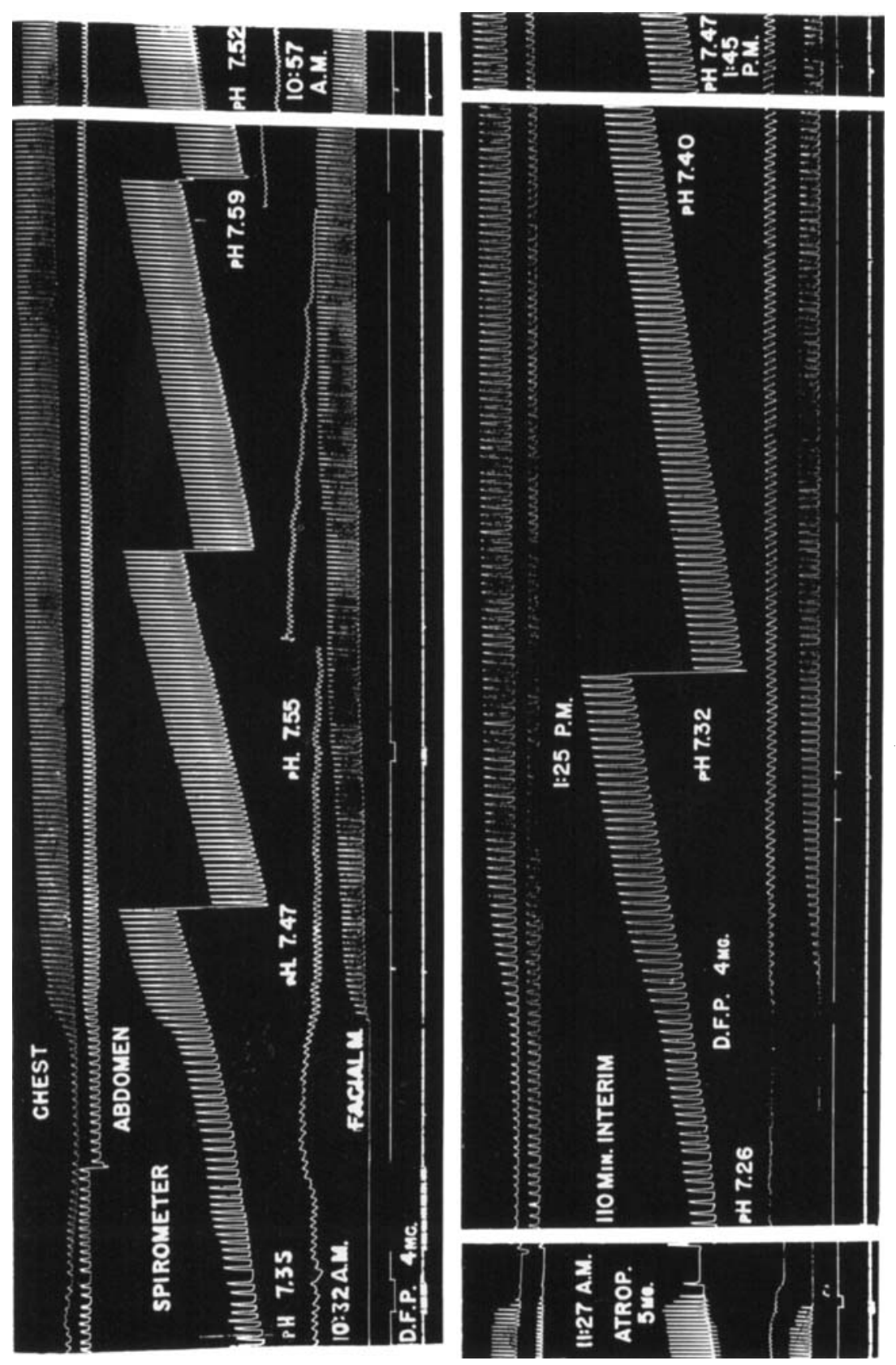

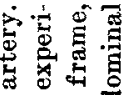
雪

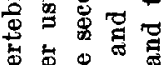
兽过

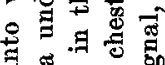
政

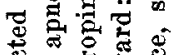

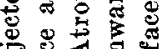
马的 毒 ค म

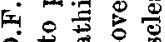

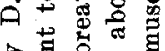
궁 옹 영 형 홍 区 के क्ष 원 证 현영 可 类 0 i \%医 \%

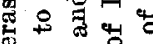

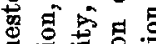
表诺 궁 要 현 ช

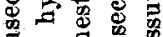
언융 웡

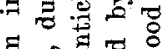
형 中ँ of $\Rightarrow$

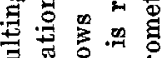
편 क्ष क्ष 政 है

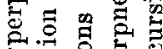
궁용 政竞 - 0 官 $三$

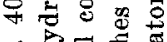

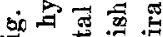

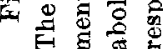


Figure 41A shows that respiratory reflexes artificially evoked by stimulation of the carotid nerve are also potentiated by artificial anticholinesterases. Note that the reflex response to all frequencies of stimulation is increased by injection of eserine (Gesell and Frey, '50).
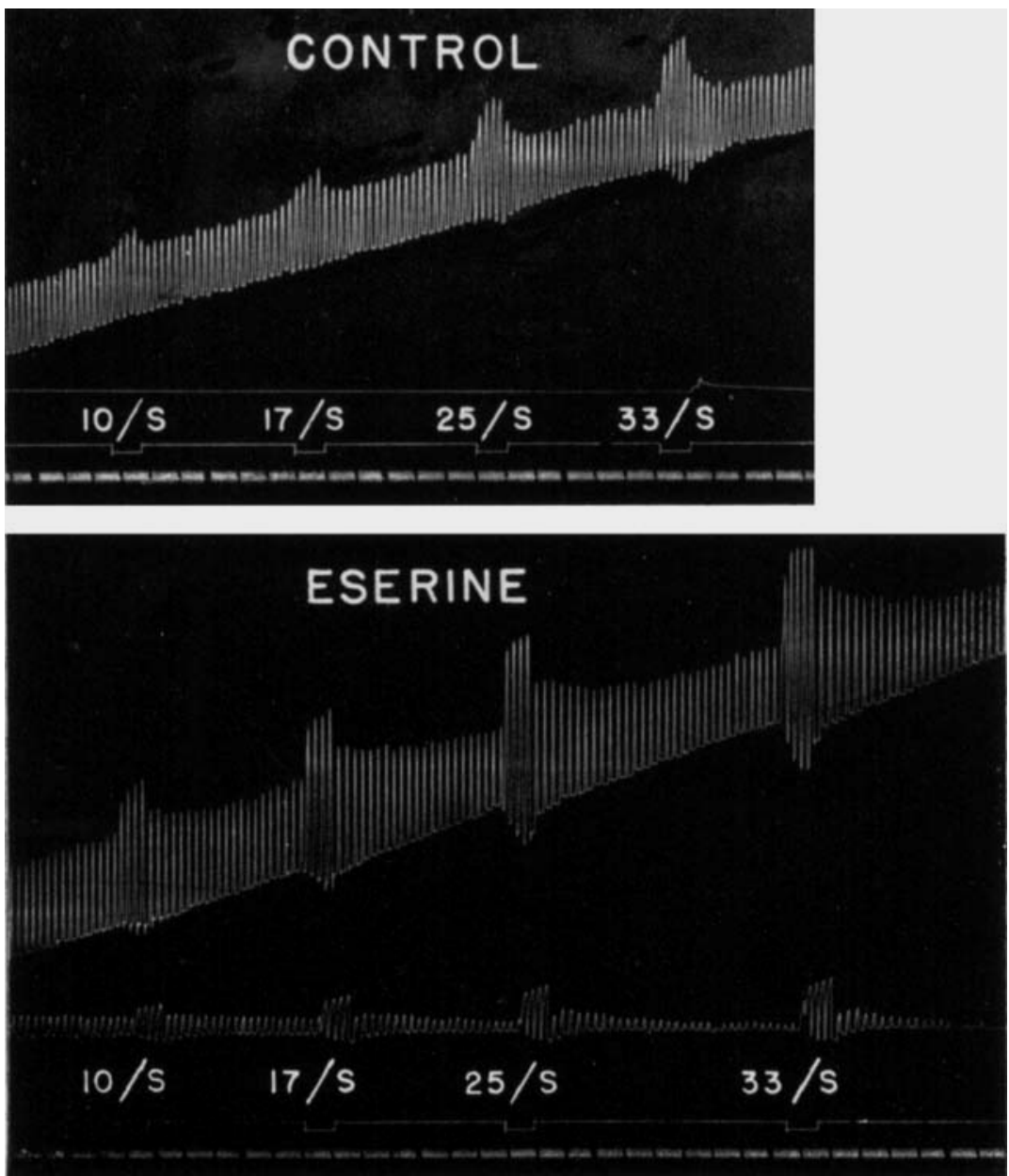

Fig. 41A Temporal summation of repetitive stimulation of carotid nerve at frequencies of $10,17,25$, and 33 per second, before and after eserine, showing potentiation of reflex response by shortening interval between shocks and by retardation of hydrolysis of acetylcholine. 


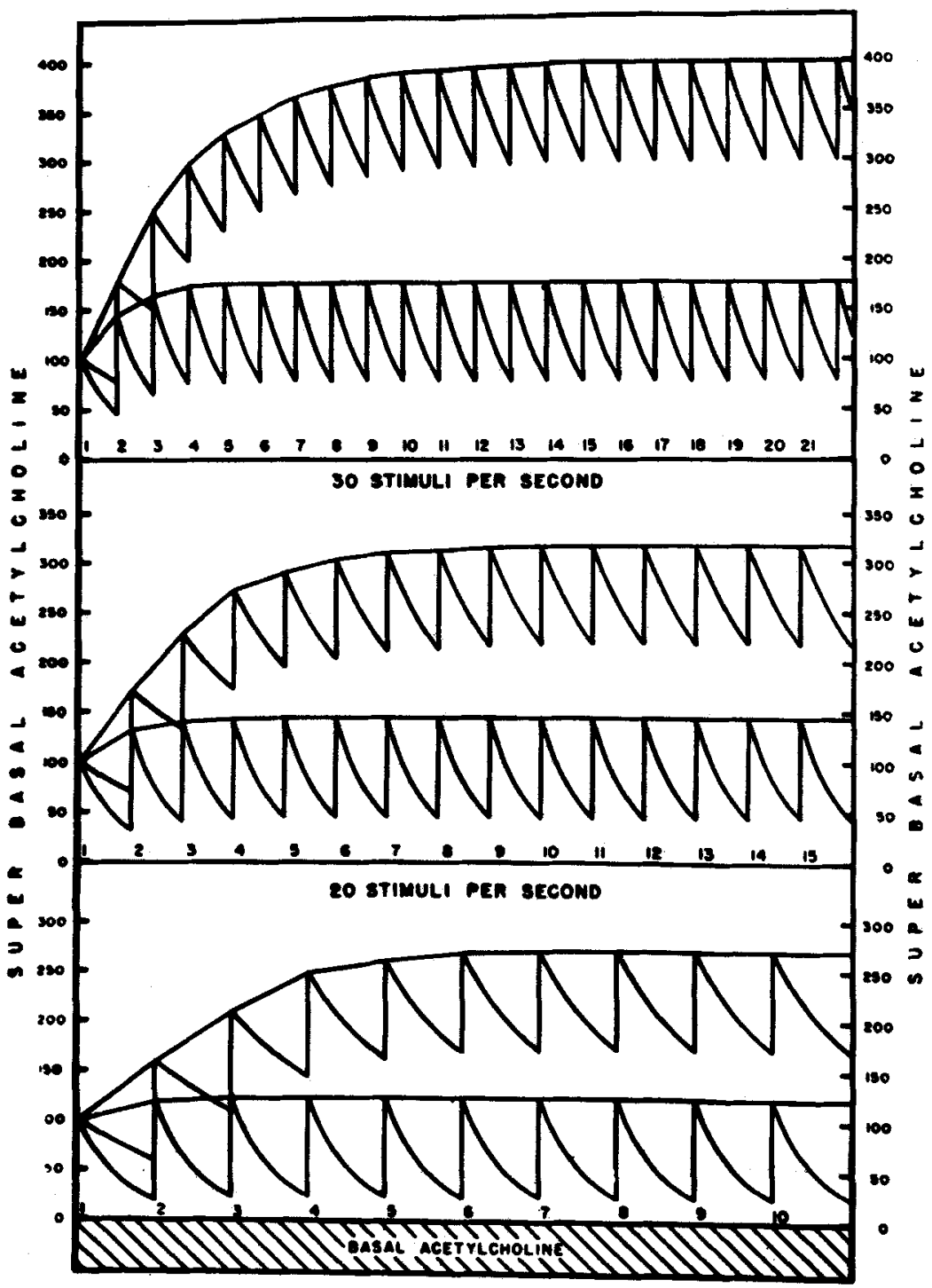

is stimul rea secono

Fig. 41B Schematic representation of central accumulation of acetylcholine resulting from temporal summation of reflex stimulation at frequencies of 15 , 20,30 stimuli per second, before and after administration of an anticholinesterase. The upper curves show the greater and more rapid accumulation of acetylcholine at respective stimulation frequencies of 15,20 , and 30 per second resulting from increased anticholinesterase activity. Ordinates: arbitrary units of acetylcholine; abscissa: time (see text). 
A schematic interpretation of figure $41 \mathrm{~A}$ is presented in figure 41B. Each of the repetitive shocks is assumed to liberate 100 arbitrary units of acetylcholine which, subjected to the hydrolyzing action of cholinesterase, disappear along an exponential curve. Granted incomplete destruction of acetylcholine in the interim between shocks, one acetylcholine residuum adds to the other until a concentration is reached at which hydrolysis equals liberation. Such steady states are slowly attained; the level of acetylcholine rises by progressively decreasing increments with each frequency of stimulation. In our schema concentrations of 120,145 , and 180 arbitrary units were reached at 15,20 , and 30 stimuli per second (see lower frames).

Diminution of speed of hydrolysis by administration of an anticholinesterase has effects equivalent to those of an increase of stimulation frequency, as seen on comparison of the lower and upper curves of each frame. Acetylcholine rises to higher steady state levels: 270,320 , and 400 as compared to 120,145 , and 180 units at normal rate of hydrolysis.

The inverse relation of breathing to hydrogen ion concentration after injection of D.F.P. (fig. 40) is a most significant point, since it indicates that increased acidity per se is not essential to hyperpnea, and that acid stimulates indirectly through its action on the cholinergic system.

Three possibilities are therefore suggested in this section: (1) that respiration and progression are basically similar forms of nervous integration; (2) that neurohumor is the common denominator of their similarity; and (3) that acids of the body function as physiological anticholinesterases and constitute the underlying chemical control of breathing.

\section{THE ANTICHOLINESTERASE ACTIVITY OF ACID AS AN EVOLUTIONARY FACTOR IN THE MOLDING OF THE NERVOUS SYSTEM}

We have reviewed the effects of acid on various parts of the cholinergic system in consideration of the role that anticholinesterase activity may have played in the evolution of 
the nervous system (Gesell, Brassfield and Hansen, '41; Brassfield and Gesell, '42; Gesell and Hansen, '45).

The rectus abdominus of the frog responds with greater contraction when immersed in a carbonated solution of acetylcholine, thus indicating an anticholinesterase activity of acid. The after-contraction of the acidulated rectus is also greater which is of interest in relation to the prolongation of reflex after-discharge to stimulation of the carotid nerve (compare inserts E, D, A, and B of fig. 39).

Inhibition of the heart, evoked by stimulation of the vagus nerve, is markedly potentiated by slight acidification of the heart.

Salivary secretion, elicited by stimulation of the chorda tympani, is augmented by administration of a carbon dioxide mixture (Brassfield, '45).

Vasomotor tonus is diminished by over-ventilation (Henderson and Haggard, '18; Dale and Evans, '22).

Reflex excitability of the spinal cord is increased by asphyxia (Mathison, '10). It is also increased by hypercapnia (see special section on "Comparison of Stepping and Breathing," Lillie and Gesell, '47).

Decerebrate rigidity is abolished by over-ventilation and returns, like breathing, after hypocapnic apnea when carbon dioxide is allowed to reaccumulate (McDowall, '30).

Discrimination of visual intensity is impaired by breathing low-oxygen mixtures, which is known to cause alkalinization of the brain, and restored by addition of carbon dioxide to the breathing mixture (Gellhorn, '36).

Intellectual incompetence and unconsciousness resulting from breathing $6 \%$ oxygen mixture is corrected by addition of $5 \%$ carbon dioxide (Garasenko, '44).

Rhythmic stepping and breathing of the spinal dog are equally potentiated by carbon dioxide (see fig. 49).

The appearance of swimming movements in the Amblystoma before gill movements (Coghill, '29) suggests their respiratory function. The mackerel does indeed retain this locomotor form of respiration for he breathes exclusively 
with his tail by pushing his immobile gills through the water (Krogh, '41).

In light of miscellaneous acid-humoral potentiations it is proposed that acid may have played a most important role in the evolution of the nervous system comparable to that of the "accidental occurrence of hemoglobin" in the evolution of the circulatory and respiratory system suggested by Barcroft ('25). This supposition is based on the all importance of duration and overlap of synaptic potentials. Just as retardation of hydrolysis of acetylcholine should theoretically increase the number of overlapped synaptic potentials comprising synaptic drive, so must speeding of hydrolysis decrease the overlap until a point is ultimately reached at which random impulses would cease to overlap. At this point integration should no longer be possible as is the case in the aviator who loses intellectual competence and consciousness at high altitude.

\section{ELECTRICAL SIGNS OF INHIBITION IN MOTOR NEURONS}

Inhibition of an actively discharging neuron should occur, as outlined in section 5, whenever the threshold of excitation rises above the capacity of the neurocellular current to stimulate, and vice versa whenever the current falls to subthreshold strength. Inhibition is therefore conceivable under three conditions (see fig. 11): (1) reduction of neurocellular current by withdrawal of excitation from the dendritic pole of the neuron, (2) reduction of neurocellular current by impingement of impulses on the inhibitory pole, and (3) increased threshold of excitation resulting from adaptation of the neuron to its neurocellular current (Gesell and Dontas, '52a, '52b).

The first variety of inhibition is theoretically producible by intravenous injection of sodium carbonate in quantity sufficient to raise the $\mathrm{pH}$ of the brain and increase hydrolysis of acetylcholine liberated at terminal boutons schematized in figure 11 (Glick, '37). The effect of rapid destruction of 
acetylcholine liberated by the basal flow of impulses is to decrease neurocellular current and diminish or abolish nerve cell discharge. On recovery of acid-base equilibrium back towards normal, acetylcholine should reaccumulate and neurocellular current should rise from subthreshold to threshold level and re-instate nerve cell discharge. Inspection of figure 42 shows that these conditions were met.

The mental incompetency and "blacking out" of aviators at high altitudes (Garasenko, '44), where alkalinization of the brain is assumed to occur, are probably comparable to

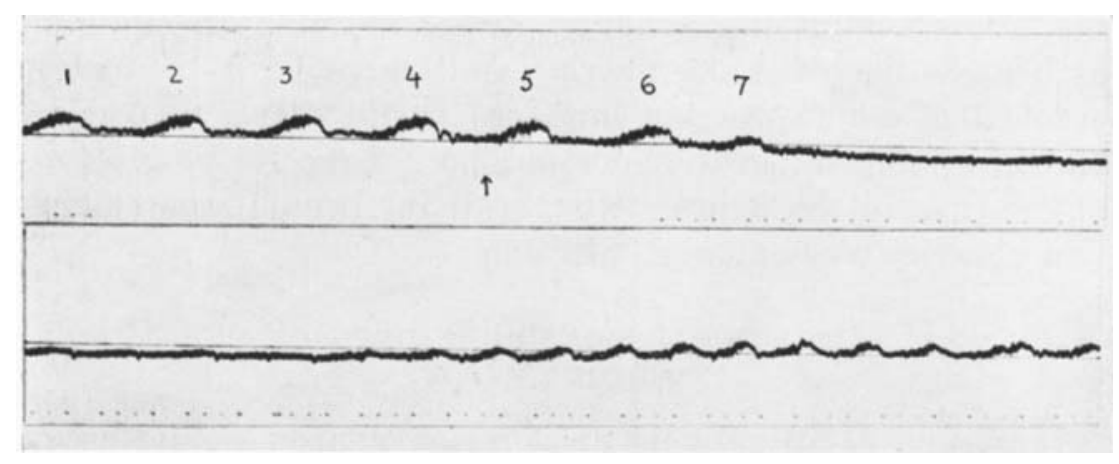

Fig. 42 Electrical record of inhibition of phrenic neurons resulting from injection of sodium carbonate. Note that inhibition occurs with fall of phrenic negativity and that function returns with increase of negativity.

hypocapnic hypopnea and apnea produced by sodium carbonate or by voluntary overventilation of the lungs at sea level.

The second variety of inhibition is theoretically producible by distention of the carotid sinus which imposes synaptic negativities on the inhibitory pole of inspiratory and expiratory neurons (see figs. 31 and 11) or by stimulation of a dominant expiratory nerve (vagus or superior laryngeal) which imposes reciprocal inhibitory impulses on the axon hillock of inspiratory neurons (see figs. 28, 29, and 11).

Figure 43 shows electrical changes of the phrenic rootlet produced by distention of the carotid sinus. There is a fall of general level of electrotonic potential and a decrease of 
slow potentials with decrease of depth of breathing in cycles $3,4,5$, and 6 , and a rise of electrotonic potential and increase of the slow waves with return of breathing back to normal in cycles 7, 8, 9, 10, and 11 .

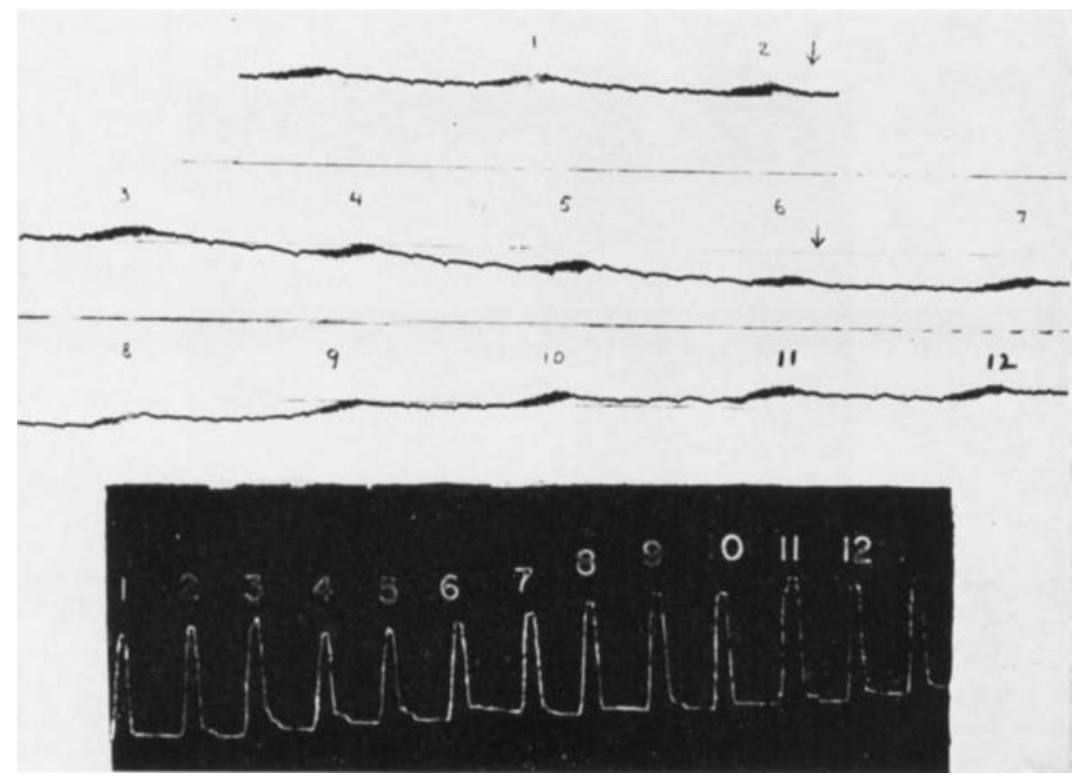

Fig. 43 Reflex inhibition of phrenic neurons resulting from distention of carotid sinus between respiratory cycles 2 and 6 . Electrical records above; spirometer tracing below. Note that sinus distention decreases tidal air slightly; lowers the general level of phrenic negativity; diminishes the height of the slow potentials; and decreases spike activity. Discontinuance of sinus distention leads: to reverse of effects.

Figure 45 shows electrical changes of the phrenic rootlet produced by stimulation of the superior laryngeal nerve which holds inspiration reciprocally inhibited. As in figure 43 there is a fall in phrenic negativity which in this instance is attended by a disappearance of periodic and spike activity. The progressive reduction of phrenic potential is ascribed to a progressive summation of impulses at the excitatory pole of the expiratory neurons and to a correspondingly 
increased reciprocal inhibition of the inspiratory neurons at the inhibitory pole.

It is interesting that each of the three varieties of inhibition described, whether chemically, reflexly, or reciprocally induced, was attended by a reduction of neurocellular current for this stands in marked contrast to the sudden

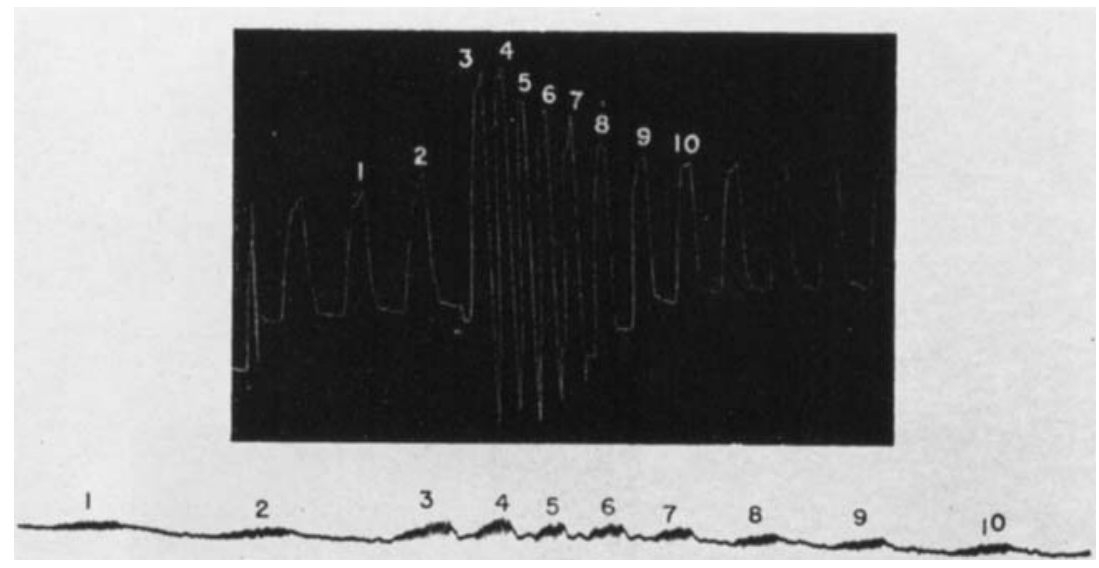

Fig. 44 Effects of injection of eyanide on breathing and on electrical activity of phrenic neurons. Observe that greater inspiratory spike activity during hyperpnea is associated with increase in magnitude of the slow potential. With the aid of a straight-edge note that hyperpnea is attended by a general rise of phrenic negativity, an effect differing from that produced by similar stimulation in fig ure 46 .

inhibition of nerve cell activity by adaptation in which increasing neurocellular current oceurs at the close of inspirations (see fig. 20).

\section{RECTIFYING ACTION OF PAIRED HALF-CENTERS}

When stimulation of the carotid nerve is added to an already prevailing stimulation of the superior laryngeal nerve, it does not elicit the usual hyperpnea, illustrated in figure 27, but produces instead a prolonged intensification of the expiration evoked by the superior laryngeal nerve. These peculiar effects are an exaggeration of the so-called phenomenon of precedence of stimulation. They are analyzed 
with the aid of figures 44,45 , and 46 . Figure 44 shows the dual excitatory action of the carotid nerve when stimulated by itself. Figure 45 shows the dominantly expiratory effect of the superior laryngeal nerve when it alone is stimulated. Figure 46 shows the response to combined stimulation of the carotid and the superior laryngeal nerve. The exclusively

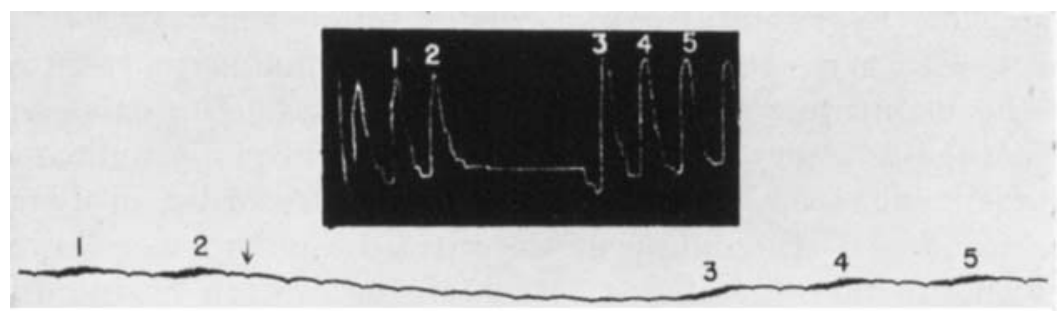

Figure 45

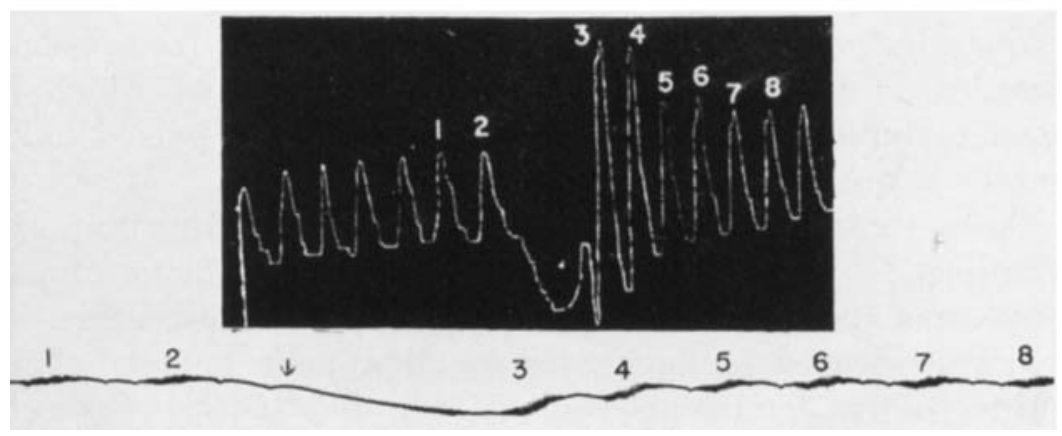

Figure 46

Figs. 45 and 46 The upper figure 45 shows effects of stimulation of the superior laryngeal nerve; sustained expiration, reciprocal inhibition of inspiration, and reduction of phrenic root negativity. The gradual reduction of negativity is attributed to temporal summation at the expiratory neurons and their increased activity which results in a corresponding increase of reciprocal inhibition of inspiratory neurons.

The lower figure 46 shows effects of superimposing stimulation of the carotid nerve (fig. 44) on stimulation of superior laryngeal nerve (fig. 45). The spirometer tracing shows an intensification of expiration equivalent to the expiratory component of figure 44. This intensification of expiration is attended by a greater and more rapid reduction of phrenic negativity in proportion to the intensification of reciprocal inhibition theoretically attending the increased activity of expiratory neurons. Note inspiratory rebound on discontinuance of stimulation of superior laryngeal. 
expiratory response to stimulation of the carotid nerve in figure 46 is attributed to the super-excitatory state of the expiratory neurons which permits them to respond to the expiratory component of the carotid nerve, i.e., to the impulses arriving via the expiratory branches of the chemoceptor afferents (see fig. 11). The inspiratory neurons, which on the other hand, were in a super-inhibited or sub-excitatory state, due to powerful reciprocal inhibition emanating from the expiratory neurons were, therefore, unable to respond to the inspiratory component of the carotid. The existence of a sub-excitatory state of the phrenic neurons is indicated by their subnormal electrotonic negativity, recorded in figure 46. Combined stimulation of the carotid and superior laryngeal nerve therefore tends to sustain expiration by intensifying reciprocal inhibition of inspiration.

The reinforcement of expiration in figure 46, by the carotid, is quantitatively equivalent to the expiratory component recorded in the respiratory tracing of figure 44 which is taken to indicate that the rectifying action of paired halfcenters is quantitative in nature.

These striking effects suggest exceedingly important applications to human behavior. The super-sensitivity of the active, and the refractoriness of the inactive half-centers, so clearly evidenced in figure 46 , would appear to have their counterpart in human psychology, for they display the earmarks of the open and of the closed mind which, on the one hand, sees and hears that which meets with the immediate intentions and, on the other hand, ignores that which fails to comply with the desires. One is almost tempted to consider the possibility that interlockings at higher levels possessed of consequences illustrated in figure 46 may be the basis of imperfections of the mind presently jeopardizing the future of mankind.

\section{REBOUND}

Sherrington described this interesting manifestation as a reflex muscular contraction which appears, as he pointed out, 
on withdrawal of a stimulation of an afferent nerve. Rebound must therefore be interpreted as an after-discharge phenomenon.

A typical example of rebound is illustrated in figure 47 in which Sowton and Sherrington recorded a series of knee extensions by rebounds in the decerebrate cat. Sherrington ('40) described the results as follows, "On applying the electrical stimulation (first rise of the signal line) to the foot nerve, the myogram line falls and remains down during

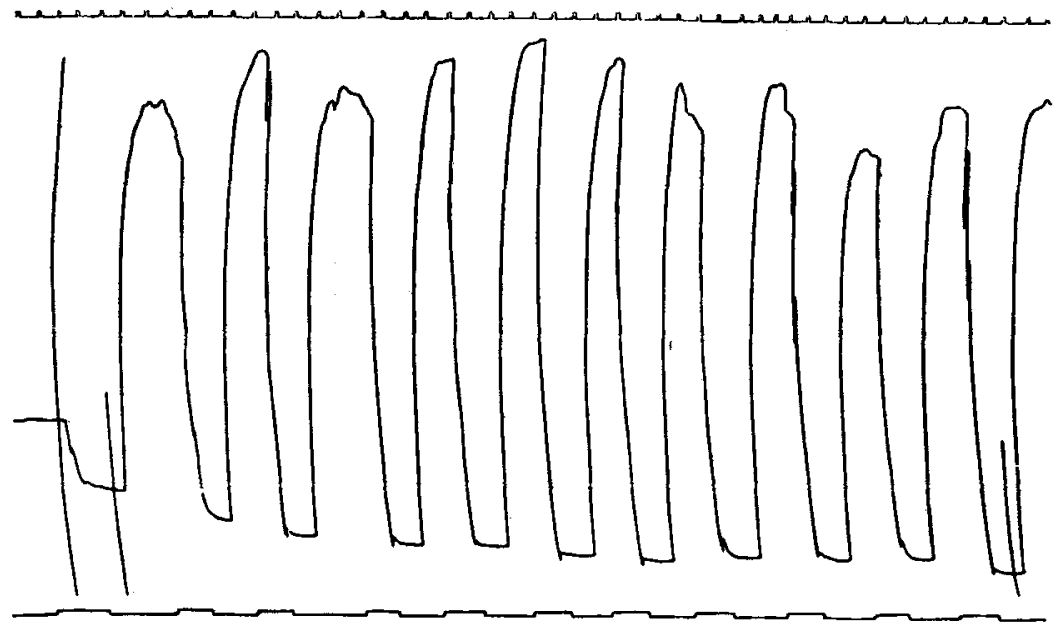

Fig. 4.7 Extensions by rebounds of decerebrate cat. See Sherrington's description in text.

the stimulation, showing the reflex inhibition of tonus. After three seconds the stimulus is discontinued (fall of the signal line); a post-inhibitory rebound contraction ensues during this discontinuance of the stimulation. This contraction is then cut down by a reapplication of the stimulus (second rise of the signal line), the muscle again relaxed by inhibition."

A remarkably similar series of inspirations by rebounds is illustrated in figure 48 in which vagal stimulations produced a series of powerful expirations, each of which was followed 
by strong inspiratory rebound (Gesell and Hamilton, '40). The dominance of the expiratory component of the vagus holds breathing in the expiratory phase and inspiration in reciprocal inhibition. Although not discharging, the inspiratory neurons are nevertheless subjected to a continuous flow of vagal impulses arriving over the vagal inspiratory branches. The effects of these impulses increase by temporal summation (see figs. 27, 28, and 41B) into a latent capacity

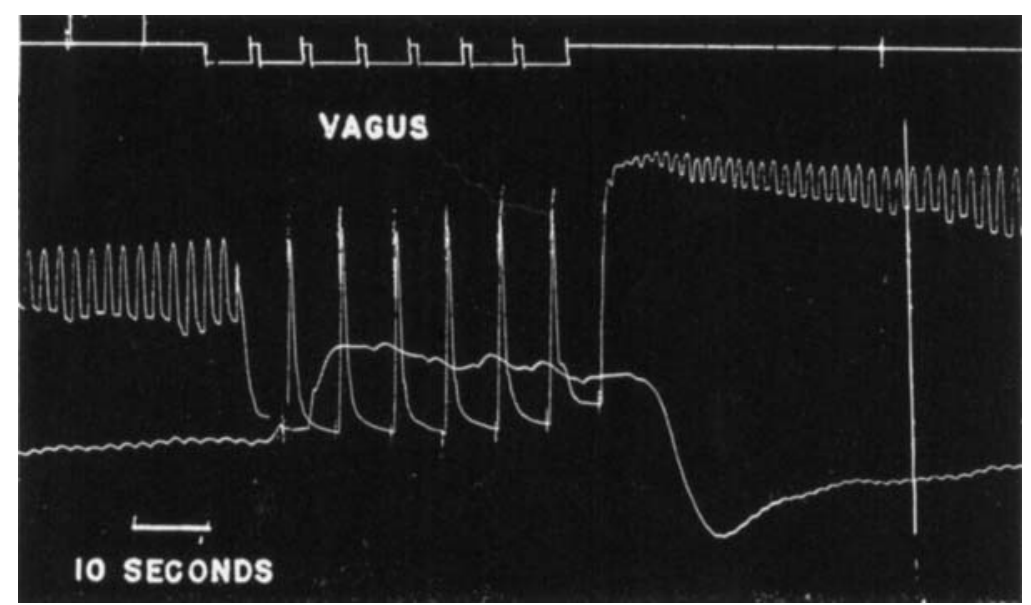

Fig. 48 Inspiration by rebounds evoked by discontinuance of a series of ragal stimulations. Inspiration, upstrolke. (Sec text.)

to stimulate on discontinuance of vagal stimulation and consequent withdrawal of reciprocal inhibition. The resulting removal of the negative sinks at the inhibitory poles of the inspiratory neurons increases their polar potentials and polar currents, thereby initiating inspiratory rebound. Moreover, this rebound comes at a moment when inspiratory excitability is high from preceding negative adaptation to subnormal neurocellular current during reciprocal inhibition.

In brief, three factors are believed to contribute to rebound: (1) Summation of vagal inspiratory impulses by inspiratory neurons during vagal stimulation. (2) Increase of polar potential by withdrawal of reciprocal inhibition and 
release of inspiratory neurocellular current. (3) Increased excitability of the inspiratory neurons at the moment of rebound resulting from negative adaptation to weak neurocellular current during the reciprocal inhibition.

The phenomenon of rebound is also to be seen in figure 46 illustrating the rectifying action of paired half-centers. In this instance the inspiratory neurons were subjected to a heavy shower of chemoceptor impulses via the carotid nerve. On withdrawal of superior laryngeal stimulation the powerful summation of chemoceptor impulses was released in rebound.

\section{Comparison of stepping and breathing}

By Richard Lillie and Robert Gesell

\section{INTRODUCTION}

"The nervous mechanism answerable for the essential rhythmicity of the scratch reflex and stepping seems a central one, not requiring rhythmic impulsion from outside. For spinal stepping, Graham Brown has especially insisted on this - The phasing of these alternating reflexes can be affected by the proprioceptive and other stimuli which they generate - but their phasing is not caused by the peripheral stimuli.', (Creed, Denny-Brown, Eccles, Liddell and Sherrington, '32).

Coghill states that "A nervous motor mechanism is established in Amblystoma for some time before the animal responds to stimulation, that this mechanism is such as to conduct impulses to the muscles from the head tailward, and that this order of conduction to the muscles gives the resulting movement locomotor value and thereby becomes the basic principle of both aquatic and terrestrial locomotion. The general pattern of the primary nervous mechanism of walking is, therefore, laid down before the animal can in the least respond to its environment."

Tinbergen cites several references emphasizing the role of central organization in animal behavior (Carmichael, '26; Grohmann, '38; Weiss, '41). 
T. Graham Brown has shown that asphyxia favors the occurrence of rhythmic stepping which he believes arises autochthonously in the center.

In these respects, stepping and breathing have much in common, for as was noted above, abolition of periodic proprioceptive reflexes by curarization does not abolish the central rhythm of breathing nor does it distort the pattern of activity of the center.

\section{EXPERIMENTAL METHOD}

Two spinal dogs, presented to the Department of Physiology by the Department of Surgery of which Doctor Lillie was resident, offered an opportunity to compare these two manifestations of motor integration and to enquire further into the neurohumoral theory as presented in sections 17 and 18.

The dog was seated comfortably on a specially constructed chair arranged to permit simultaneous recording of respiration and of stepping movements of the pendant hind legs. The legs were placed under slight tension with the aid of spiral springs affixed to vertical writing rods. A transparent lucite mask, allowing unobstructed vision, was fitted airtight around the shaved neck with the aid of a soft rubber cuff and vaseline. The mask was connected with rebreathing tanks provided with a Hutchinson recording spirometer. With this arrangement it was possible to administer room air or carbon dioxide mixture $\left(\mathrm{CO}_{2}, 10 \% ; \mathrm{O}_{2}, 30 \%\right.$; and $\mathrm{N}_{2}$, $60 \%$ ) alternately and record the effects of these gaseous mixtures on stepping and breathing. Small amounts of seconal and phenobarbital were administered prior to the experiment to prevent the dog from becoming nervous or restless.

\section{RESULTS}

The tracings recorded in figure 49 show the effects of administering a 10\% mixture of carbon dioxide for approximately $3 \frac{1}{2}$ minutes. The tracings from above downward represent pulmonary ventilation, stepping movements of the right 


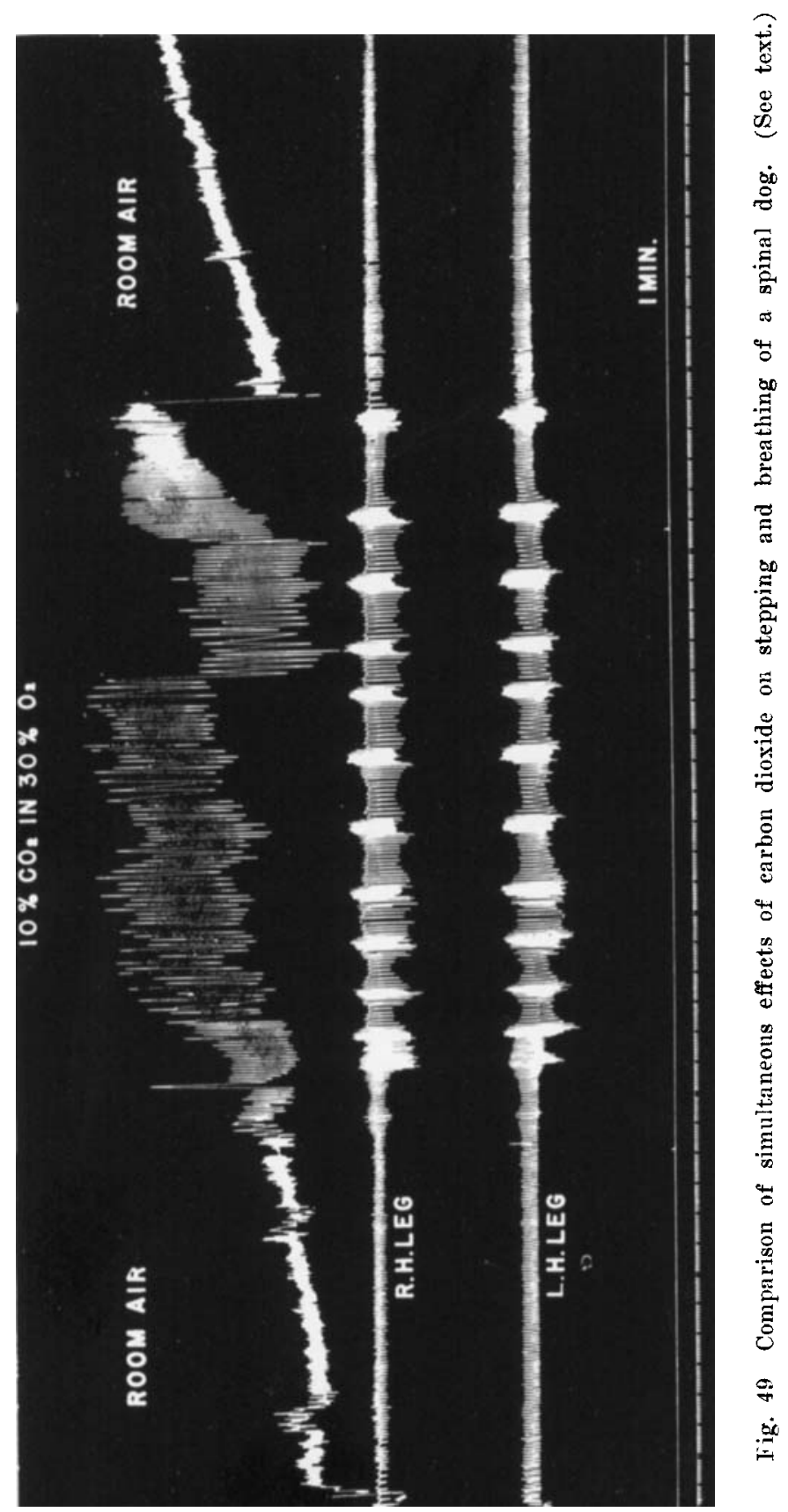


and left hind legs, signal indicating change of respired gas, and time in seconds. Inspiration and expiration, and extension and flexion are indicated by up and down strokes respectively. As saturation of the animal with carbon dioxide progressed on changing from room air to carbon dioxide, breathing increased in a manner characteristic of hypercapnic hyperpnea. Intensity of stepping augmented proportionately. On re-administration of room air, both activities

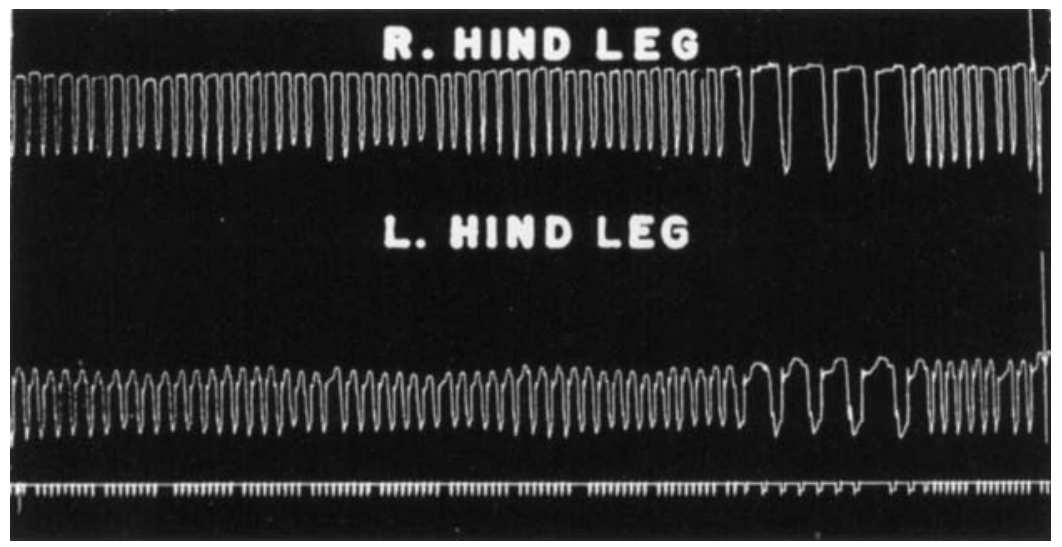

Fig. 50 Stepping of spinal dog recorded on rapidly moving paper to illustrate similarity of the stepping and breathing cycles.

subsided in a manner well-known in recovery of breathing from hypercapnia.

\section{DISCUSSION}

It seems pertinent in relation to the acid humoral theory outlined above that inspiration and expiration, and flexion and extension, should all increase in parallel fashion during: hypercapnia, and recede together on desaturation of the animal when room air was readministered. It indicates that acid potentiated the activity of all half-centers involved, those of stepping as well as those of breathing.

In consideration of the observations on the central effects of acid cited in section 18, especially those of MacDowall 
('30) on decerebrate rigidity, it appears that spinal motor mechanisms are as sensitive to acid as any motor integration including respiration. It would consequently seem necessary that some mechanism exist in the intact animal to hold progression movements in abeyance while the respiratory center reacts to hypercapnia. When inhibition of the cord by higher centers is missing, e.g., as in decerebrate rigidity, hypercapnia intensifies rigidity. Nerve fibers carrying impulses from a hypercapnic respiratory center to the inhibitory poles of spinal motor neurons might conceivably accomplish the needed adjustment in the intact animal.

It is interesting to note in figure 49 that the stepping movements of the extremities show greater regularity than that of breathing. This difference is attributed to the elimination, by transection of the cord, of the fluctuating influence of the higher centers on the spinal centers of progression. In the anesthetized animal, e.g., breathing is as regular as stepping of the spinal $\mathrm{dog}$ in figure 49 .

Hind leg movements, when recorded on a rapidly moving surface (fig. 50) in fact show a striking resemblance to breathing which suggests that alternation of flexion and extension of a single extremity is based on mechanisms similar to those of alternation of inspiration and expiration, set forth in section 6 and figure 11, and thus poses the problem of the mechanism of coordination of these movements into a natural walk, trot or gallop. We are aware of the possibility of fine individual differences in gaits and of the exquisite central arrangements necessary to these differences. Nevertheless, we have attempted in figure 51 to conceive of a simplified system of reciprocal interlockings between the 8 half-centers of flexion and extension of the 4 extremities which might possibly result in a crude progression movement of walking or trotting. Internuncial neurons were excluded, not to deny their importance, but rather to simplify the circuits in our theoretical description of the trot cycle.

Dog trot is arbitrarily assumed to begin with extension of the left front leg. This movement, as outlined below, is 
associated with a surprisingly large number of intimately related events before the left front leg is extended in the second trot cycle. A preliminary inspection of figure 51 will show that all interlockings are inhibitory in nature and can be grouped into three types: (1) Reciprocal inhibitory interlockings by fiber types 1 and 2 between extensor and flexor neurons, similar to those of figure 11, joining inspiratory and expiratory neurons. These are found in each of the 4 , paired half-centers representing the 4 extremities.

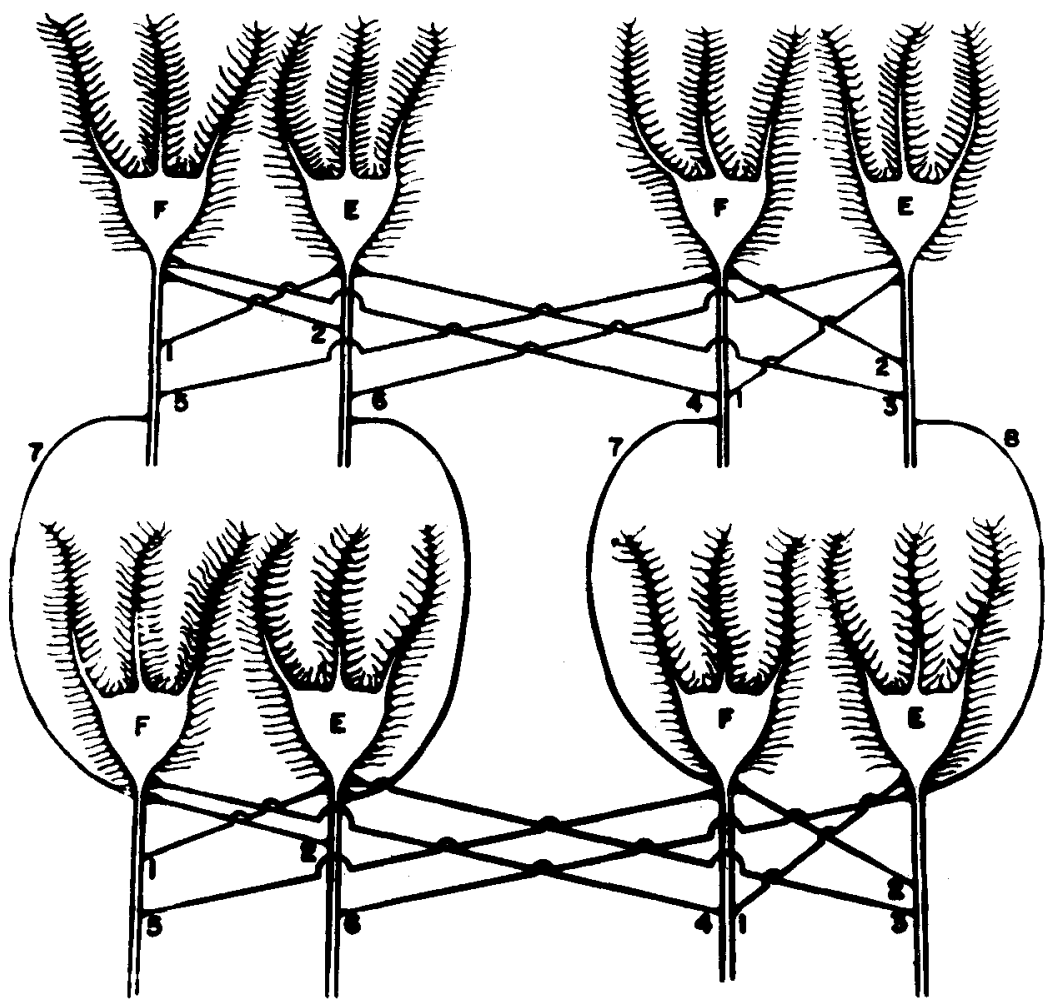

Fig. 51 Paired half-centers of extremities hypothetically interiocked for integration of dog trot. All postulated interlockings are inhibitory. Collaterals 1 . and 2 interlock the half-centers of extension and flexion of each extremity reciprocally; collaterals $3,4,5$, and 6 interlock front and rear paired half-centers respectively, in a manner to prevent gallop; collaterals 7 and 8 interlock left and right paired centers respectively, in a manner to prevent pace. Careful inspection will reveal a double mechanism throughout to insure trot. 
Crossed inhibitory interlockings $3,4,5$, and 6 , joining the front left and right and the hind left and right half-centers for purposes of crossed coordination. (3) Longitudinal interlockings 7 and 8 , joining the front and hind half-centers for homolateral coordination of front and hind extremities.

When the left front leg is extended, the corresponding extensor neurons dispatch inhibitory impulses to the antagonistic left front flexor neurons via interlocking fibers 2. Simultaneous dispatch of inhibitory impulses across to the front right extensor neurons, via crossed interlocking 6, prevents left front gallop. At the same time, reciprocal inhibition of left front flexor neurons withdraws inhibitory impulses from the right front flexors, via crossed interlocking 5 , thus initiating right front flexion. These interlockings thus serve to keep the front extremities in opposite phase of activity required for trot.

Longitudinal interlockings 7 and 8 , in their turn, hold the front and hind legs of both sides in opposite phase. Right front flexor neurons inhibit right hind flexor neurons via 7 , and right extensor neurons excite hind extensor neurons by withdrawal of inhibitory impulses from them, via 8 .

Rear crossed interlockings 3 and 4 prevent hind leg gallop. Connection 3 prevents simultaneous left hind extension by inhibition, and connection 4 initiates left hind flexion by withdrawal of inhibitory impulses.

The left longitudinal interlockings 7 and 8 reinforce the effects of the hind crossed connections 3 and 4, namely, inhibition of left hind extension and excitation of left hind flexion. It is thus apparent that a dual system of interlocking, crossed and longitudinal, is at work tying all 8 half-centers together in a doubly secure mechanism preventing the extremities from getting out of step.

Impulsions from higher centers is presumably a dominant factor in the acquirement of special gaits, as in the 5-gaited horse.

In comparison of stepping and breathing it is pointed out that: 
The close resemblance of the stepping movements of a single extremity and the respiratory cycle indicates a basically similar pairing of opposed half-centers and a common mechanism of interlocking and integration.

Equal increase of activity in stepping and breathing, by administration of carbon dioxide in a oxygen mixture, indicates an equal sensitivity of both rhythms to acid-humoral potentiation.

This finding favors a broader application of the neurohumoral theory.

A system of inhibitory interlocking of spinal half-centers offers a possible explanation of progression movements.

\section{SUMMARY AND CONCLUSIONS}

The nervous system is assumed to perform its multifarious functions by instrumentation of electrical energy.

The electrical energy so implemented is thought to originate importantly in two ways - by differential metabolism of the nerve cell and from synaptic negativities of impulses impinging on the neuron.

These so-called centrogenic and reflexogenic sources of energy combine their effects to generate neurocellular currents. Centrogenic neurocellular current provides a relatively uniform base upon which rapid fluctuations of reflexogenic origin superimpose their regulative effects.

The number of nerve impulses impinging on a nerve cell varies considerably. Mauthner's cell of the fish may e.g. receive as many as 300,000 per second.

It is suggested that fusion of overlapping exponentially decaying synaptic potentials produces a continuing excitatory potential. The theoretically large number of residual potentials contributing to this effect converts impinging nerve impulses into a so-called synaptic drive.

In harmony with this concept it is proposed that the nerve cell is structurally and functionally specialized in several ways - the cell body and dendrites as generator of neurocellular current, the axon hillock as generator of nerve im- 
pulses in response to this current, the neuraxon as transmitter of the newly created nerve impulses, the end bouton as electrical booster of nerve impulses and stimulator of neurons or end organs, and the axon hillock as site of convergence of inhibitory impulses whose synaptic negativities fuse and oppose those of the cell body and dendrites and thus inhibit the nerve cell.

Interlocking of antagonistic nerve cells into paired halfcenters plus polar function of the neuron confers important characteristics upon the nervous system (see fig. 11) and offers explanation of the outstanding basic nervous phenomena viz. nerve cell excitation and inhibition, summation of heterogeneous stimuli, neurohumoral integration, simultaneousness of summation at antagonistic neurons, dual action of excitatory and inhibitory afferents, after-discharge, rebound, periodic nervous rhythms, etc.

Similarities of motor and higher nervous function, e.g. sensory perception, sensory interpretation, intellectual judgement, paired emotions, emotional rebound, open and closed mind, etc. suggest that the paired half-center is the structural and functional unit of the nervous system as a whole.

\section{LITERA TURE CITEI)}

Adrian, E. D. 1930 Effects of injuries in Mammalian nerve fibers. Proc. Roy. Soc. London. $106(\mathrm{~B})$ : 596-618.

AdRIAN, E. D., AND D. W. BRONK 1929a The discharge of impulses in motor nerve fibers. Part I. J. Physiol., 66: 81-101.

1929b The discharge of impulses in motor nerve fibers. Part II. J. Physiol., 67 : 119-151.

Atkinson, A. K., R. C. Brown and R. Gesell 1940 The nervous gradation of muscular contraction. Am. J. Physiol., 129 (Proc.) : 303.

BarciofT, J. 1925 Respiratory Function of the Blood. Part I. Lessons from High Altitudes. Cambridge Univ. Press, Cambridge. 207 pp.

Barron, D. H., AND B. H. MatThews 1938 The interpretation of potential changes in the spinal cord. J. Physiol., 92: 276-321.

Bonnet, V., AND F. BREMrs 1952 Les potentiels synaptiques et la transmission nerveuse central. Arch. Int. Physiol., 60: 33-93.

Brassmard, C. R. 1945 Flow and $\mathrm{pH}$ changes of submaxillary saliva associated with variations in acid-base equilibrium. Am. J. Physiol., 144: 43-50.

Brassmeld, C. R., AND R. Grsell 1942 Examples of the acid-neurohumoral mechanism of gradation of nervous integration. Fed. Proc., 1: 10. 
BRASSFTELD, C. R., AND W. W. STEINBERGER 1951 Collective end-plate potentials as analogy of generation of neurocellular current. Fed. Proc., 10:19.

Bronk, D. W., AND L. K. FERGUSoN 1935 The nervous control of intercostal respiration. Am. J. Physiol., 110: 700-714.

Brown, G. L., AND J. C. ECcles 1934 The action of a single volley on the rhythm of the heart beat. J. Physiol., 82 : 211-240.

Brown, T. G, 1911 The intrinsic factors in the act of progression in the mammal. Proc. Roy, Soc. London, 84 (B) : 308-319.

CARmichati, L. 1926 The development of behavior in vertebrates experimentally removed from the influence of external stimulation. Psychol. Rev., 33: $51-58$.

Cogmill, G. E. 1929 Anatomy and the Problem of Behavior. Cambridge Univ. Press, Cambridge. 114 pp.

1934 New anatomieal relations and the probable function of Mauthner's fibers. Psyehiat. en neur. b1., 38: 122-127.

Creed, R. S., D. Denny-Brown, J. C. Ecciess, E. G. T. Liddeul and C. S. ShrerRINGton 1932 Reflex Activity of the Spinal Cord. Claredon Press, Oxford. $179 \mathrm{pp}$.

DALE, H. H. 1914 The action of certain esters and ethers of choline and their relation to musearine. J. Pharmacol, and Exp. Therap., 6: 147-190.

Dale, H. H., ANd C. L. Evans 1922 Effeets on the circulation of changes in the carbon dioxide content of the blood. J. Physiol., 56: 125-145.

Garasenko, V. M. 1944 The use of carbon dioxide at lowered barometric pressures. Am. Rev. Sov. Med., 2: 119-125.

Gasser, H. 1937 The control of excitation in the nervous system. Harvey Lect., 32: $169-193$.

GellhoRn, E. 1936 The effectiveness of carbon dioxide in combating the changes in visual intensity discrimination produced by oxygen deficiency. Am. J. Physiol., 117: 75-78.

GESELL, R. 1940 A neurophysiological interpretation of the respiratory act. Ergebn. Physiol., 43: 476-639.

Gesell, R., A. K. Atrinson ANd R. G. Brown 1940 The origin of respiratory activity patterns. Am. J. Physiol., 128: 629-634.

Gesell, R., AND M. A. HAMIITON 1940 Some reflexogenic components of respiratory rhythm. Am. J. Physiol., 129 (Proc.) : 323.

Gesell, R., C. S. MaGeE AND J. W. Brioker 1940 Response of medullary respiratory action potentials to modifications of respiration. Am. J. Physiol., 129 (Proc.) : 415.

Geseld, R., C. R. Brassfield ANd E. T. HANsen 1941 An acid-neurohumoral mechanism of gradation of nerve cell activity. Univ. Mich. Hosp. Bull., $7: 105$.

Gesell, R., C. R. Brassfield and M. A. Hamitton 1942 An acid-neurohumoral mechanism of nerve cell aetivation. Am. J. Physiol., 136: 604-608.

Gesell, R., AND E. T. HANSEN 1945 Anticholinesterase activity of acid as a biological instrument of nervous integration. Am. J. Physiol., 144: 126-163.

GESELI, R., J. HUNTER AND R. LILLIE 1949 Electrical and functional activity of motor neurons. Am. J. Physiol., 159: 15-28. 
Gesell, R., AND J. S. Frey 1950 Temporal summation of stimuli studied with the aid of anticholinesterases. Am. J. Physiol., 160: 375-384.

GeSell, R., AND A. S. DonTas 1952a Central inhibition; reflexly, reciprocally, and chemically induced. Am. J. Physiol., 170: 690-701.

1952b An electrical study of manifestations of paired motor halfcenters (excitation, inhibition, precedence of stimulation, adaptation, and rebound). Am. J. Physiol., 170: 702-716.

GLICK, D. 1937 Properties of cholinesterase in human serum. Biochem. J., 31: 521-525.

Grohmann, J. 1938 Modification der Funktionsreifung? Ztschr. f. Tierpsychol., 2: $132-144$.

Henderson, Y. J., AND W. H. Haggard 1918 Respiratory regulation of the carbon dioxide capacity of the blood. J. Biol. Chem., 33: 333-365.

Herrick, C. J. 1924 Neurological Foundations of Animal Behavior. Henry Holt and Co., New York. $334 \mathrm{pp}$.

Krogh, A. 1941 The Comparative Physiology of the Respiratory Mechanisms. Univ. of Pennsylvania Press, Philadelphia. $170 \mathrm{pp}$.

LILlIE, R. S. 1923 Protoplasmic Action and Nervous Action. Univ. of Chicago Press, Chicago. 417 pp.

LILLIE, R. H., AND R. GESELL, 1947 Comparison of rhythmic movements of breathing and progression; evidence for common mechanisms. Fed. Proc., 6: 153.

LoEwI, O. 1921 Über Humorale Ubertagbarkeit der Herznervenwirkung. Pfiïger's Arch. Physiol., 189: 239-242.

McDowall, R. J. S. 1930 The effect of carbon dioxide on certain reflex activities. J. Physiol., 69 (Proc.) : IX.

Mathison, G. C. 1910 The action of asphyxiation upon the spinal animal. J. Physiol., 41: 416-419.

1911 The action of asphyxiation upon the medullary centres. Part I. The vasomotor centre. J. Physiol., 42: 283-300.

OsterhouT, W. J. V., AND S. E. HILL 1930 Negative variations in the nitella produced by ehloroform and by potassium chloride. J. Gen. Physiol., 13: $459-467$.

Partridge, L. D. 1952 Reflex latency changes associated with temporal summation. Fed. Proc., 11: 117-118.

Peters, D. C., and R. Gesell 1952 Comparison of central and peripheral summation of nerve impulses. Am. J. Physiol., 170: 717-723.

Schröpinger, E. 1940 What is Life Cambridge Univ. Press, Cambridge. 91 pp. Sherrington, C. S. 1906 The Integrative Action of the Nervous System. Seribners, New York. 433 pp.

1940 Selected Writings of Sir Charles Sherrington. (Edited by D. Denny-Brown.) Paul B. Hoeber, Inc., New York. 532 pp.

Skoglund, C. R. 1942 Response to linearly increasing eurrents in mammalian motor and sensory nerves. Acta Physiol. Scandinav., \& (Suppl. 12): 5-75.

Tinbergen, N. 1951 The Study of Instinct. Claredon Press, Oxford. 228 pp. 
R. GESELL, C. R. BRASSFIELD AND R. H. LILLIE

WEIss, P. 1941 Self-differentiation of the basic patterns of coordination. Comp. Psychol. Monogr., 17 : 1-96.

Winterstern, H. 1911 Die Automatische Tatigkeit der Atemzentren. Pflüger's Areh. Physiol, 138: 159-166. 